\title{
Feasibility and effectiveness of environmental interventions in worksite cafetarias and supermarkets
}

Citation for published version (APA):

Steenhuis, I. H. M. (2002). Feasibility and effectiveness of environmental interventions in worksite cafetarias and supermarkets. [Doctoral Thesis, Maastricht University]. Unigraphic. https://doi.org/10.26481/dis.20020524is

Document status and date:

Published: 01/01/2002

DOI:

10.26481/dis.20020524is

Document Version:

Publisher's PDF, also known as Version of record

\section{Please check the document version of this publication:}

- A submitted manuscript is the version of the article upon submission and before peer-review. There can be important differences between the submitted version and the official published version of record.

People interested in the research are advised to contact the author for the final version of the publication, or visit the DOI to the publisher's website.

- The final author version and the galley proof are versions of the publication after peer review.

- The final published version features the final layout of the paper including the volume, issue and page numbers.

Link to publication

\footnotetext{
General rights rights.

- You may freely distribute the URL identifying the publication in the public portal. please follow below link for the End User Agreement:

www.umlib.nl/taverne-license

Take down policy

If you believe that this document breaches copyright please contact us at:

repository@maastrichtuniversity.nl

providing details and we will investigate your claim.
}

Copyright and moral rights for the publications made accessible in the public portal are retained by the authors and/or other copyright owners and it is a condition of accessing publications that users recognise and abide by the legal requirements associated with these

- Users may download and print one copy of any publication from the public portal for the purpose of private study or research.

- You may not further distribute the material or use it for any profit-making activity or commercial gain

If the publication is distributed under the terms of Article $25 \mathrm{fa}$ of the Dutch Copyright Act, indicated by the "Taverne" license above, 
Feasibility and effectiveness

of environmental interventions

in worksite cafeterias and supermarkets 



\title{
Feasibility and effectiveness of environmental interventions in worksite cafeterias and supermarkets
}

\author{
PROEFSCHRIFT
}

ter verkrijging van de graad van doctor aan de Universiteit Maastricht, op gezag van de Rector Magnificus, Prof.dr. A.C. Nieuwenhuijzen Kruseman, volgens het besluit van het College van Decanen, in het openbaar te verdedigen op vrijdag 24 mei 2002 om 14.00 uur

door

Ingrid Hendrika Margaretha Steenhuis 


\section{Promotores}

Prof. dr. G.J. Kok

Prof. dr. K. Glanz (University of Hawaii, USA)

\section{Co-promotor}

Dr. P. van Assema

\section{Beoordelingscommissie}

Prof. dr. ir. J. Brug (voorzitter)

Dr. I. de Bourdeaudhuij (Universiteit van Gent, België)

Prof. dr. ir. P.A. van den Brandt

Prof. dr. R.A. Knibbe

Prof. dr. F.J.N. Nijhuis

(C) Steenhuis, Ingrid

Feasibility and effectiveness of environmental interventions in worksite cafeterias and supermarkets

ISBN: 90-9015697-6

Printed by Unigraphic, Maastricht (2002)

The studies presented in this thesis were performed at the Nutrition and Toxicology Research Institute Maastricht (NUTRIM), which participates in the Graduate School VLAG-2 (Food Technology, Agrobiotechnology, Nutrition and Health Sciences) accredited by the Royal Netherlands Academy of Arts and Sciences.

The studies described in this thesis were financially supported by the Dutch Cancer Society (NKB). The study described in chapter 4 was also financially supported by the Netherlands Heart Foundation (NHS).

Financial support by the Netherlands Heart Foundation and the Dutch Cancer Society for the publication of this thesis is gratefully acknowledged. 


\section{Contents}

Chapter 1 Overview

Chapter 2 Strengthening environmental and educational nutrition programs in worksite cafeterias and supermarkets in the Netherlands

Chapter 3 Short-term behavioral effects of educational and environmental interventions in Dutch worksite cafeterias

Chapter 4 The short-term effectiveness of nutrition education and labeling in Dutch supermarkets

Chapter 5 A process evaluation of two environmental nutrition programs and an educational nutrition program conducted at supermarkets and worksite cafeterias in the Netherlands

Chapter 6 'Eet Smakelijk, Eet Gezond': Evaluation of a self help guide

References

Summary

Samenvatting

Dankwoord

Curriculum Vitae

Publicaties 

Chapter 1

Overview 


\section{Chronic diseases and dietary habits}

Chronic diseases such as cardiovascular diseases (CVD) and cancer are major causes of death and illness in the Netherlands and in many other countries. In the Netherlands, CVD is the primary cause of mortality, being responsible for 37\% of mortality in 1997. Cancer was responsible for $27 \%$ of mortality in 1994 , and was the second cause of mortality in 1997 (Konings-Dalstra \& Reitsma, 1999). Lifestyle factors play an important role in the prevention of both CVD and cancer (van Leer et al., 1999; Maas et al., 1997; Ruwaard \& Kramers, 1993). One important lifestyle factor influencing both is diet. Two aspects of dietary behavior, fat intake and fruit and vegetable intake, have received a considerable amount of attention in relation to primary prevention of CVD and cancer.

\section{Fat consumption}

A high serum cholesterol level is associated with a higher risk of CVD (Maas et al., 1997; Ruwaard \& Kramers, 1993; Willet, 1994). In general, serum cholesterol levels increase with higher consumption levels of cholesterol and especially with an increased intake of saturated fat. A higher intake of poly-unsaturated fat on the other hand, leads to a decrease in serum cholesterol levels, while mono-unsaturated fat seems to have a neutral effect (Willet, 1994). Furthermore, a high total fat intake is associated with obesity, which is also known to be a risk factor for CVD (Larsson, 1990). Obesity has also been found to be a risk factor for other diseases. Obesity and a diet with a high energy and saturated fat intake and a low intake of unsaturated fat and fiber increase the risk of non-insulin dependent diabetes mellitus (Feskens, 1992; Maas et al., 1997; Ruwaard \& Kramers, 1993; Seidell \& Löwik, 1993).

The relationship between a high fat intake and the risk of cancer is less clear than the relationship between fat intake and CVD. A high fat intake, with a concurrent high energy intake and high body weight, were considered to be agents that increase the risk of cancer. In recent decades, a lot of research has been conducted in this area. The results and conclusions of these studies have been summarized in a number of reports (van Leer et al., 1999; World Cancer Research Fund/American Institute for Cancer Research, 1997). Fat, in particular, has been studied as a risk factor for two of the most common cancers: breast cancer and cancers of the digestive tract, especially the colon. 
It can be concluded there is not enough evidence for a positive association between fat and breast cancer. In the case of cancer of the colon, the conclusion is that there does not seem to be any close relationship between fat intake and the risk of colon cancer. Consumption of red meat is possibly related to a higher risk of colon cancer (van den Brandt et al., 1999; van Leer et al., 1999; World Cancer Research Fund/American Institute for Cancer Research, 1997; Willett, 2001) .

\section{Fruit and vegetables}

Research shows a protective effect of a high consumption of fruit and vegetables on cancers at various locations: mouth and thorax, esophagus, lung and stomach (van den Brandt et al., 1999; van Leer et al., 1999; Steinmetz \& Potter, 1996; World Cancer Research Fund/American Institute for Cancer Research, 1997). For cancer of the colon, the protective effect of a high intake of vegetables has been demonstrated, but not of a high intake of fruit (van Leer et al., 1999). It is not yet clear which nutrients in fruit and vegetables are responsible for their protective effects. Some examples of nutrients which may have a protective effect are vitamins, fiber, indoles, flavonoids and selenium (van Leer et al., 1999). However, the research conducted on this up to now is inconclusive.

A high consumption of fruit and vegetables also seems to be protective as regards the development of CVD (Joshipura et al., 1999; Liu et al., 2000; Ness \& Powles; 1997). Again, it is not yet clear which nutrients are responsible for these possible protective effects (Joshipura et al., 1999).

\section{Dietary guidelines and current dietary practices}

The official Dutch Guidelines for Healthy Nutrition formulated by the Dutch Nutrition Council in 1986 and 1991, recommended a dietary fat intake of $30-35 \%$ of total calories, to be achieved especially by reducing the intake of saturated fat to a maximum of $10 \%$ of total calories (Dutch Nutrition Council, 1986; 1991). Recently, these guidelines have been adjusted by the Health Council of the Netherlands (Health Council of the Netherlands, 2001). The new guidelines recommend a dietary fat intake of $20-40 \%$ of total calories for people with a normal body weight, while for people with 
Chapter 1

overweight a dietary fat intake of $20-30 / 35 \%$ of total calories is recommended. The guideline for saturated fat intake remained the same, a maximum intake of $10 \%$ of total calories is recommended (Health Council of the Netherlands, 2001). It is also recommended that one should eat 200 grams of vegetables and two pieces of fruit a day (Dutch Nutrition Council, 1986; Netherlands Bureau for Food and Nutrition, 1992). Although these guidelines have been established for more than ten years now, there is still a discrepancy between the guidelines and the actual reported food intake of the Dutch population. The most recent Food Consumption Survey showed that mean actual fat intake in $1997 / 1998$ was $35.9 \%$ of total calories, the mean intake of saturated fat was $14.2 \%$, mean fruit intake was 105 grams a day and mean vegetable intake 123 grams a day (Netherlands Bureau for Food and Nutrition, 1998). Compared to the previous Food Consumption Surveys in 1987/1988 and 1992, fat intake was lower (39.8\% of total calories in $1987 / 1988$ and $36.9 \%$ in 1992), and the intake of saturated fat had also decreased (16.5\% of total calories in $1987 / 1988$ and $14.1 \%$ in 1992) (Anonymous, 1988, 1993). Although this change represents good progress, the ideal level, especially as regards the intake of saturated fat, is still somewhat lower. Consumption of fruit and vegetables has decreased over the past decade. The mean fruit intake in 1987/1988 was 125 grams and in 1992114 grams a day (Anonymous, 1988; 1993). The mean intake of vegetables in 1987/1988 was 143 grams and in 1993 128 grams a day (Anonymous, 1988; 1993).

\section{Environmental strategies}

The Dutch government underlines the importance of healthy nutrition and has prioritized promotion of healthy eating behavior (Keijsers \& Vaandrager, 2000; Ministry of Public Health, Welfare and Sport, 1998). If the existing discrepancy between the dietary guidelines and the actual food intake of the Dutch population is to be reduced, effective interventions are needed to influence eating behavior. The Dutch government and organizations such as the Dutch Center for Food and Nutrition (Voedingscentrum), the Dutch Cancer Society (NKB), the Dutch Heart Association (NHS) and the Public Health Services (GGD) have initiated a number of public health initiatives aimed at reducing (saturated) fat intake and increasing fruit and vegetable consumption. The Dutch Steering Committee on Good Nutrition has been active in 
organizing national nutritional education campaigns (for example the national "Goede voeding wat let je?" [A healthy diet, what's stopping you?] campaign) and to develop further initiatives to inform the public about healthy eating behavior (Ministry of Public Health, Welfare and Sport, 1998). Research conducted in the United States has shown that traditional nutrition education methods together with environmental interventions may help consumers to meet the guidelines for a healthy diet (Glanz \& Mullis, 1988; Glanz, 1993). It is increasingly being argued that educational interventions are not sufficient to achieve population-wide behavioral changes and that they should be supplemented by environmental interventions (Bracht, 1999; Contento et al., 1995; Glanz et al., 1990; Glanz, 1993). Environmental interventions can be defined as "all those strategies that do not require individuals to self-select into a defined educational program (i.e. a class, a group, a self help program)". Environmental interventions can also be defined as strategies that reduce barriers or increase opportunities for healthy choices, i.e. by creating more healthy choices, making them more accessible (convenient to find and not too expensive) and establishing policies that require healthy options to be available or limiting the number of less healthy options. In other words, environmental strategies are strategies to create a physical environment that supports healthy nutrition. Environmental interventions aimed at changing dietary behavior include such things as food labeling, regulation of health claims, shelf labeling at supermarkets, changes in food preparation or the foods available at places where food is prepared, served or sold, catering policies and pricing policies (Glanz, 1993; Holdsworth \& Haslam, 1998).

Environmental interventions are viewed as promising strategies with which to change dietary behavior (Bracht, 1999; Contento et al., 1995; Glanz, 1993). However, just how effective they in fact are is still unclear. There are numerous discussions in the literature of environmental initiatives that were not evaluated, not formally reported, or not evaluated rigorously enough to provide effective information on their impact. In this thesis, two types of environmental interventions are studied, namely changes in the foods available and food labeling. These types of environmental interventions can be controlled and implemented on an institutional level as opposed to strategies that are controlled by the (national) government (for example health claims on food packages or taxation on high-fat foods). 


\section{Chapter 1}

Although the effectiveness of changes in the foods available and food labeling have not yet been investigated thoroughly in the Netherlands, a number of initiatives have been taken to incorporate these environmental intervention components into nutritional education programs (Engelberts, 1998; Ronda et al., submitted). However, before implementing interventions on a large scale, it is important to assess what can be achieved with such interventions and how effective they are.

\section{Environmental interventions: theoretical basis}

A number of theoretical explanations can be given for the potential effects of environmental strategies. The Social Learning Theory (SLT) (Bandura, 1986) postulates that there are dynamic relationships between the physical and social environments, observable behavior, and the cognitive personal dimension. A key concept in the SLT is that of reciprocal determinism, which posits that a person both affects and is affected by his or her environment. Changes induced simultaneously in the individual and in the environment are more likely to be maintained. Bandura (1986) therefore explicitly states that health promotion interventions should not only focus on changing people's perceptions but also on reducing actual barriers. Food labeling enables consumers to identify healthy foods quickly and easily (Light et al., 1989). Increasing the range of foods available also enables people to select a healthy food choice (Jeffery et al., 1994). In this way, barriers to healthy eating behavior are reduced.

A number of authors provide explanations for the possible effectiveness of labeling based on information processing models. These models state that people have a limited capacity to store and retrieve the information with which to make decisions (Contento et al., 1995). The information processing load is the amount of cognitive effort required to make an informed decision about a label on a food product (Scott \& Worsley, 1994). Labeling is described as an effort-reducing activity, where the information environment is adapted to the people concerned. People only use nutritional information when the perceived benefits of using the information exceed the cost (i.e. the effort involved in processing the information) (Russo, 1986). In addition, people first search for information internally (in their memory) and only if they do not have enough 
information to make a decision do they then search the environment. Providing useful, relevant, and user-friendly nutritional information is therefore important in improving the use made of information about healthy foods (Contento et al., 1995).

Levin (1996) cites Rogers' Diffusion of Innovations theory to explain the effectiveness of their labeling intervention. Rogers (1983) defined a number of attributes of innovations that influence their rate of diffusion:

- relative advantage: the unique benefits of the innovation over other practices;

- compatibility: the match between the innovation and the socio-cultural, economic, and ideological value system of the adopter;

- complexity: the degree of difficulty in understanding and using an innovation;

- trialability: the degree to which the innovation can be split up for small-scale experiments;

- observability: the visibility of the innovation's results.

Levin's labeling program (1996) was described as simple, practical and providing relevant information. The program reflected attributes of innovations that contribute to adoption by being simple, convenient, compatible with existing nutritional recommendations, requiring little effort, making it possible to try products on a limited basis, and allowing participants to see or talk to other similar people who had already chosen the labeled items (Levin, 1996).

According to the 'Attitude-Social influence-Self-efficacy model' (ASE model), behavior is determined by people's attitude towards that behavior, social influence and selfefficacy (de Vries et al., 1988; Kok et al., 1991). An attitude represents a person's general feeling (favorable or unfavorable) towards the behavior concerned, and is determined by the perceived positive and negative consequences of that behavior. Social influence refers to the influence of others, both directly (expectations of significant others), and indirectly (what others do). Self-efficacy refers to a person's expectation regarding his capability to realize a behavior. Attitudes, social influence, and self-efficacy predict the intention to perform the behavior, which in turn predicts the behavior itself. External variables, such as demographic variables, influence behavior via the three determinants and the intention. Between intention and behavior there may be barriers and/or a lack of skills. These become important if the behavior is 
actually performed. Furthermore, self-efficacy expectations are assumed to be partly dependent on these barriers and skills. Actual performance of the behavior leads to a feedback process which in turn influences the three determinants. Various studies have been carried out on determinants in the field of nutrition. Where attitudes towards healthy nutrition are concerned, a number of different considerations appear to play a role: expectations as to taste, healthiness, price, convenience and familiarity (Brug, 2000b; Stafleu, 1991). In the light of the research conducted up to now, the role of social influences on food choice would seem to be limited, although influences within families, for example, do play a role in food choice (de Bourdeaudhuij, 1997; Brug, 2000b). Research also identified some specific situations in which people tend to have lower self-efficacy expectations regarding healthy eating behavior. People perceive eating less fat more difficult during weekends, at parties, when they see other people eating and when they are going out for dinner. For eating more fruit and vegetables, people have lower self-efficacy expectations when in lack of time, in weekends and when alone (Brug, 1997). Where these behavioral determinants for food choice are concerned, it is assumed that environmental interventions may influence certain attitudinal beliefs related to environmental circumstances. For example, providing prepared fruit (peeled and sliced) may affect people's belief that eating fruit every day involves a lot of work or takes a lot of time (de Vries \& Backbier, 1994). Moreover, environmental interventions may lead to additional increases in self-efficacy expectations by decreasing actual barriers to eating a healthy diet (de Vries \& Backbier, 1994; Holdsworth \& Haslam, 1998). Besides these ASE-determinants, research shows that awareness of one's own consumption pattern is also an important determinant. Many people are not aware of their own levels of consumption of fat, fruit and vegetables. They underestimate their fat consumption, while they overestimate their fruit and vegetable consumption (Brug et al., 1994; 1998; Lechner et al., 1997). Research into the causes of such misconceptions shows that the optimistic bias plays a key role: an individual thinks that he eats more healthily than most other people, and that his own diet is therefore not too bad (van Assema et al., 1996). Environmental interventions may influence the awareness of own consumption levels. For instance, people will become more aware of their high fat intake by reading nutritional labels. 


\section{Point-of-choice settings: worksite cafeterias and supermarkets}

Point-of-choice settings (i.e. places where food is provided, prepared, sold or served) are especially suitable for environmental interventions because a substantial proportion of buying decisions are made at the point of choice (Glanz et al., 1995; Mayer et al., 1989; Philips \& Bradshaw, 1993). Interventions at point-of-choice settings such as supermarkets and eating establishments can be highly effective in changing buying and eating behavior (Contento et al., 1995) (see next section "Review of studies ...").

\section{Worksite cafeterias}

Besides being in a point-of-choice setting, interventions at worksite cafeterias offer some additional advantages. One important one is the availability of a daily eating situation with opportunities for follow-up, monitoring and reinforcement of messages. The potential social influence and social support present at the worksite can also be advantageous for nutritional interventions (Glanz et al., 1986). Furthermore, food consumption research has shown that food consumption outside one's own home (for example at the worksite cafeteria) accounts for a substantial proportion of total daily food consumption. In 1998, $25.8 \%$ of total daily food intake in the Netherlands was consumed outside people's own home (Holla, 2001).

\section{Supermarkets}

Supermarkets are visited regularly by a large proportion of the community, which implies that they offer high potential for reaching a large target audience (Glanz, 1995, Närhinen, 2000). A substantial proportion of buying decisions (65\%-80\%) are unplanned and made at the supermarket (Light et al., 1989; Scott et al., 1991; Mayer et al., 1989; Närhinen, 2000). Research shows that consumers frequently use information on food packaging to obtain information about food products (De Almeida et al., 1997; Marietta et al., 1999). More than half of consumers use information on the packaging when buying a product for the first time (Marietta et al., 1999). Research conducted by Scott \& Worsley (1994), showed that about $50 \%$ of respondents had read nutritional information on the packaging of a food item within the past ten days, and almost all of them claimed that it had an influence on their purchasing behavior. Information provided at the point of choice, for example on packaging, can influence food choice or determinants for food choice (see also next section). 
Chapter 1

\section{Review of studies of the effectiveness of changes in foods available and food labeling at worksite cafeterias and supermarkets}

Not many studies have been conducted into the effectiveness of increasing the range of foods available at worksite cafeterias (see also Table 1). Mixed effects were found in the two studies conducted: for some nutrients or food products, significant effects were found (sodium, fruit and salad), while for others no effects were observed (fat, cholesterol) (Jeffery et al., 1994; Schmitz \& Fielding, 1986). More studies have been conducted into the effectiveness of labeling, both at worksite cafeterias and supermarkets (see Table 2 and 3). The labeling programs were targeted at various nutrition goals. Some focused on stimulating consumers to eat more high-fiber products, fruit or vegetables, while other programs encouraged consumers to eat less fat, cholesterol, sugar or sodium. The labeling was in almost all studies combined with a wide range of educational program elements such as brochures, posters, in-store advertisements, cookbooks or radio and television advertisements. Most of the environmental interventions conducted at worksite cafeterias and supermarkets were part of a multi-component educational intervention program. The interventions at worksites, in particular, were of short duration, and in most projects only short-term effectiveness was measured. None of the earlier studies studied the effects of a program involving only educational elements compared to a program involving both educational elements and the environmental component of labeling. Moreover, most previous studies, especially those conducted at worksites, used within-setting designs. These are much weaker than designs which include control groups. The various studies reported ambiguous results as regards the effectiveness of the programs. Some studies did not measure the effects on food consumption or on sales but used such measures as awareness or interest instead. Some of the studies which did measure effects on eating or buying behavior reported positive effects but some also reported no behavioral effects. Because a large number of studies measured only the effects of the program on purchases or consumption of targeted food items, the influence of the programs on overall diet is not clear. For more information on the studies so far conducted at worksite cafeterias and supermarkets, see chapter 3 and chapter 4 . 


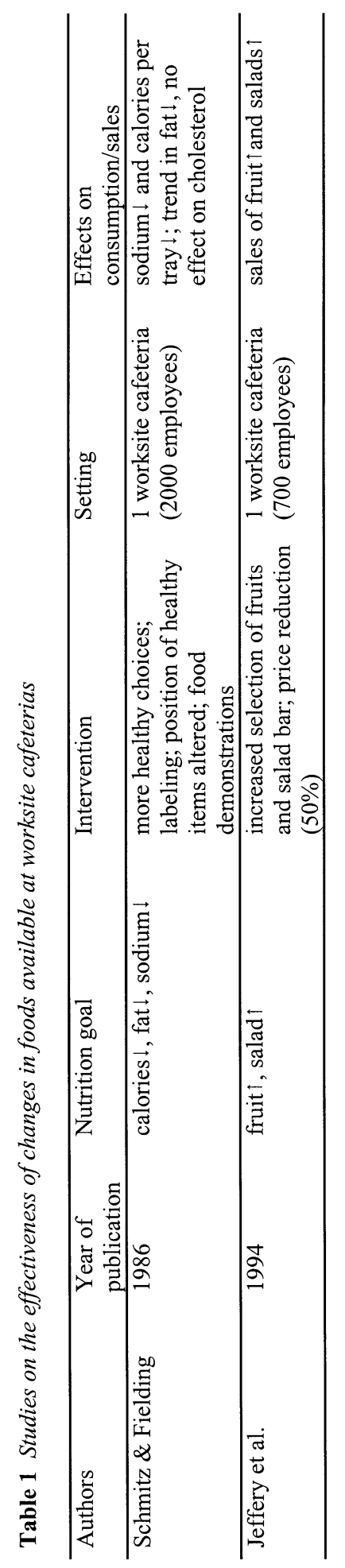




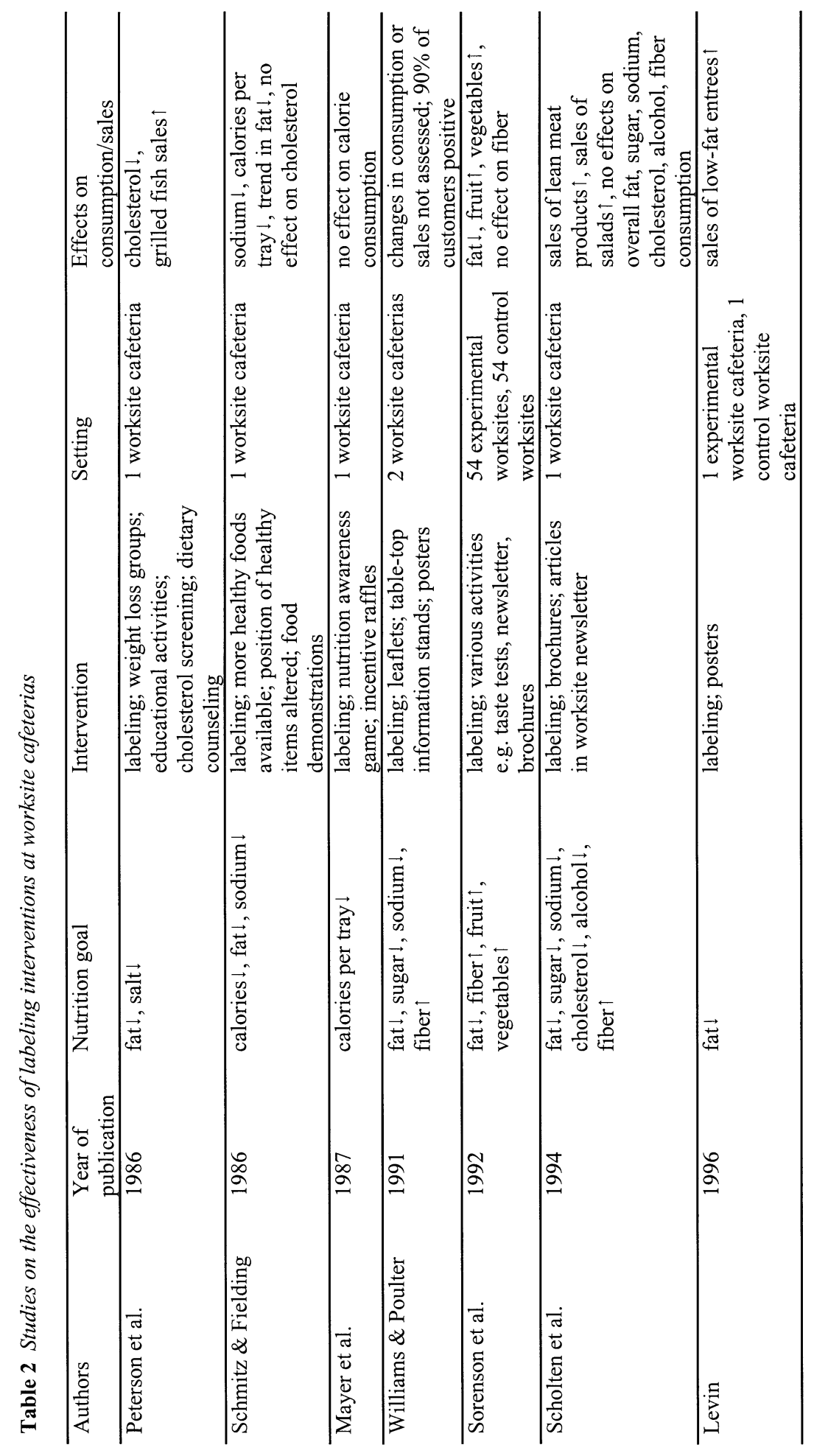




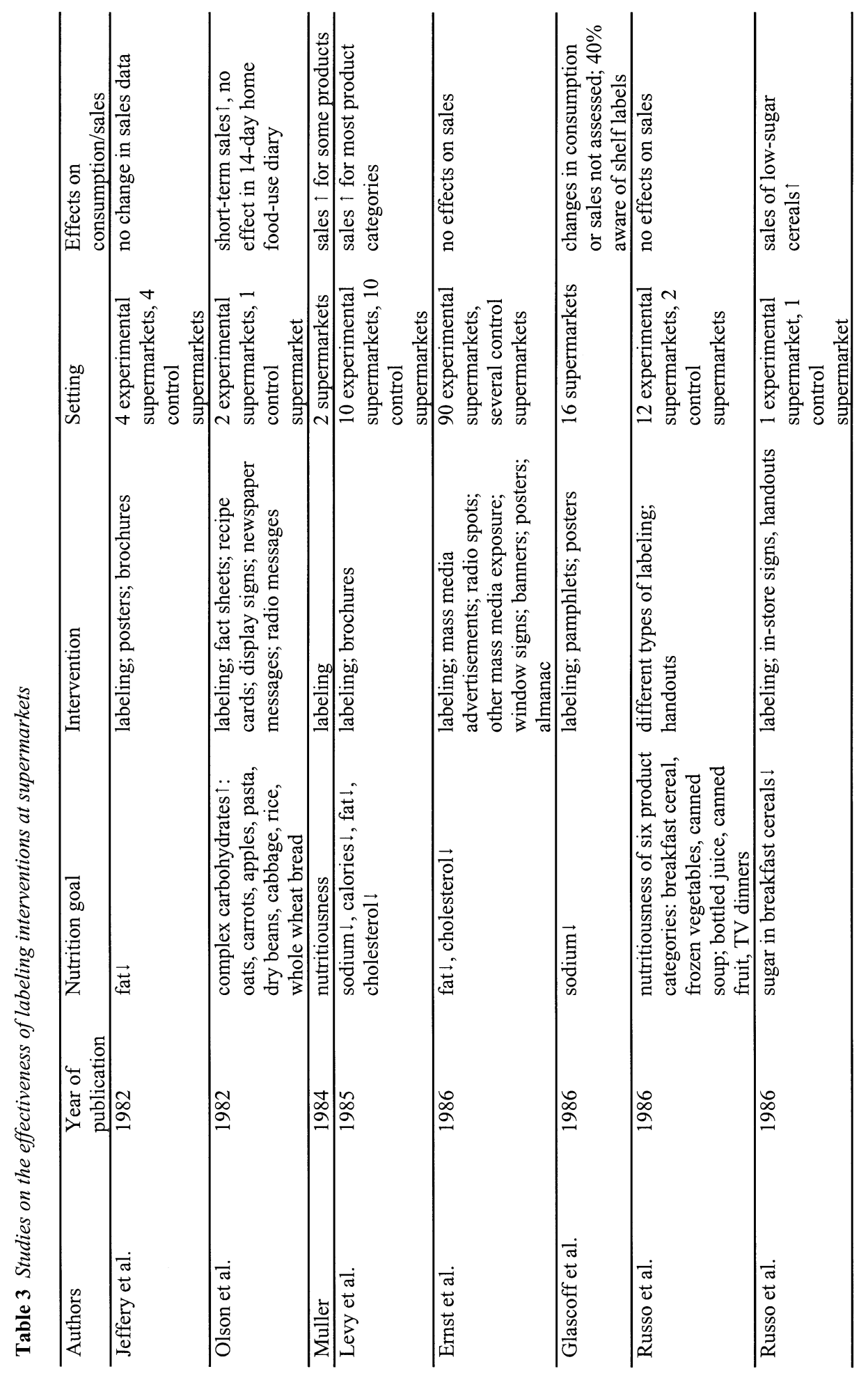




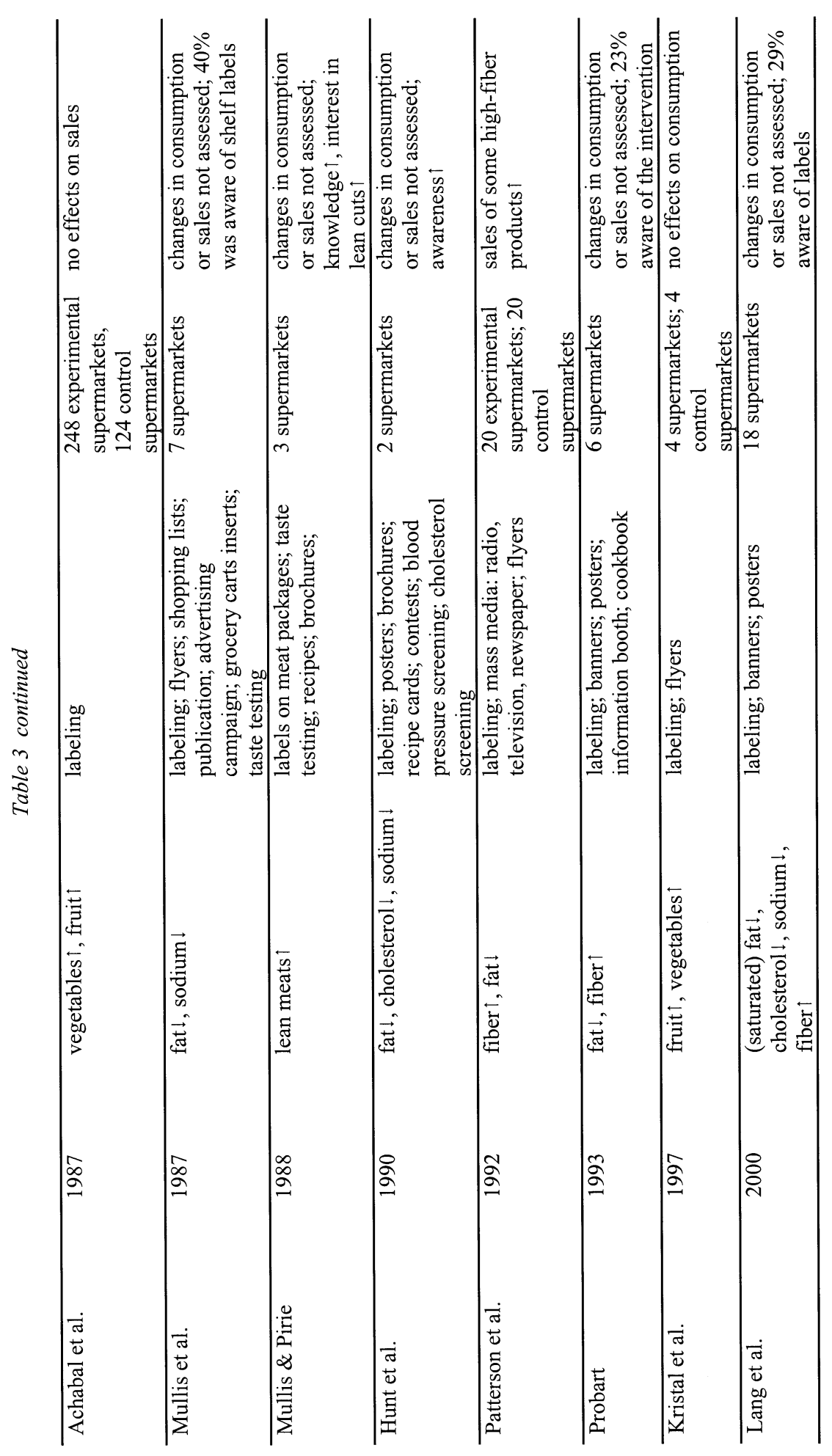


Overview

\section{Study objectives}

The purpose of the studies described in this thesis was twofold. The first objective was to assess the feasibility of environmental interventions aimed at changing dietary behavior at worksite cafeterias and supermarkets in the Netherlands. The second objective was to study the effectiveness of two environmental interventions (food labeling and changes in the range of foods available) aiming at reducing total fat intake ${ }^{1}$ and increasing total fruit and vegetable consumption. The assumption most frequently made in previous studies is that the effectiveness of nutrition education programs will increase if they are supplemented by an environmental strategy. The main research topic regarding the effectiveness of the environmental interventions was whether a general nutrition education program supplemented by one of the environmental interventions (food labeling or changes in the range of foods available) would be more effective in changing dietary behavior than a nutrition education program alone. The range of foods available was only increased at the worksite cafeterias, since nearly all Dutch supermarkets already have an extensive range of low-fat products and fruits and vegetables. The labeling intervention at supermarkets focused only on low-fat products.

\section{Feasibility of environmental programs in the Netherlands}

The great majority of the studies presented in the previous sections were carried out in the United States. The many examples of environmental interventions in point of choice settings indicate that such interventions are in fact feasible. However, these studies gave limited information about the feasibility of maintenance of environmental interventions or about factors influencing that feasibility. Before developing environmental interventions for implementation within Dutch organizations, it is important to assess the feasibility of such interventions in the Netherlands and to identify factors which determine feasibility. The first study presented in this thesis studied the conditions for adoption and continued implementation of a labeling intervention and an intervention involving changes in the range of foods available at Dutch worksite cafete-

\footnotetext{
${ }^{1}$ The interventions were aimed at reducing total fat intake because at the time the studies described in this thesis were conducted, both total fat intake and the intake of saturated fat of the Dutch population were too high and not in accordance with the official Dutch nutrition guidelines. It is assumed that if total fat intake decreases, the intake of saturated fat also will decrease.
} 
rias and supermarkets, as well as the conditions for a general nutrition education program in these settings (see chapter 2). Concepts derived from theories of diffusion were used as a framework for this study. Twenty semi-structured interviews were conducted with representatives of worksite cafeterias and supermarkets. Worksite cafeterias and supermarkets were willing to participate in both environmental and educational programs if these programs satisfied certain requirements as to program design and program implementation. Apart from the fact that the programs should be positive and practicable for both staff and customers, programs must meet a large number of practical requirements (see also chapter 2). In order to ensure that the programs are implemented correctly, implementation strategies should focus on the perceived advantages of nutrition programs at worksite cafeterias and supermarkets (e.g. greater customer satisfaction), and on diminishing the expected difficulties in conducting nutrition programs (e.g. the necessary time investment) (for more information see chapter 2).

\section{Short description of intervention development and intervention programs}

Three different types of intervention programs were developed for the studies described in this thesis: a labeling program (for worksites and supermarkets), a program involving changes in the range of foods available (for worksites) and a general nutrition education program (for worksites and supermarkets) to be carried out in combination with the environmental programs. The intervention programs were planned and the necessary materials developed in conjunction with potential adopters of the programs. A project advisory committee was also appointed to advise on intervention development. The committee consisted of representatives of national organizations in the field of health and nutrition education: the Dutch Heart Association (NHS), the Dutch Center for Food and Nutrition (Voedingscentrum), the Dutch Cancer Society (NKB), the Association of Regional Cancer Centers (VvIK), the Dutch Center for Workplace Health Promotion (Centrum GBW), and the Dutch Association of Caterers (Vereniging van Nederlandse Cateraars). The content of the intervention programs used at the supermarkets and worksite cafeterias was almost identical but the program materials were in part different en specifically adjusted for the setting in question (See also chapters 3 and 4 for more detailed information about the intervention programs.) The research team 
assisted in the implementation of the programs at the supermarkets and worksite cafeterias. Staff were informed about the programs at a special meeting organized by the research team. A program manual was also available for all supermarkets and worksites participating in the study. During the intervention period, the research team regularly visited the experimental sites to ensure optimum implementation of the programs.

\section{Labeling}

The aim of labeling was to make healthy choices visible and easily recognizable. Lowfat products in various food product categories such as 'meat and meat products' and 'desserts' were labeled with a shelf label (supermarkets) or a sign in front of the product (worksites). The information on the label consisted of the program logo, the name of the item and an indication of whether the product was a low-fat product. In the case of the worksite cafeterias, fruit and vegetables were also labeled.

\section{Changes in the range of foods available}

The range of low-fat products (such as low-fat cheese) and of fruit and vegetables at the worksite cafeterias was increased by adding at least four products. Attention was drawn to the new products by placing a sign in front of them, bearing the words "new and healthy".

\section{General nutrition education program}

The 'Attitude-Social influence-Self-efficacy model' formed the theoretical basis for the educational intervention. In the general nutrition education program, determinants for eating less fat and more fruit and vegetables were targeted, including attitudes towards eating less fat and more fruit and vegetables, social influences on healthy eating habits, self-efficacy, and skills for selecting and preparing low-fat products/meals and eating two pieces of fruit and 200 grams of vegetables a day. The program also addressed awareness of personal consumption levels. Not all the information was given at the same time. At the beginning, more information concerning awareness and attitudes was given, while later on the other determinants were emphasized more. The program consisted of a number of different elements. Of these, some were optional for the supermarkets and worksites participating in the study, while others were basic elements 
and therefore obligatory. For supermarkets, the basic elements were posters, brochures, recipe cards and a self help manual which could be obtained by filling in a coupon included in the brochure. Optional elements included badges for supermarket staff, "Next customer" bars on checkout conveyer belts bearing the program logo and slogan, and a contest. For worksites, the recipe cards were replaced by table-top information stands, and an article in the worksite newsletter was added to the optional elements.

\section{Study designs of evaluation studies}

The two studies on the effectiveness of the designed interventions are described in chapters 3 and 4 of this thesis. Seventeen worksite cafeterias and thirteen supermarkets participated in the studies. Both studies used a randomized pretest-posttest experimental control group design. Besides a control condition with no program, a condition with a nutrition education program only and conditions with an educational program supplemented by an environmental component (labeling or changes in the range of foods available) were included in the studies. This design made it possible to assess the effects of the intervention including an education and an environmental component in comparison to a no-intervention condition as well as to a program including only educational elements. In this way, the additional value of the separate environmental components could be assessed. Including control groups and measuring the effects of the interventions on overall consumption also made it possible to address important shortcomings of earlier studies. Besides these two studies on the effects on dietary behavior, a qualitative study was conducted among key figures at the worksite cafeterias and supermarkets in order to acquire data on the implementation and progress of the intervention programs. In addition, one intervention element of the educational program, the self help guide, was evaluated in a separate study.

\section{Measurements in evaluation studies}

Several data collection methods were used to evaluate the interventions. A cohort of customers were asked to fill out a questionnaire before (t1), one month (worksites) or two months (supermarkets) after the start of the intervention ( $\mathrm{t} 2$ ), and six months after the start of the intervention ( $\mathrm{t} 3$ ). The questionnaire was used to measure the overall 
effects on consumers' fat, fruit and vegetable consumption, their consumption of individual food items and determinants for eating less fat and more fruit and vegetables, and to assess the opinions and reactions of consumers to the intervention (see also chapters 3 and 4). Sales data were collected on individual items in targeted product groups, both at the worksite cafeterias and at the supermarkets. However, numerous problems in collecting and analyzing the sales data meant that the sales data could ultimately not be used to assess the effectiveness of the interventions at the supermarkets (see chapter 4 for more details). Qualitative semi-structured interviews were also held with the key figures involved in the implementation of the interventions within their organizations so as to assess factors which positively and negatively influence the maintenance of the programs (see chapter 5). The self help guide was evaluated by means of a questionnaire among a small group of users of the guide (see chapter 6).

\section{Results of evaluation studies}

For both the worksite cafeterias and the supermarkets, no significant difference was found between both the short-term and long-term effects on total fat, fruit, and vegetable intake of the environmental programs and the educational or control condition. Nor were significant effects found on food consumption during lunch at the worksite cafeteria. Sales data from the worksite cafeterias revealed that the labeling program had a significant effect on the consumption of desserts, but not on other products. In the study conducted at supermarkets, no significant effects were found on the consumption of labeled food items. In addition, no convincing effects were found between the environmental programs and the educational or control condition regarding behavioral determinants of eating less fat and more fruit and vegetables. For respondents in the worksite cafeterias who believed they ate a high fat diet, the data showed a significant treatment effect of the labeling program on total fat intake. However, this effect was only present at the short term, was not found in the study conducted in supermarkets and was only observed for total fat intake and not for fruit or vegetable intake. The results of the evaluation studies are described in chapter 3 (worksite cafeterias) and chapter 4 (supermarkets). The two evaluation studies show that neither the nutrition education intervention nor the nutrition education intervention 


\section{Chapter 1}

supplemented by labeling or changes in the range of foods was effective in changing dietary behavior among the worksite cafeteria and supermarket population.

Process evaluation data revealed that respondents at both worksite cafeterias and supermarkets had a positive opinion of the programs. Respondents at worksite cafeterias were a little more negative about certain aspects of the program. They reported, for example, that the program was of low personal relevance and that they did not gain a greater knowledge of healthy nutrition because of the program. Although the effect-evaluation did not show any effects, at the supermarkets respondents who were aware of the intervention reported that the programs had a positive effect on determinants for eating less fat and more fruit and vegetables. For example, more than half of these respondents reported that they had looked at their own fat consumption level as a result of the intervention, and almost half of the respondents reported their intention to follow one or more suggestions given in the program.

The qualitative study among worksite cafeteria managers and supermarket managers showed that the degree of implementation of the programs was quite good. In general, the supermarket and the cafeteria managers were positive about the intervention programs. The programs were described as clear, professional, informative, wellorganized and with good coherence between the various program elements. Furthermore, this study revealed some additional explanations for the ineffectiveness of the intervention programs (see also next section and chapter 5).

Evaluation of the self help guide showed that it was well used and rated positively by those who read it. Respondents reported that the guide had positive effects on their fat, fruit and vegetable consumption, and the corresponding determinants for behavior. Based on the evaluation, the self help guide would seem to be a valuable complement to existing nutrition education materials (see also chapter 6). 


\section{Possible explanations for the ineffectiveness of the programs and future directions}

In chapters 3, 4 and 5, a number of possible explanations are offered for the ineffectiveness of the environmental (and educational) interventions in achieving large scale dietary changes. Some of the explanations are specific to the interventions designed for the studies described in this thesis; others relate more to the characteristics of labeling programs and programs including changes in the range of foods in general. Specific explanations for the interventions described in this thesis included the incompatibility of the labeling system used with the shelves of some supermarkets and the program materials (including the labels) not being striking enough to catch the attention of customers to any great extent. Program materials should be designed in such a way that they are fully compatible with the various systems used at the supermarkets, and they should also be striking enough for customers. Also, the programs should be promoted extensively and seek more publicity. Furthermore, it is possible that the programs did not continue long enough. In worksite cafeterias, the initial intervention period was one month, in supermarkets two months. The intervention could be prolonged up to six months. Most worksites and supermarkets continued with certain intervention components such as the self help guide, brochures and table tents/recipe cards. The environmental intervention components were also prolonged for a certain period of time in most experimental worksites and supermarkets. Another factor in relation to the type of labeling might have been the information on the labels. Perhaps, people would have responded more to labels with information on the caloric value of products, or specific nutrient value information such as grams of fat instead of the indication low-fat. Brand-specific labeling might be more effective in changing dietary behavior than non brand-specific labeling. Future research should focus on identifying the factors in labeling programs which can potentially make them effective in changing dietary behavior.

Possible explanations for ineffectiveness which apply to labeling programs and programs involving changes in the range of foods in general include the limited availability of suitable low-fat alternatives to be sold at worksite cafeterias, and the fact that the supermarket is a highly competitive environment for nutrition education. The relevant manufacturers and wholesalers supplying worksite cafeterias should be 


\section{Chapter 1}

encouraged to increase their range of suitable low-fat products for sale there. Despite the advantages of the supermarket as a setting for nutrition education (possibility of frequent exposure and being a point-of-choice setting), the highly competitive environment makes it very difficult to get attention for nutrition education. Therefore, nutrition education programs to be implemented in supermarkets should be promoted more intensively, for instance through advertisements in different media by the supermarkets.

The fact that a lot of people are not aware of their unhealthy eating habits could be another factor explaining the ineffectiveness of the programs. People who believe they eat healthy, are less likely to be interested in nutrition education (Glanz et al., 1997a). It might have been that people saw the intervention programs, but did not perceive the programs to be personally relevant for themselves. However, this hypothesis was tested in this thesis, and results indicate that even for people who believe they eat a high fat diet or a diet low in fruit and vegetables, no convincing and relevant intervention effects were found for the (environmental) interventions.

Another hypothesis suggested in this thesis is that labeling programs or programs involving changes in the range of foods in combination with pricing strategies might be a more effective strategy. To explore the possibility of an environmental intervention based on a pricing strategy and effects, a pilot study was conducted at two worksite cafeterias (Steenhuis et al., submitted(c)). An experimental control group design was used to test whether the free provision of two low-fat products (low-fat cheese spread and low-fat butter) during a one-week intervention period would lead to a higher consumption of these products during the intervention, a more positive attitude towards the products, and a more positive intention to consume the products after the conclusion of the intervention. Evaluation data were collected by means of a questionnaire for consumers, sales data and observations at the experimental cafeteria. The results showed that about a third of the respondents noticed the free products and that about $20 \%$ of them did in fact consume them. No significant differences were found between the experimental group and the control group regarding attitude and intention to use the products in the future. Within the experimental group, respondents 
who consumed the free products during the intervention period had a significantly more positive attitude towards the products and also had a significantly higher intention regarding future consumption of the products than respondents who did not consume the products during the intervention period. The study showed that the free provision of products only resulted in higher consumption of those products in a small proportion of respondents. Possible explanations for this low level of effectiveness were that the products did not attract enough attention, that people often chose the same products as they usually consumed, that people seemed to be suspicious towards products provided for free, and the expectations people had about the taste of the free products. Combinations with labeling strategies, as well as more extensive interventions using pricing strategies, should be investigated further.

\section{Conclusions}

The first research topic of this thesis -to determine the feasibility of environmental interventions at worksite cafeterias and supermarkets in the Netherlands- can be answered in the affirmative. Environmental interventions at worksite cafeterias and supermarkets are indeed feasible, although some requirements regarding program design and implementation must be taken into account. Based on the studies described in this thesis, the second research topic -the effectiveness of labeling and changes in the range of foods available in decreasing fat intake and increasing fruit and vegetable intake- must be answered in the negative.

The results found in the studies described in this thesis, combined with the mixed results found in previous studies in this research area, show that it is not yet clear whether environmental interventions aimed at decreasing total fat intake and increasing total fruit and vegetable intake are effective. Where intervention programs including changes in the range of foods available at worksite cafeterias are concerned, it can be concluded that no evidence has yet been found that this is an effective strategy. As regards interventions involving labeling, no unambiguous conclusion can be drawn as to the effectiveness of such intervention strategies. It is clear that although some labeling programs described in the literature seem to be effective, not all types of 


\section{Chapter 1}

labeling programs are in fact effective. However, it is still not known which type of labeling program will be effective and in what combination with other nutrition education components. 


\section{Chapter 2}

\section{Strengthening environmental and educational nutrition programs in worksite cafeterias and supermarkets in the Netherlands ${ }^{2}$}

${ }^{2}$ Published as: Steenhuis, I.H.M., Assema, P. van, Glanz, K. (2001). Strengthening environmental and educational nutrition programs in worksite cafeterias and supermarkets in the Netherlands, Health Promotion International, 1, 21-31. 


\title{
Chapter 2
}

\begin{abstract}
The purpose of this study was to assess conditions for the adoption and continued implementation of different healthy nutrition programs in worksite cafeterias and supermarkets, i.e. an educational program and two environmental programs (a food labeling program and a food supply program). Twenty semi-structured interviews were conducted with representatives of worksite cafeterias and supermarkets. Concepts of theories of diffusion were used as a framework for the study. Questions were formulated about the attributes of the innovation, and organizational and personal characteristics that might influence program adoption and implementation. Results indicated that educational and environmental programs in both worksite cafeterias and supermarkets should meet specific requirements regarding program design, methods and materials in order to be adopted and implemented. Besides, some important implementation strategies of the educational and environmental programs were identified. It is concluded that it seems feasible to conduct educational and environmental intervention programs in worksite cafeterias and supermarkets, but that certain conditions for adoption and continued implementation have to be met. Based on the implications of this study, the development of an educational program, a labeling program, and a food supply program was completed.
\end{abstract}




\section{Introduction}

Different aspects in the diet have been found to be important in the prevention of cancer and coronary heart diseases (CHD), for example the consumption of fat, fruit, and vegetables (Willet, 1994). Although the exact role of dietary factors in cancer and CHD is still being studied, the evidence is sufficient to have resulted in official dietary guidelines in the Netherlands (Dutch Nutrition Council, 1986b), and in many other countries (e.g. US Departments of Agriculture and Human Services, 1990; Benito, 1992). In the Netherlands priority has been given to the implementation of the guideline on fat intake, i.e. to reduce dietary fat intake to $30-35 \%$ of total calories, especially by reducing intake of saturated fat to a maximum of $10 \%$ of total calories (Dutch Nutrition Council, 1986b; 1991). ${ }^{3}$ The guidelines also recommend eating ample amounts of fruit and vegetables (Dutch Nutrition Council, 1986b). A more specific recommendation for adults is given by the Netherlands Bureau for Food and Nutrition: 200 grams of vegetables and 2 pieces of fruit per day (Netherlands Bureau for Food and Nutrition, 1992). The third Dutch National Food Consumption Survey showed that in 1997-'98 total fat intake was $36 \%$ of total calories, and the intake of saturated fat $14 \%$ of total calories. Mean consumption of vegetables was 123 grams per day and mean consumption of fruits 105 grams per day (Netherlands Bureau for Food and Nutrition, 1998). This discrepancy between dietary guidelines and actual intake shows that effective methods for achieving large scale dietary changes are needed. It is now widely accepted that contemporary health promotion strategies need to go beyond education and communication strategies to include environmental strategies. Strong pleads are being made for educational programs to be extended with environmental programs in order to achieve population wide behavioral changes (e.g. Bracht, 1990; Glanz et al., 1990; Glanz et al., 1996, Green and Kreuter, 1991). According to Glanz (1993), environmental programs comprise all those strategies that do not require individuals to self-select into a defined educational program. Furthermore, environmental strategies can be defined as strategies that reduce barriers or increase

\footnotetext{
${ }^{3}$ These were the guidelines at the time this study was conducted and published. Recently, the guidelines on fat intake have changed. The official Dutch Guidelines for Healthy Nutrition now recommend a dietary fat intake of $20-40 \%$ of total calories for people with a normal body weight, while for people with overweight a dietary fat intake of $20-30 / 35 \%$ of total calories is recommended (Health Council of the Netherlands, 2001).
} 
opportunities for healthful choices, i.e. more healthful options, make healthy choices more accessible (convenient to find, not too expensive), and policies that require healthful options being available, or even prohibit/limit the number of 'less healthy' options. Examples of environmental strategies are nutrition labeling, regulation of health claims, shelf labeling in supermarkets, changes in food preparation, or offerings in supermarkets, restaurants and worksite food services and vending areas. Environmental interventions to encourage the adoption of healthful eating patterns can be implemented in different settings. Settings where food is provided, prepared, sold or served are especially suitable for environmental programs (Glanz, 1993). Point-ofchoice settings are, for example, worksite cafeterias, restaurants, school canteens, and supermarkets.

The present study was conducted as part of developing a nutrition education program and two environmental programs (a labeling program and a food supply program) aiming at reducing fat intake and increasing fruit and vegetable consumption, to be implemented in two point-of-choice settings (worksite cafeterias and supermarkets). The nutrition education program was developed to be used separately or in combination with one or both environmental programs. The educational program provides through different channels (for example brochures or posters) information about eating less fat and more fruit and vegetables, such as about the advantages of eating less fat and more fruit and vegetables, the guidelines for the amount of fruit and vegetables, and practical tips to eat less fat and more fruit and vegetables. The labeling program consists of the labeling (that is putting an extra label on the product or in front of a group of products) of low fat products, and fruit and vegetables, in order to make the healthy choices easily recognizable. The food supply program implies that cafeterias and supermarkets enlarge their range of products with low fat products and fruit and vegetables.

Before developing environmental and/or educational programs for point-of-choice settings, it is important to assess the feasibility and the conditions for the adoption and continued implementation of the programs in these settings. Information from potential adopters in the development of the programs and in the development of implementation strategies might help to enlarge the possibilities of adoption and continued implementation and maintenance (Oldenburg et al., 1997; Orlandi et al., 1990). The 


\section{Feasibility and conditions for implementation}

goals of the present study were to assess the feasibility of both the educational and environmental programs, and to identify factors possibly influencing the adoption and continued implementation of these programs by worksite cafeterias and supermarkets. Based on the results, implications for actual program development and implications for development of implementation strategies were formulated.

\section{Methods}

\section{Recruitment}

Semi-structured interviews were conducted with key persons of worksite cafeterias and supermarkets. First, the worksite cafeterias and supermarkets were approached by means of a letter in which the purpose of the study was explained as well as the interview procedure. Subsequently, respondents were asked by telephone to participate in the study. Companies and supermarkets were selected on a few characteristics. For the companies the presence of a worksite cafeteria was required. Both companies with a majority of white collar workers and those with a majority of blue collar workers were included. For the supermarkets also different types of supermarkets were recruited: those belonging to a national chain of supermarkets, those belonging to a regional chain, and franchise-supermarkets. During the interviews respondents were asked to point out other key persons in their company or supermarket who should be interviewed as well. For example, a local supermarket manager might say that the manager of the chain's head-office should also be interviewed.

\section{Theoretical framework}

Concepts of theories about the diffusion of innovations were used as a framework for the study. Rogers (1983) defines diffusion as the "process by which an innovation is communicated through certain channels over time among the members of a social system", and an innovation is defined as a "policy, program, or technology that is new to its potential users". Healthy nutrition educational and environmental interventions can be seen as innovations, while worksite cafeteria and supermarket representatives can be seen as potential adopters of these programs. The diffusion of a program can be seen as a five-stage process. Firstly an organization obtains knowledge about the program. Secondly the organization's decision makers form an attitude toward the 
program. Thirdly the organization, through its decision makers, adopts or rejects the program. When the program is adopted, the fourth stage is implementation. Finally the program is institutionalized, or becomes part of the ongoing activities of the organization (Rogers, 1983).

Many factors have been suggested to be related to program diffusion. Rogers (1983) for example, defined several attributes of innovations that influence the rate of diffusion of innovations:

- relative advantage: the unique benefits of the innovation over other practices;

- compatibility: the match between the innovation and the socio-cultural, economic, and ideological value system of the adopter;

- complexity: the degree of difficulty in understanding and using an innovation;

- trialability: the degree to which the innovation can be split up for small-scale experiments;

- observability: the visibility of the innovation's results.

Other attributes of innovations related to program diffusion include, among others, reversibility, communicability, and modifiability (Oldenburg et al., 1997).

Furthermore, characteristics of the adopting organization have been found to be related to diffusion, such as the organizational climate, concern and interest in the organization about the subject, social influence toward program participation, size and structure of the organization, and the decision making process (Rogers, 1983; Basch et al., 1986; Steckler et al., 1992; de Vries, 1993). Other factors that have been found to influence the diffusion process are characteristics of the adopting persons (e.g. socio-economic characteristics, self-efficacy expectations and personality), and the perceived level of success of program implementation (Rogers, 1983; Steckler et. al, 1992; de Vries, 1993).

\section{Interview topics}

Before the interview started, the three types of programs (educational, labeling, food supply) were roughly explained to the respondents. Also was explained that the results of this study were going to be used to further design the programs. Relevant constructs for this study from the theories about diffusion of innovations were used to formulate 


\section{Feasibility and conditions for implementation}

the interview questions. Questions were asked about attributes of the innovation, characteristics of the adopting organization, and characteristics of the adopting persons (Table 1). Besides questions directly derived from theoretical constructs (e.g. what are the relative advantages of the programs) some practical questions concerning program requirements and program materials were added (e.g. what are the preferences regarding program materials). In order to give respondents the maximum possibility to express their opinion, all questions were open-ended. Depending on the answers of the respondent, the interviewer asked more detailed questions in order to get as much information as possible.

Table 1 Main interview topics

\begin{tabular}{|c|c|c|}
\hline Attributes of the innovation & $\stackrel{\bullet}{\bullet}$ & $\begin{array}{l}\text { What are important program requirements? } \\
\text { What are the preferences regarding program materials? } \\
\text { Which factors might increase the complexity of the } \\
\text { programs? } \\
\text { What are the relative advantages of the programs? }\end{array}$ \\
\hline $\begin{array}{l}\text { Characteristics of the } \\
\text { adopting organization }\end{array}$ & • & $\begin{array}{l}\text { What is the concern and interest of the organization } \\
\text { about nutrition education? } \\
\text { What experience has the organization with educational } \\
\text { activities? } \\
\text { How is the decision making process regarding the range } \\
\text { of products and educational activities organized? } \\
\text { What social support can be expected in the } \\
\text { organization? }\end{array}$ \\
\hline $\begin{array}{l}\text { Characteristics of the } \\
\text { adopting persons }\end{array}$ & - & $\begin{array}{l}\text { What is the attitude of the adopting person towards } \\
\text { nutrition education? }\end{array}$ \\
\hline
\end{tabular}

\section{Analysis}

The interviews were recorded to tape, and full transcripts were made. Subsequently, the transcripts were divided into small text-units. The text-units were coded and categorized by the researcher according to the list of interview topics. Text-units could be relevant and coded for more than one interview topic. After the coding-process, the text-units were sorted per interview-topic. Finally, summary-reports of each topic were written. In some cases the type of respondent (e.g. a local supermarket manager or a representative of the head office of the supermarket) was taken into account. In order to 


\section{Chapter 2}

facilitate this, all text-units were coded by the type of respondent. This so-called 'cutand paste'-technique is described as a quick, cost-effective and very useful method for analyzing transcripts (Stewart \& Shamdasani, 1991). A word processing program was used to carry out the procedure.

\section{Results}

In total 12 interviews were conducted with worksite cafeterias and 8 with supermarkets. Five worksite cafeterias and four supermarkets refused an interview, for reasons of time. Six representatives of the worksite cafeterias were head or employee of the Service Department of their company, five were local catering managers employed by a catering organization but detached to a specific worksite cafeteria, and two were employees at the head office of a catering organization. Different types of companies were included in the study, for example a hospital, a governmental organization and a cement factory. All the companies had a worksite cafeteria serving 70 to 600 clients a day. The greater part of the employees of the companies included in the study, attended the cafeteria regularly, varying from $50 \%$ till $85 \%$ per company. Concerning the supermarkets six interviews were conducted with local supermarket managers, and two with representatives of head offices of large national supermarket chains. The supermarkets were all related to some supermarket chain. The mean number of customers per week varied from 2,200 till 10,000 per week. Three supermarket managers were franchisers, and three were branch managers. The duration of the interviews in both the worksite cafeterias and the supermarkets varied from one hour till an hour and a half.

\section{Attributes of the innovation}

\section{Program requirements}

Tables 2 and 3 show requirements on the programs and program materials spontaneously mentioned by the respondents. Most frequently mentioned was that a nutrition education program should not be too obtrusive. Not too obtrusive, according to the respondents, means that people should not be forced to take part in a program, and that people should not get feelings of guilt as a result of a nutrition education program because of the way they eat. Among other requirements, the nutrition 


\section{Feasibility and conditions for implementation}

education program should not be too time-consuming (for both cafeteria or store personnel and clients), it should be practicable, the program materials should be attractive, and eco-friendly. Specific tor supermarkets is that a program should increase profit. Further, the labeling program should not be too time-consuming for cafeteria or store personnel, be hygienic, the labeling should not be too excessive, and labels should not move around. Some respondents indicated that the food supply program should be an extension of the range, while other respondents preferred a replacement of unhealthy products with healthy products. Other requirements for the changes in food supply program included that the turn over rate of products should remain high enough, and that the prices of the healthy products should be the same as those of other products. A specific requirement for worksite cafeterias is that the labeling program and food supply program should not cause delays at the counter.

\section{Program materials}

Respondents were asked specifically about their preferences for certain program materials. Brochures, flyers, hand-outs, posters, displays, and self help guides were seen as good intervention materials to use in worksite cafeterias by almost all respondents. Publicity in the worksite newsletter was also seen as a good possibility by most respondents. Table tents were preferred by all respondents, except two who gave the limited space on the tables as main reason for not preferring them. Due to possible technical difficulties and the disturbance it might cause, using audio messages was not a good idea according to the respondents. Giving clients information on their receipt (about the amount of fat of the products purchased, for example) was not an option for several reasons: it is too obtrusive, most clients do not take their receipt, and some cash-desks do not have the technical possibilities. Respondents came up with several other ideas for program elements, namely placemats (four respondents), video, lowering the prices of healthy products, change in composition of products and meals, a symposium about healthy nutrition, messages through the computer network or internal television circuits, special offers, putting all the healthy products together on one counter, giving clients recipes of healthy meals offered in the cafeteria, a flag in the cafeteria with the logo of the program, and finally announcements via notice-boards. 


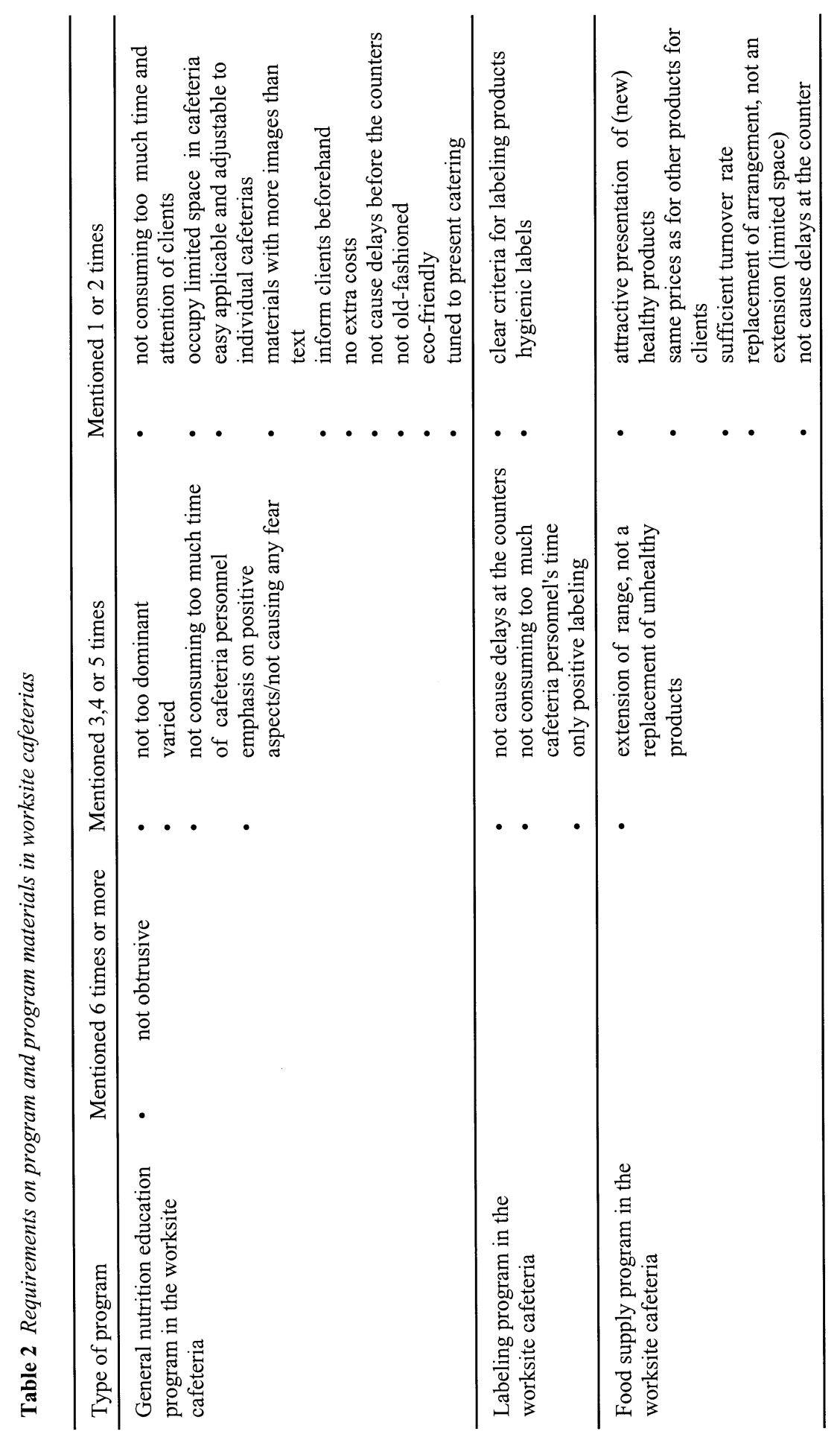




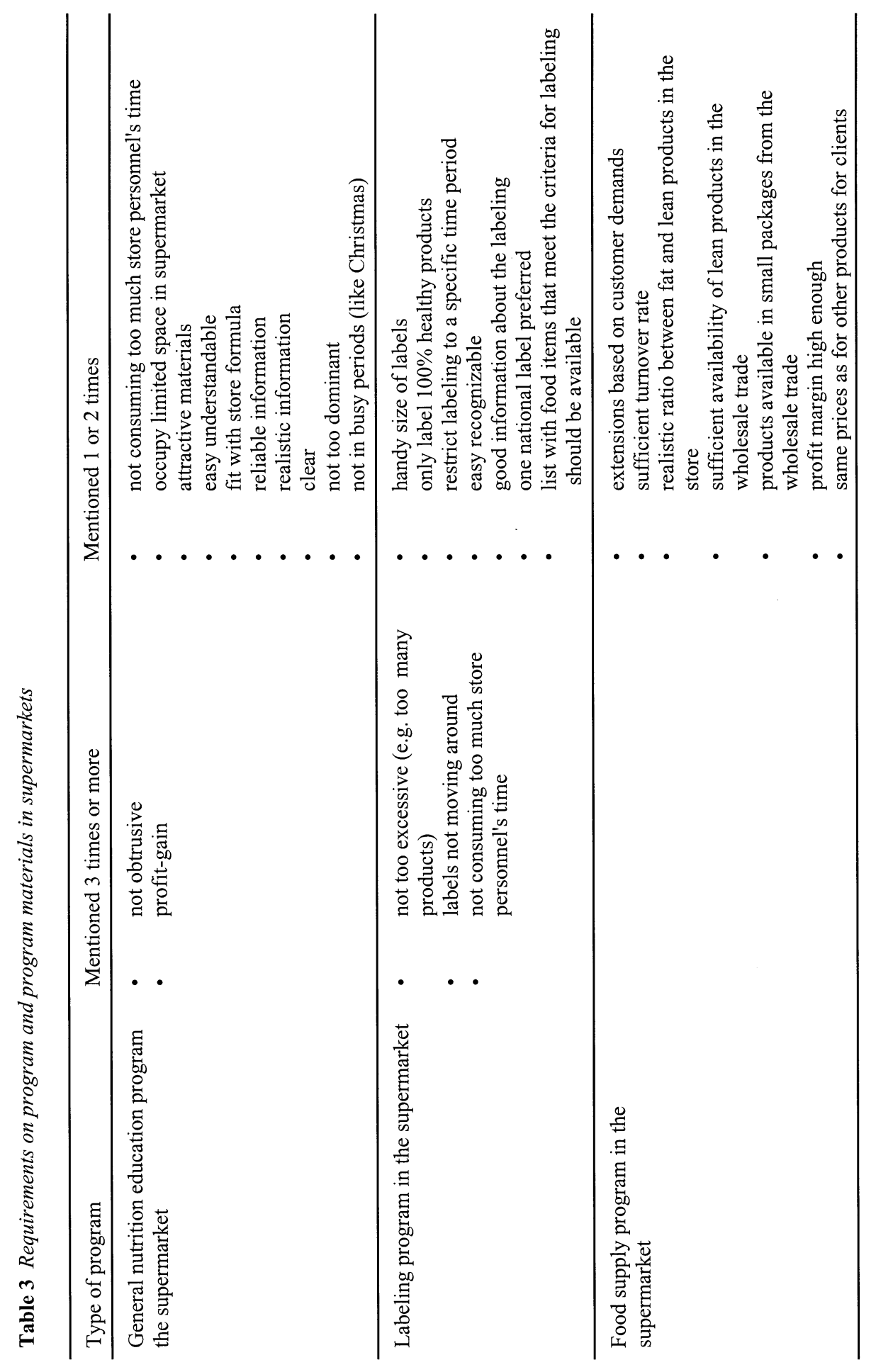


For supermarkets, nearly all respondents indicated brochures, flyers, posters, displays, information in the already existing store advertisements, and self help guides as good program elements. Respondents had mixed feelings about audio-messages. For some respondents audio-messages could be an option, while others did not think so because they thought it would be too complicated. Regarding hand-outs (giving each client a paper with information at the pay-desk), respondents had some doubts too. They were concerned that customers would leave the hand-outs in their grocery carts, and therefore increase rubbish in the store. All respondents were not in favor of giving clients information on their receipts because clients do not read their receipts and it would be too much trouble to add the information on the receipts (i.e. technical problems). Also, if something could be added to the receipts, respondents would add other information than information about healthy nutrition. Furthermore, respondents came up with some other ideas for a healthy nutrition program in the supermarket, namely cooking or product demonstrations, healthy menu information together with special offers of the needed ingredients, connecting the labeling with some kind of saving-system, billboards on the parking-lot of the supermarket, test-tasting of certain products, and making a healthy products corner in the supermarket.

Specific questions about the format of the labeling intervention revealed that most respondents (both worksite cafeterias and supermarkets) prefer labeling of healthy products only, instead of labeling all products. This is more distinctive and requires less time. Moreover, respondents only want to promote products (positive labeling), instead of creating a negative image of products high in fat content. Also, labeling all kinds of products available in the supermarket is impossible according to the respondents, because of the number of products in a supermarket. One respondent thought that the labeling should be restricted to certain product categories in order to decrease the complexity of the labeling program: labeling of fresh products was feasible, while labeling of prepacked products would be more difficult. Concerning the information on the labels, some respondents indicated that product information such as the fat-content or the caloric value would be desirable, but most respondents only wanted a program logo and slogan (for example 'healthy choice') on the labels. The reason for this was because less time is required for clients to read the labels (in connection with possible delays at the counters). Furthermore, they thought product information was irrelevant 


\section{Feasibility and conditions for implementation}

for clients and also difficult to count for prepared meals. Because of the limited time available to put the labels in the cafeteria or supermarket, respondents preferred a label that could be used to label a group of items (for example shelf labeling) instead of labeling every single product. Most respondents would like to have both self-adhesive labels and little cards in bearers to put on the counter. Furthermore, the appearance of the labels should be colorful.

\section{Complexity}

Respondents mentioned several difficulties that increase the degree of complexity of the programs. Possible difficulties in using the programs included the amount of time, space and money the program might cost, and possible lower sales of unhealthy products. Possible difficulties regarding participating in the labeling program included the amount of time and money, difficulties in deciding which products should be labeled, risk of irritating clients, the risk of labels moving around, and finally the risk of putting the labels on the wrong products. Respondents did not expect problems with manufacturers or the wholesale trade regarding labeling certain food products. Specific problems expected in the supermarkets included the risk of product discrimination and the lack of an efficient updating-system for the labeling. Expected problems regarding the food supply program were the availability of healthy products in the whole sale trade and the limited space in cafeterias and supermarkets. Possible problems mentioned specific for worksite cafeterias included the time required to prepare low fat snacks, the higher price of healthy products, and the limited shelf-life of low fat products. Possible restraints mentioned for the food supply program in supermarkets were too much left-over stock if customers did not buy the new products, the preference of customers for products with a high fat content, and the fact that customers always buy the same products out of habit.

\section{Relative advantages}

Respondents were asked to indicate relevant relative advantages with respect to current practices of the three programs. Tables 4 and 5 show the relative advantages that were mentioned spontaneously by the respondents. Respondents indicated aspects relevant for the employees or clients as well as for the worksite cafeteria /company or supermarket itself. 
Additionally, respondents were questioned about a few other possible relative advantages of program participation. When specifically asked, respondents indicated that increasing customer satisfaction could be a possible relative advantage of program participation as well as a positive influence on company or store image. Most respondents did not expect increased overall sales as a result of program participation. Concerning worksite cafeterias, some respondents expected a positive effect on wellbeing of employees and less absence due to illness. A better competitive position towards other companies was not a reason to conduct a nutrition program in the worksite cafeteria for either the company representatives or the local catering managers. However, for the representatives of the catering organizations it was an important reason. A better competitive positioning towards other supermarkets could be a relative advantage, according to the respondents, but only if their supermarket were the only supermarket/chain with the program. Finally, a majority of the respondents thought that a nutrition program could possibly attract more customers for the supermarkets and could increase customer satisfaction.

Table 4 Relative advantages of nutrition education programs in the worksite cafeteria

\begin{tabular}{lll}
\hline Type of program & Relative advantages \\
\hline $\begin{array}{l}\text { General nutrition education } \\
\text { program in the worksite } \\
\text { cafeteria }\end{array}$ & - & $\begin{array}{l}\text { it shows more concern for the employees } \\
\text { it gives a more positive image/good public relations } \\
\text { possible higher sales of certain products } \\
\text { positive influence on the well-being of employees and } \\
\text { therefore more productivity }\end{array}$ \\
$\begin{array}{ll}\text { Labeling program in the worksite } \\
\text { cafeteria }\end{array}$ & - & $\begin{array}{l}\text { healthy products will be easier recognizable } \\
\text { it will raise more consciousness about healthy nutrition } \\
\text { possible higher sales for the labeled products } \\
\text { it adds something to the cafeteria by making healthy } \\
\text { choices visible }\end{array}$ \\
$\begin{array}{l}\text { Food supply program in the } \\
\text { worksite cafeteria }\end{array}$ & - & $\begin{array}{l}\text { the well-being of employees will increase } \\
\text { employees will have more choice in the cafeteria }\end{array}$ \\
\hline
\end{tabular}


Feasibility and conditions for implementation

Table 5 Relative advantages of nutrition education in the supermarket

\begin{tabular}{lll}
\hline Type of program & \multicolumn{2}{l}{ Relative advantages } \\
\hline $\begin{array}{l}\text { General nutrition education } \\
\text { program in the supermarket }\end{array}$ & - & $\begin{array}{l}\text { possible higher sales of certain products (more profit) } \\
\text { it gives more variation in the store }\end{array}$ \\
& - & $\begin{array}{l}\text { it gives a more positive image/good public relations } \\
\text { it might attract new customers }\end{array}$ \\
\hline $\begin{array}{l}\text { Labeling program in the } \\
\text { supermarket }\end{array}$ & - & $\begin{array}{l}\text { healthy products will be easier recognizable } \\
\text { possible higher sales for the labeled products }\end{array}$ \\
\hline $\begin{array}{l}\text { Food supply program in the } \\
\text { supermarket }\end{array}$ & - & it will raise more consciousness about products \\
\hline
\end{tabular}

\section{Characteristics of the adopting organization}

Concern and interest of organization about nutrition education

All company representatives and local catering managers acknowledged providing nutrition education in their worksite cafeteria as one of their tasks. However, they did not perceive it as a very important task. All catering organizations, on the contrary, attached considerable importance to their task and role in providing nutrition education. For supermarkets, some respondents acknowledged providing nutrition education as one of the tasks of a supermarket. However, the majority of the respondents did not see providing nutrition education as a task or priority of the supermarket. Making profits is the first priority. Besides, supermarkets are willing to provide some product information.

\section{Experience of organization with educational activities}

All companies had some experience with educational activities in the worksite cafeteria. However, not all companies had experience with healthy nutrition activities. Activities are mostly organized in so-called 'action weeks' with themes such as 'nutrition and sports', 'bread', 'food from a different country'. During these weeks different materials are used such as posters, leaflets, brochures, displays and articles in the worksite newsletter. Some cafeterias had offered new food products during these action weeks. One catering organization had experience with the labeling of healthy 
food products. Respondents reported that the employees had always reacted positively towards these actions. All the supermarkets had also some experience with giving information in the supermarket, and most of the supermarkets had experience with giving information about healthy nutrition. Product demonstrations are widely used, often in connection with the introduction of new products. Some supermarkets participated in national campaigns such as the Dutch National Fat Watch Campaign. Elements of this campaign were for example supermarket tours guided by a dietician and brochures. One supermarket chain has a sponsored shop magazine in which they regularly pay attention to topics about healthy nutrition.

\section{Decision making process regarding range of products and educational activities}

In most worksites, the local catering managers and the representatives of the companies had a shared responsibility towards the range offered in the worksite cafeteria. Most catering managers received guidelines from their head office, while sometimes the representatives of the companies were advised by the company health services and/or a canteen committee. In selecting the cafeteria range several factors are important. First of all cafeterias offer what customers ask for. Besides this, factors like the price, healthiness, and (seasonal) availability of the product are important, as well as the variety of the range. In most companies there is no structural policy about giving customers information about (healthy) nutrition. Most catering organizations propose a few 'action weeks' during the year with a specific theme. The final decision about these theme weeks, however, is the responsibility of the Service Department of the company. All respondents thought both the catering organization (catering manager) and the representative of the company should be involved in the decision making process concerning program participation. A few respondents also indicated that cooks, cafeteria personnel, the works council, the company health services, and the canteen committee should be involved in the decision making process, although these people do not play a key role.

In the case of supermarket chain stores, the head office determines the range of products of the supermarkets. In the case of franchise stores, the owner has the responsibility for the range of the supermarket, although the range has to satisfy certain conditions of the store formula. The selection of the range of the supermarket is based 


\section{Feasibility and conditions for implementation}

on a lot of different factors, but most important is the profit (margin) of products. Besides this, the number of products sold and unsold, the price of a product, the (local) demand of customers, the range in competing stores, the supply from the wholesale dealer, the size of the package available of the wholesale trade, the ratio between store brands and proprietary articles, the size and location of the store, the kind of customers, and the quality of the products are important. The head offices of the chain stores are responsible for the information given to the customers, in the other cases the owner of the supermarket is responsible. This also applies to information about healthy nutrition. People who should be involved in the decision making process concerning a healthy nutrition intervention in a chain store are, according to the respondents, product managers at the head office, the board of the chain, and the branch manager. In the case of franchise-stores, the owner of the store and sometimes the executive staff in the supermarket are the ones to be involved in the decision making about a healthy nutrition program.

\section{Social support}

Respondents were asked from which persons they would receive cooperation and social support when conducting a nutrition program. Besides the company itself and the catering manager, several actors in the worksite cafeterias were mentioned by one or more respondents, namely cafeteria personnel, the company health service, the works council, people with responsibility concerning working conditions, the department of public relations, and finally the department of support and services of the head office of the catering organization. The actors who should be involved if a supermarket participates in a nutrition education program were, according to the respondents, the board of the supermarket chain, the store personnel, in case of a franchiser the storeowner, in other cases the branch manager, and some departments of the head office (for example the department that decides about the range).

Almost all respondents thought that their personnel would react positively on program participation and would be willing to help to carry out the program. In order to gain social support from the worksite cafeteria or store personnel, respondents indicated that their personnel should be educated, and informed about the program and healthy nutrition beforehand. Personnel should learn more, for example, about the importance 
of healthy nutrition and the fat content of food products. Some respondents preferred to inform the personnel during a regular work meeting, others preferred an extra meeting or class. In addition to this, written information about healthy nutrition and the program should be given to the personnel. An additional way of informing supermarket personnel is through an instruction video. A lot of supermarkets use this already to inform their personnel.

\section{Characteristics of the adopting persons}

The personal attitude of the respondents towards giving nutrition education in the cafeteria or supermarket was positive, although a major concern was that nutrition education may restrict people's own choices. The majority of the respondents agreed also that the cafeteria setting and the supermarket setting offered good opportunities for influencing people's eating habits.

\section{Discussion}

The purpose of the study was to assess conditions for adoption and continued implementation of both educational and environmental programs, aimed at changing dietary behavior, to be implemented in worksite cafeterias and supermarkets. The study provided information that can be used for the further development of programs, as well as the development of implementation strategies.

Concerning program development for worksite cafeterias, it appeared that the educational program should not be too obtrusive, not be too dominant, not consume too much time, and should have an emphasis on positive aspects. Different program materials seem appropriate for use in the cafeteria (brochures, flyers, hand-outs, posters, displays, self help guides, publications in the worksite newsletter). Audiomessages and information on receipts are not considered to be applicable. For the labeling program a few features can be added: the labeling program should only label healthy products, the labels should be hygienic, and very comprehensible. Labeling a group of products instead of labeling single products is preferred, with not too much information on the labels. Furthermore, labels should be available both as self-adhesive and little cards in bearers. For the food supply program also a few features can be 


\section{Feasibility and conditions for implementation}

added. Prices should not increase and only limited changes of the range are desirable. However, respondents could not agree whether these changes should be an extension of the range or rather a replacement of certain products. In order to link up with the existing way of working, the programs should be designed as a short action-period (a few weeks).

Concerning implementation strategies for worksite cafeterias, some factors can be identified. First of all, in order to persuade companies to implement a nutrition education program the following advantages should be stressed: the concern for employees, the positive influence on company image, and (if we can prove that in further research) possible higher sales for certain products. Furthermore, expected difficulties mentioned by the respondents should be diminished, by stressing that the intervention will be delivered ready made, that the aim of the intervention is not to ban eating unhealthy products, or that only small changes in the range will be necessary. When disseminating the intervention, it is appropriate to approach both the catering organization and the company, because the decision to participate in an intervention program is a shared decision. Finally, in order to facilitate good implementation of the intervention, the cafeteria personnel should be informed before the start of the intervention.

In general the same factors regarding program development and implementation strategy are important for supermarkets. The importance of increasing profit (either directly or indirectly through more customer satisfaction), and the need for program materials to be professionally and attractively produced, are additional factors requiring consideration in supermarket programs. Again, several types of materials can be used (brochures, flyers, posters, displays, information in store-magazines or advertisements, self help guides). The possibility of using audio-messages and hand-outs should be studied in individual cases. According to this study, it is not possible to provide nutrition information on receipts. Regarding the labeling program, a specific feature for the supermarkets is the fact that not too many products can be labeled. Therefore, the labeling should be restricted to the most important product categories, and shelf labeling should be used instead of labeling each single product. Also, the duration of the labeling should be limited and the appearance of the labels should prevent labels 
Chapter 2

moving around in the supermarket. It remains unclear whether (some) product information should be given on the labels in the supermarkets. The results reported in this article are based on interviews with intermediairs. In a review of Glanz et al. (1996) results of studies among consumers are described. In this review it is concluded that consumers only use nutrition information if it is easy available, clear, perceived as useful and new, and simple to use. Besides program requirements mentioned by the intermediairs in our study, requirements of consumers should be taken into account.

Regarding implementation strategies some factors can be added to the factors already described for the worksite cafeterias. Because a profit gain is so important for supermarkets, the profit gain of nutrition programs should be studied, and also the possible indirect profit gains (other than money) should be stressed when persuading supermarkets to start a nutrition education program. More customer satisfaction or attracting more customers are important for the supermarkets. In the case of franchisers, the franchisers themselves should be approached for participation in a program. In other cases, the head office of the supermarket chain should be approached since chain stores cannot take the decision whether to take part in a nutrition education program or not. Because most supermarkets do not see nutrition education as one of their tasks, it is very important to stress the advantages of program participation for the supermarkets.

In order to achieve the ideal 'fit' between an innovation and its users (and through this consequently enhance its successful implementation), understanding of the environment and context in which a diffusion occurs is important (Orlandi et al., 1997). The results of this study are very useful for the development of nutrition programs and implementation strategies that have the maximum possible fit between program and users or environment. Because of the number of respondents in this study, generalization of the results is limited. Due to the consistency of responses from interviewees, it is unlikely the findings would have been substantially different if a greater number of interviews had been conducted. The study revealed a lot of information that is useful in further development of nutrition programs. 
Glanz et al. (1992) reviewed 26 studies on worksite nutrition and cholesterol intervention programs. This review showed that worksite nutrition and cholesterol programs are feasible in the United States. Moreover, it appeared that strategies that combine both educational and environmental strategies have the greater effect. Based on the results of our study, it is concluded that educational and environmental nutrition interventions in worksite cafeterias and supermarkets are feasible in the Netherlands, provided that the conditions identified for adoption and implementation regarding program development and implementation strategies are taken into account.

One similar study about conditions for adoption and implementation of nutrition programs was conducted by Peterson and colleagues (1986). In that study, seventeen food vendors were interviewed (among them caterers and grocery managers). It showed that the most important reasons for adopting "healthy heart marketing practices" were health concerns of customers and vendors, e.g. food vendors were sensitive to customer demands. The second most important was the food vendors' profit motivation. In this case, profit was for example free publicity and positive public relations, but also increased business and profit. Other factors influencing the adoption of "healthy heart marketing practices" included the fact that a nutrition education program should entail an opportunity to provide a customer service, and that it should show how food vendors could make easy and inexpensive changes. The results of the Dutch study described in this article, are consistent with the results of the study conducted in the United States by Peterson et al.. Other studies do not report the results of pilot studies separately, but include them shortly within the results of evaluation research of the intervention program in question. It often concerns meetings with key persons, representatives or steering committees, which are organized to fit the program to the target population. For the 'Treatwell program' for example, formal and informal interviews were held with employees, including representatives of human resources, food service and health promotion or medical departments (Sorensen et al., 1990). The interviews provided information useful for planning the intervention, such as information about individuals and resources that would enhance program and policy adoption. Also, existing and potential barriers were identified in the interviews, and possible ways to eliminate or diminish them. However, no more detailed information is given regarding the methods and results of the interviews. For the 'Pawtucket Heart Health Program', 18 interviews 
with key informants were conducted and were reported as part of a case history of nutritional information on menus (Lefebvre, 1986). The respondents represented restaurants, supermarkets, food services, food distributors and food journalists. Based on, among other things, the interviews, a couple of food vending strategies were defined. Examples of these food vending strategies are that programs have to appeal to the profit motive of the restaurant managers, that labeling has to be easy and simple, and that programs have to be economical for both the restaurants and its consumers to implement them. These food vending strategies are also in accordance with the findings of our study. Furthermore, it is concluded in the 'Pawtucket-study' that good taste of healthy products is a critical component of successful food vending strategies (Lefebvre, 1986).

It is regrettable that results of pilot studies in which conditions for adoption and implementation are identified are not published in more detail. Such information may be useful for the development of other programs. From the present study, it can be concluded that worksite cafeterias and supermarkets are willing to participate in both educational and environmental nutrition programs, if these programs satisfy certain demands concerning program design and program implementation. Except that programs should be positive and easy practicable for both personnel and customers, programs have to meet a lot of practical demands. In order to get these programs implemented correctly, implementation strategies should focus on the perceived advantages of nutrition programs by worksite cafeterias and supermarkets, and on diminishing expected difficulties of conducting nutrition programs. The results of the present study were used to develop a nutrition education program, a labeling program, and a food supply program for use in worksite cafeterias and supermarkets. For a brief description of program elements see Table 6 . 


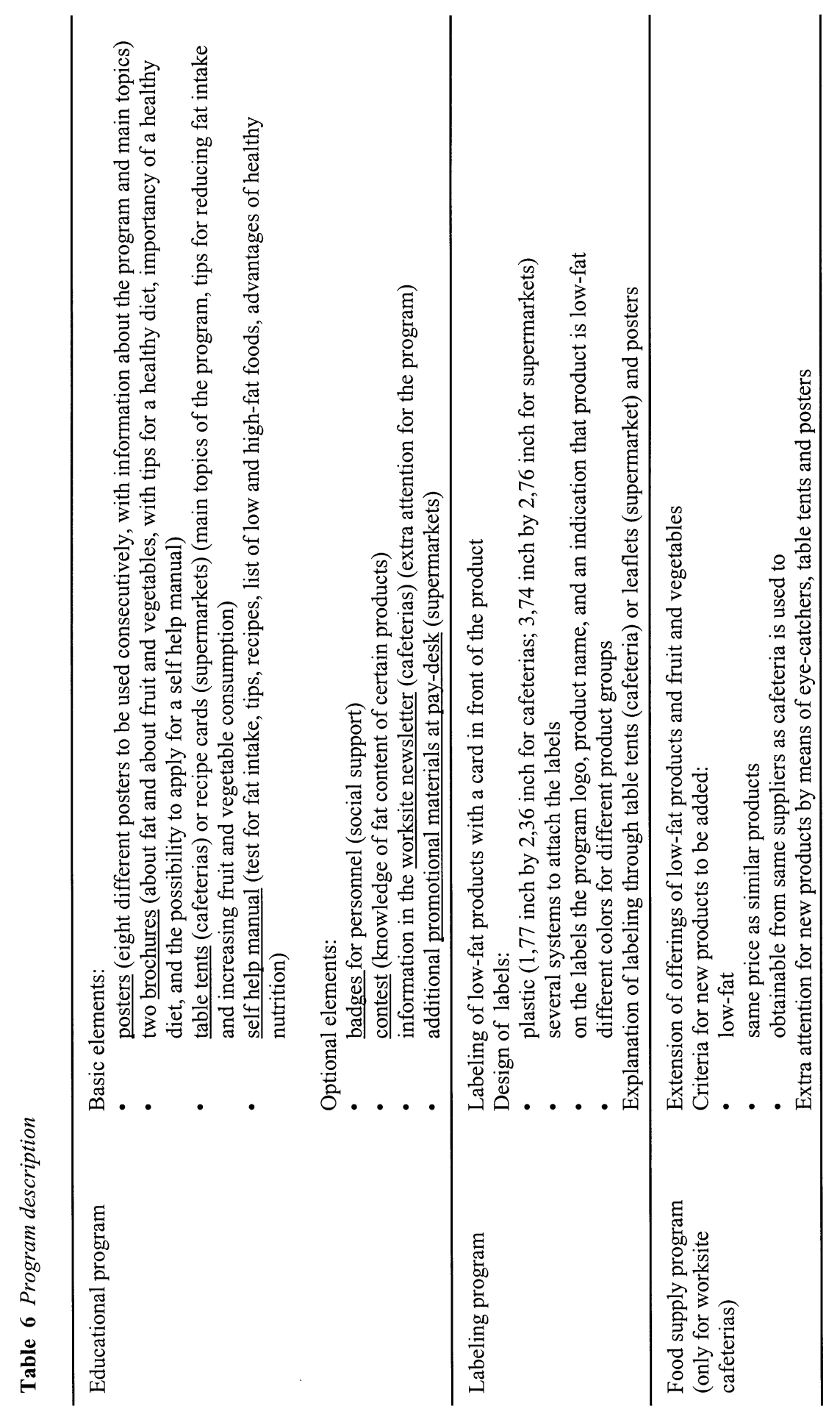




\section{Chapter 3}

\section{Effects of educational and environmental interventions in Dutch worksite cafeterias ${ }^{4}$}

${ }^{4}$ Submitted for publication as: Steenhuis, I.H.M., Assema, P. van, Breukelen, G.J.P. van, Glanz, K., Kok, G.J., Vries, H. de. Effects of educational and environmental interventions in Dutch worksite cafeterias. 


\begin{abstract}
Environmental interventions as labeling of healthy foods and changes in the food supply may help consumers to meet the guidelines for a healthy diet. This article describes a study into the effectiveness of two environmental programs to be used in worksite cafeterias along with an educational program. The aim of the interventions was to reduce fat intake and increase fruit and vegetable intake. In the Labeling Program, low fat products were labeled. The Food Supply Program comprised an extension of the offerings of low-fat products, as well as an expansion of the fruit and vegetable supply in worksite cafeterias. The Educational Program consisted of information about healthy nutrition through brochures, table tents, a self help manual and posters. The design consisted of a pretest-posttest experimental control group design, with four conditions: the Educational Program, the Food Supply Program plus Educational Program, the Labeling Program plus Educational Program and a control group. Seventeen worksites were randomly assigned to one of the four research conditions. Total fat, fruit, and vegetable intake, as well as intake during lunch in the cafeteria and behavioral determinants were measured. Furthermore, sales data for targeted product categories were collected. No significant effects on consumption data were found for any of the programs. Sales data revealed a significant effect of the labeling program on desserts, but not for the other products. In this study, nutrition education, extension of the offerings and labeling did not prove to be effective strategies for achieving changes in dietary behavior of the whole study population. A program including labeling of low fat alternatives, might be effective on the short term for people who believe they have a high fat intake.
\end{abstract}


Effectiveness in worksite cafeterias

\section{Introduction}

Dietary factors have been found to be important in the prevention of cancer and coronary heart diseases (Willett, 1994). In the Netherlands, several efforts have been made to reduce the risk of these diseases by trying to decrease fat consumption and increase the fruit and vegetable consumption of the population. The official Dutch Guidelines for Healthy Nutrition recommend a dietary fat intake of $20-40 \%$ of total calories for people with a normal body weight, while for people with overweight a dietary fat intake of $20-30 / 35 \%$ of total calories is recommended (Health Council of the Netherlands, 2001). At the time this study was conducted, the guidelines were somewhat different: a dietary fat intake of no more than $30-35 \%$ of total calories was recommended, and an intake of saturated fat of no more than $10 \%$ of total calories (Dutch Nutrition Council, 1986, 1991). The Dutch guidelines also recommend eating 200 grams of vegetables and 2 pieces of fruit per day (Dutch Nutrition Council, 1986; Netherlands Bureau for Food and Nutrition, 1992).

There is still a discrepancy between the guidelines and the actual reported food intake of the Dutch population (Netherlands Bureau for Food and Nutrition, 1998). Actual fat intake of the Dutch Population in 1998 was $35.9 \%$ of total calories, the intake of saturated fat $14.2 \%$, fruit intake was 105 grams per day and vegetable intake 123 grams per day (Netherlands Bureau for Food and Nutrition, 1998). Therefore, effective methods for achieving large scale dietary changes are needed. It is now widely accepted that health promotion strategies need to go beyond education and communication strategies. Environmental strategies should be included in order to achieve wide behavioral changes among the target population (Bracht, 1999). This is also the case for health promotion aimed at changing dietary behaviors. Environmental strategies can be defined as strategies that reduce barriers or increase opportunities for healthful choices, e.g. more healthful options, make healthy choices more accessible, and establishing policies that require healthful choices or restrict the number of 'less healthy' options (Glanz et al., 1986). Environmental interventions to allow and encourage adoption of healthful eating patterns can be implemented in different settings. Point-of-choice settings, i.e. where food is provided, prepared, sold or served, are especially suitable for environmental interventions (Glanz et al., 1986). The worksite cafeteria is such a point-of-choice setting. Additional advantages of nutrition 
interventions in worksite cafeterias are the potential social influence and social support present in the worksite, the availability of a daily eating situation, and opportunities for follow-up, monitoring, and reinforcement of messages (Glanz \& Seewald-Klein, 1986).

Different environmental intervention strategies have been used in worksites. A few studies reported on changes in food offerings. Jeffery et al. (1994) used a reduction of $50 \%$ in the price of fruit and salads in combination with an increase of fruit and salad bar choices. After the intervention ended the increased purchases during the intervention period dropped, but remained significantly higher than at baseline. Wilbur et al. (1981) found positive effects for extending low-calorie offerings in vending machines. Various studies analyzed the impact of labeling of healthy food items in worksite cafeterias (e.g. Dubbert et al., 1984; Levin, 1996; Mayer et al., 1987; Schmitz $\&$ Fielding, 1986; Sorenson et al., 1992). Most of the reported labeling programs were implemented in combination with an educational program including, for example, posters, brochures, advertisement campaigns, et cetera (Sorenson et al., 1992). Two types of food labels have been reported in the literature. The first type of labels were only placed on healthy food items and indicated through a symbol, a color or a text that the item is a good choice (Levin, 1996; Albright et al., 1990). The second type of labels gave specific nutrient information (Mayer et al., 1987). These labels indicated for instance the number of calories or grams of fat per serving. In most studies using labeling, effects on the purchases of labeled items were found (Dubbert et al., 1984; Levin, 1996; Schmitz \& Fielding, 1986; Sorenson et al., 1992). The effects varied in magnitude, duration and consistency. Mayer et al. (1987) did not find increases in the purchases of labeled items.

While environmental interventions to change dietary behaviors in worksites are promising strategies, it is still unclear exactly how effective they are. Many studies using environmental interventions were combined with educational elements (Mayer et al., 1987; Sorenson et al., 1992) or with other environmental interventions (e.g. Jeffery et al., 1994). Hence, it is impossible to determine the unique contribution of separate environmental interventions. The objective of this study was to assess the separate effects of two environmental interventions (i.e. changes in food supply and labeling) 
Effectiveness in worksite cafeterias

aiming at reducing fat intake and increasing fruit and vegetable consumption in worksite cafeterias. An educational program with an environmental component (the changes in food supply or the labeling) was compared to a program with only educational elements, as well as with no intervention at all.

\section{Methods}

\section{Study design and procedures}

The study used a randomized pretest-posttest experimental design. Seventeen worksite cafeterias of large Dutch companies and governmental organizations with mainly white collar workers were recruited. The main inclusion criteria were a minimum of 400 cafeteria visitors a day, offerings that allow extension with at minimum four products as well as labeling, and sufficient opportunity for data collection. After recruitment, the cafeterias were randomly assigned to one of four experimental conditions (see Figure 1). This design allows to assess the effects of the two environmental programs in comparison to a no-intervention condition as well as to a program that only includes educational elements.

\footnotetext{
1. Food Supply Program plus Educational Program

2. Labeling Program plus Educational Program

3. Educational Program

4. No Program, control
}

Figure 1 Overview of research conditions

\section{Measures}

Two different data collection methods were used for the effect evaluation. A cohort of regular visitors of the cafeteria were asked to fill out a questionnaire one month before, one month after and six months after the start of the intervention. For the baseline measurement, respondents were recruited during lunch time in the cafeteria. In total, 5,425 questionnaires were handed out (varying from 255-350 per cafeteria). The second questionnaire was distributed through company mail to persons who had completed the 
first survey, and the third questionnaire to persons who also had completed the second survey.

In the questionnaires, fat-, fruit-, and vegetable intake were measured with a short food frequency list, validated in earlier research (van Assema et al., 1992; van Assema et al., 2001; van Assema et al., in press). In this list, fat consumption was expressed in 'fatpoints'. One fat point is about four grams of fat. The list consists of 35 questions covering 19 (categories of) food items. The food items were selected based on their contribution to the fat intake of the Dutch population (Netherlands Bureau for Food and Nutrition, 1993). Also in the questionnaires, food choice during lunch in the cafeteria was measured by asking respondents to write down what they ate the last time they had a meal in the cafeteria. Socio-demographic variables were measured, as well as possible influencing factors such as BMI (body mass index), household size, cooking behavior, shopping behavior, following a diet or being a vegetarian. Furthermore, psycho-social determinants of eating less fat and more fruit and vegetables were measured. Included psycho-social determinants were attitudes, social influence, selfefficacy and intention, following the 'Attitude-Social influence-Self-efficacy model' (ASE model) (de Vries et al., 1988; Kok et al., 1991). An attitude represents a person's general feeling (favorable or unfavorable) towards the behavior concerned. Social influence refers to the influence of others, and can be directly (expectations of significant others), or indirectly (what others do). Self-efficacy refers to a person's expectation regarding his capability to realize a behavior. Attitudes, social influence, and self-efficacy predict the intention to perform the behavior, which in turn predicts the behavior itself. Attitudes were in this study measured with one item on a 'good-bad' scale. Two aspects of social influence were measured: social support and modeling of colleagues. Self-efficacy was measured with one item, as well as intention to eat less fat or more fruit or vegetables within the next month. These variables were measured on a 7-point scale. In addition, possible misconceptions about own consumption levels were measured, since in recent years this has been identified as another important factor determining dietary behavior (Brug et al., 1994). Possible misconceptions were computed by combining scores on fat, fruit and vegetable intake derived from the food frequency questionnaire with an item about the amount of fat, fruit or vegetables a respondent indicated he or she was eating. Respondents were classified in three groups: 


\section{Effectiveness in worksite cafeterias}

realistic about their own consumption, underestimating their own consumption and overestimating their own consumption. In the posttest questionnaire one month after the start of the intervention, respondents were also asked about their opinions and reactions toward the nutrition program in their cafeteria. This was measured on seven point scales. Data of the third questionnaire were only used to compute total fat, fruit and vegetable intake.

Sales data of all individual items in the six targeted product categories were collected for each company. Mean sales data per week were collected the three weeks before and during the first month of the intervention period for the following product categories: milk and milk products, butter, cheese, meat products, desserts, snacks, vegetable salads, fruits. Some cafeterias provided computerized lists of sales data, while other cafeterias counted the products by hand. By measuring sales data as well as selfreported purchase ánd consumption data multiple indicators of the dependent variable (nutrition behavior) are included to allow triangulation of measures.

\section{Statistics}

Total fat, fruit, and vegetable consumption scores were computed in SPSS (SPSS INC., 1999). Fat, fruit, and vegetable intake during lunch was computed in the Becel-program (Becel, 1995). Because the data were clustered, a random-effects regression model was initially used for the analysis. Random-effects regression models allow data within clusters (i.e worksites) to be dependent to some degree by assuming a random cluster (worksite) effect (Hedeker et al., 1994). The degree of this dependency is estimated (expressed in the intraclass correlation) along with other model parameters. In this way, the estimates and significance tests of model parameters are corrected for this dependency due to the clustered data (Hedeker et al., 1994). The software packages MIXREG and MIXOR were used to perform the multi-level analysis (Hedeker \& Gibbons, 1996).

The same regression model was used for all outcomes, as well as for the attrition analysis. The independent variables used in the model were the baseline recording of the outcome at hand, study arm, educational level, BMI and shopping behavior. For assessing intervention effects, dummy variables were used with control (NP) and 
education only (EP) as reference category, depending on the relevant comparison (i.e. of an environmental program with EP or NP). In this way it is possible to compare the effects of the environmental interventions with a program with only educational elements, as well with no intervention at all, which was the aim of this study.

For most outcomes (including fat, fruit and vegetables intake in general and during lunch and behavioral determinants) the multi-level analysis ran into numerical estimation problems, probably due to a near-zero intraclass correlation and/or small sample size (i.e. only 17 worksites). In that case, covariates were removed from the model until an estimate of the intraclass correlation could be obtained. This estimate was nearly always $<0.001$, indicating absence of a random cluster effect. If the intraclass correlation is zero, an ordinary regression analysis with persons as unit of analysis and ignoring their nesting within worksites is correct. However, it is also known that an estimated intraclass correlation of 0 can also be due to a small sample size at the highest level, i.c. a small number of worksites. If the intraclass correlation is not zero, even if it is very small, this ordinary analysis is invalid and will underestimate the standard errors of the intervention effects. In that case, an aggregated analysis with worksites as unit of analysis (using the average of all persons within that worksite as observation) is a valid method to evaluate our intervention effects, albeit less powerful than multilevel analysis due to varying sample sizes per worksite and the fact that only very few covariates can be included into this analysis (Moerbeek, 2000). Since in this study the estimates of the intraclass correlation were nearly always $<0.001$, indicating absence of a random cluster effect, we chose to run the full model with covariates with individuals as unit of analysis. However, to check the validity of our conclusions, for the main outcomes (fat, fruit and vegetable intake at baseline and first posttest) as well as for significant results found with the individuals as unit of analysis, an aggregated analysis (using worksites as level of analysis) was also run.

Thus, multi-level analysis is the valid method to analyze the data. However, this analysis could not always be performed and two alternative methods were considered: analysis with the individuals as unit of analysis and analysis with worksites as unit of analysis (aggregated analysis). The analysis with individuals as unit of analysis is too liberal and invalid, unless the intraclass correlation is zero $(0)$. The aggregated analysis 


\section{Effectiveness in worksite cafeterias}

is a bit conservative, but valid whether the intraclass correlation is zero or not. Since in this study the estimated intraclass correlation was nearly always $<0.001$, analyses with individuals as unit of analysis were performed. To check these results, for some outcomes (including fat, fruit and vegetable intake at baseline and first posttest) an aggregated analysis with worksites as unit of analysis was also run.

For the other outcomes (reach of the intervention and respondent's reactions) multilevel analyses were performed. The intraclass correlation varied from 0.001 to 0.028 , except for the variable 'number of people that ordered the self help manual' which had an intraclass correlation of .20, indicating a very strong worksite effect on this variable.

To test for differences in baseline characteristics of research groups such as age or educational level, and respondents' reactions to the programs, an alpha of .05 was used. Also for the main outcomes, fat-, fruit- and vegetable intake, an alpha of .05 was used. To avoid Type I errors due to multiple testing outcomes, an alpha of .01 was used for all the other outcomes. In the tables, both p-values of $<.01$ and $<.05$ are reported.

Sales data were analyzed with SPSS, with worksite as the unit of analysis $(\mathrm{n}=17)$. The three pre-intervention scores were combined to one mean pre-intervention score. Missing data were treated for each product separately following these rules:

- a maximum of two missing values per worksite was allowed, otherwise the worksite was excluded from the analysis of sales data for the specific product;

- a missing value on the pre-intervention score was replaced by the mean preintervention score of other worksites in the same research group;

- a missing value on intervention week 1,2 or 3 was replaced by the mean of the surrounding scores of the same worksite (for example a missing on week 3 was replaced by the mean of week 2 and 4 of the same worksite);

- a missing value on week 4 was replaced by the score of week 3 of the same worksite;

- and finally, at least 2 worksites per research group had to remain for the analysis, otherwise the product was excluded from the analysis. 


\section{Chapter 3}

As a result, only data for milk, butter, cheese, meat products and desserts were included in the analysis; for the other products, there were too many missing data. First, a repeated measurements procedure was run with treatment as a between-subject factor, the pre-intervention score as covariate, and the post-intervention weeks (1-4) as repeated measures. No linear trend was found in the sales data, and therefore final analyses were conducted using the mean sales data for the intervention period. ANCOVA was used to analyze differences between the environmental programs and other programs, with a correction for pre-intervention sales data. Comparisons were made within product groups, and not across product groups. An alpha of .05 was used for these analyses.

\section{Intervention}

Two environmental programs and one educational program were developed. The duration of the programs was one month, and they could be prolonged and supported up to six months. All three programs were based on the outcomes of a preliminary study analyzing conditions for program development and implementation (Steenhuis et al., 2001). The intervention programs were pretested among catering managers and consumers. Based on the pretest results, parts of the intervention were adapted.

\section{Educational Program (EP)}

In the EP, determinants of eating less fat and more fruit and vegetables were targeted, including awareness, attitude, social influence, self-efficacy and skills. Not all information was given at the same time, and during the program the information was tuned to the different stages of behavioral change (Prochaska et al., 1992). This meant that in the beginning of the program more information was given to move people from precontemplation to contemplation by increasing awareness and changing attitudes in a positive direction. After that, the program focused more on moving to preparation and action by increasing self-efficacy and teaching skills. The EP consisted of several elements, some of which were basic and therefore obligatory, and others were optional for the worksite cafeterias. The basic elements were posters (changed weekly) with announcements of the program and slogans about healthy nutrition (for example, the guidelines for fruit and vegetable intake), brochures (one about eating less fat and one 


\section{Effectiveness in worksite cafeterias}

about eating more fruit and vegetables), table tents with tips for eating less fat, and a self help manual. People could obtain the self help manual for free by filling out a coupon that was included in the brochures. The goal of the self help manual was to guide people through the different stages of change for reducing fat intake and increasing fruit and vegetables intake. To start with, the awareness about their own consumption levels was addressed in the manual. For this purpose a self-test to measure fat, fruit and vegetable intake was included. After that, attitudinal information was given, for example about the advantages of eating less fat. For people who wanted to change their dietary behavior, skills for healthy eating were addressed with practical tips on how to cook a low-fat meal, and how to read nutrient information in the grocery store. Also, some recipes were included as well as a list with high- and low-fat foods. Finally, several tips were given on how to sustain new dietary behavior. Optional elements in the educational program were information in the worksite newsletter, badges for worksite cafeteria personnel and a contest in which people had to guess the amount of fat of a meal that was displayed. The duration of the EP was one month. After this month, cafeterias could extend the program by repeating it, or repeating parts of it. Some cafeterias for example repeated the table tents after a month. The brochures and self help guide could be obtained up to six months after the start of the program in all cafeterias.

\section{Food Supply Program (FSP)}

The FSP comprised an extension of the offerings of low-fat products, as well as an extension of the fruit and vegetable supply. The purpose was to enlarge the number of healthy choices available in the cafeteria. In order to carry out the FSP, a dietitian made an inventory of low-fat products and fruit and vegetables already available in the cafeteria, and suggested which low-fat products could be added. Six product categories were included: butter/margarine, milk, cheese, meat products, desserts and snacks. All these categories contribute a fair amount of fat to the total fat consumption of the Dutch population (Netherlands Bureau for Food and Nutrition, 1998) and are consumed frequently in worksite cafeterias. Several factors were taken into account when deciding which products were added, such as the price of similar products and the available space on the cafeteria counters. Attention was drawn to the new added products by putting a sign in front of them with the phrase "new and healthy" on it. 


\section{Chapter 3}

Furthermore, attention was drawn to the new products by means of posters and table tents. The new added products were available for at least one month, but in most cases for a longer period of time.

\section{Labeling Program (LP)}

The goal of the LP was to make healthy choices visible and easy recognizable. In the LP, low-fat products in the six food product categories (see above) were labeled with a sign in front of the product. Information on the label consisted of the program logo, the name of the item and the indication that the product was low-fat. Fruits and vegetables were also labeled. The labeling was explained to the cafeteria visitors on posters and table tents. Specific criteria for which items should be labeled and which should not were developed in cooperation with the Netherlands Bureau for Food and Nutrition. The criteria were in accordance with the Dutch Guidelines on Healthy Nutrition (Dutch Nutrition Council, 1986). The products were labeled for at least one month.

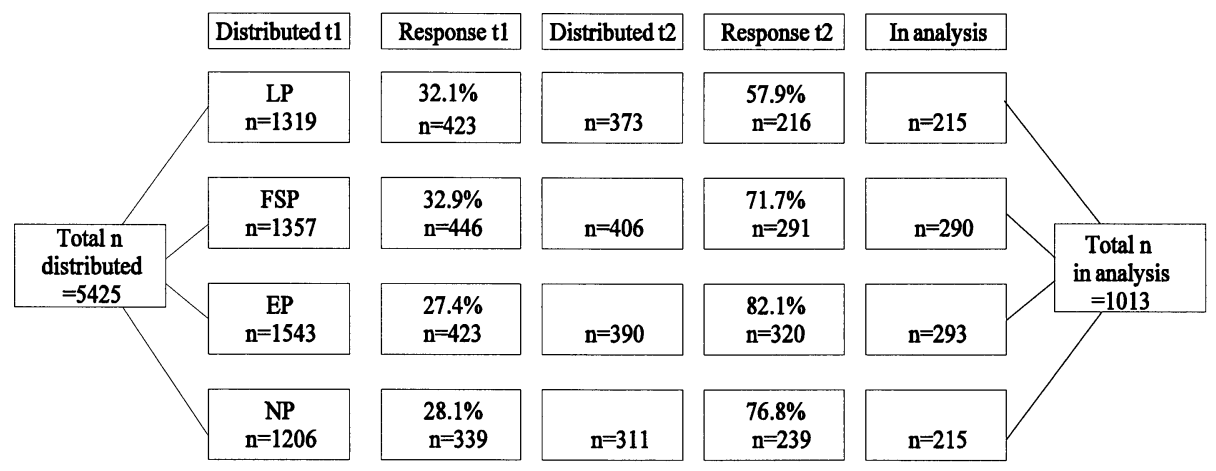

$(\mathrm{LP}=$ Labeling program; $\mathrm{FSP}=$ Food supply program; $\mathrm{EP}=$ Educational program; $\mathrm{NP}=$ No program)

Figure 2 Number of respondents and response 
Effectiveness in worksite cafeterias

\section{Results}

\section{Response and respondents}

Total response at baseline (t1) was $30.1 \%$, and varied from $28.1 \%$ to $32.9 \%$ in the various conditions (see Figure 2). Of the questionnaires, received at baseline, 151 were excluded from the study, because they were not filled out or had more than $50 \%$ missing items. Response at t 2 was $76.4 \%$, and varied from $57.9 \%$ to $82.1 \%$ in the various conditions. At $\mathrm{t} 2,53$ questionnaires were excluded, again because they were not completely filled out (see also Figure 2). In total, complete data (t1 and t2) from 1,013 respondents were used in the analysis. Of these 1,013 respondents, $61.3 \%$ also completed the third questionnaire $(n=621)$. Data of these respondents were used for the analysis of the effects on total fat, fruit and vegetable consumption after six months. Attrition-percentages at $\mathrm{t} 2$ did not differ significantly between the conditions. The attrition analysis showed that gender, age, level of education and fat, fruit and vegetable consumption were not significantly associated with attrition.

Mean age of the respondents was 38 years (range 18-64). The majority of respondents were male ( $62 \%$ male, $38 \%$ female), and had a high level of education ( $60 \%$ high, $38 \%$ middle, $2 \%$ low). Mean BMI of the study population was 23.6. A large majority of the respondents lived together with others $(81 \%)$, cooked regularly $(64 \%)$ and did the shopping for their household regularly (79\%). Only a few respondents were following a diet $(8 \%)$ or were vegetarian $(6 \%)$. Table 1 shows that respondents in the FSP had a lower level of education compared to respondents in the EP. The categories low and medium educational level were combined, because the percentage with low educational levels was very small ( $<4 \%$ in all groups). Also, respondents in the FSP had a significantly higher BMI than respondents in the EP and a larger proportion of the respondents in the FSP did the shopping for their household regularly compared to respondents in the NP condition (see Table 1). The other socio-demographic variables did not differ significantly at baseline between both environmental intervention groups and the EP or NP. Further, no significant differences at baseline were found between the conditions for consumption levels of fat, fruit and vegetables. 
Chapter 3

Table 1 Differences in educational level, BMI, and shopping behavior

\begin{tabular}{|c|c|c|c|c|c|}
\hline Total $n=1013$ & $\begin{array}{l}\mathrm{LP} \\
(\mathrm{n}=215)\end{array}$ & $\begin{array}{l}\text { FSP } \\
(n=290)\end{array}$ & $\begin{array}{l}\mathrm{EP} \\
(\mathrm{n}=293)\end{array}$ & $\begin{array}{l}\mathrm{NP} \\
(\mathrm{n}=215)\end{array}$ & \\
\hline $\begin{array}{l}\text { Educational level } \\
\% \text { low/medium } \\
\% \text { high }\end{array}$ & $\begin{array}{l}35.8 \\
64.3\end{array}$ & $\begin{array}{l}56.5 \\
43.5\end{array}$ & $\begin{array}{l}28.6 \\
71.4\end{array}$ & $\begin{array}{l}35.0 \\
65.0\end{array}$ & $\mathrm{EP}>\mathrm{FSP} *$ \\
\hline BMI (mean(sd)) & $23.8(3.5)$ & $24.0(3.4)$ & $23.3(2.4)$ & $23.4(2.9)$ & $\mathrm{FSP}>\mathrm{EP} *$ \\
\hline $\begin{array}{l}\text { Regular shopping } \\
\text { household } \\
\% \text { yes } \\
\% \text { no }\end{array}$ & $\begin{array}{l}82.4 \\
17.6\end{array}$ & $\begin{array}{l}83.9 \\
16.1\end{array}$ & $\begin{array}{l}75.3 \\
24.7\end{array}$ & $\begin{array}{l}72.2 \\
27.8\end{array}$ & $\mathrm{FSP}>\mathrm{NP} *$ \\
\hline
\end{tabular}

\section{Reach of the intervention and respondents' reactions}

Almost all respondents had seen at least something of the nutrition programs in the cafeteria (see Table 2). Nearly half of the respondents in the LP reported having seen the labels. A quarter of the respondents in the FSP reported that they had noticed new, healthy products in the assortment of their cafeteria. On average, the worksites in the FSP added seven low-fat products or servings of fruit and vegetables to their offerings. Examples of food items added to the supply were low-fat yoghurt or low-fat cheese. In the LP and EP, 7\% ordered the self help manual, while in the FSP almost a third of the respondents ordered the manual. However, this was due to a worksite effect and was not an effect of study arm (p-value FSP vs EP .68 using multilevel analysis; icc .20). Respondents in all three programs had a positive general opinion about the programs. The personal relevance of the programs was rated lower. After correction for educational level, BMI and shopping behavior, significantly more respondents in the FSP found the information interesting, reported to have gained more knowledge about healthy nutrition as a result of the program and that after the program they saw more advantages of eating more fruit than respondents in the EP (p-values <.05). Furthermore, significantly more respondents in the FSP than in the EP reported that after the program they had a better notion how to eat healthy $(p=.01)$. For the other 
Effectiveness in worksite cafeterias

variables in Table 2, no significant differences were found between the environmental interventions and the EP, correcting for educational level, BMI and shopping behavior.

Table 2 Reach of the intervention (\%) and respondents' reactions (mean(sd))

\begin{tabular}{|c|c|c|c|}
\hline Total $n=798$ & $\begin{array}{l}\mathrm{LP} \\
(\mathrm{n}=215)\end{array}$ & $\begin{array}{l}\text { FSP } \\
(n=290)\end{array}$ & $\begin{array}{l}\mathrm{EP} \\
(\mathrm{n}=293)\end{array}$ \\
\hline Have you seen the program? (\%) & 90 & 91 & 86 \\
\hline Have you seen the labeling? (\%) & 46 & & \\
\hline Have you seen new products? $(\%)$ & & 26 & \\
\hline Did you order the self help manual? (\%) & 7 & 30 & 7 \\
\hline \multicolumn{4}{|l|}{ Range -3 (very negative) +3 (very positive) } \\
\hline What's your general opinion about the program? & $1.1(1.2)$ & $1.1(1.2)$ & $1.0(1.2)$ \\
\hline How interesting was the information? & $0.3(1.4)$ & $0.6(1.4)$ & $0.4(1.4) \mathrm{FSP}>\mathrm{EP} *$ \\
\hline $\begin{array}{l}\text { What did you think about the appearance of the } \\
\text { information? }\end{array}$ & $0.3(1.1)$ & $0.7(1.1)$ & $0.6(1.2)$ \\
\hline How personally relevant was the program for you? & $-0.3(1.6)$ & $-0.1(1.6)$ & $-0.1(1.8)$ \\
\hline \multicolumn{4}{|l|}{ Range -3 (very negative) +3 (very positive) } \\
\hline $\begin{array}{l}\text { As a result of the program ... } \\
\ldots \quad \text { do you have more knowledge about healthy } \\
\text { nutrition? }\end{array}$ & $-0.8(1.6)$ & $-0.4(1.6)$ & $-0.7(1.6) \mathrm{FSP}<\mathrm{EP} *$ \\
\hline $\begin{array}{l}\text {... did you look at your fat, fruit and } \\
\text { vegetables consumption? }\end{array}$ & $-0.1(1.9)$ & $0.0(1.9)$ & $-0.1(1.9)$ \\
\hline $\begin{array}{l}\text {... do you perceive more advantages of eating } \\
\text { less fat? }\end{array}$ & $-0.1(1.7)$ & $0.3(1.6)$ & $0.1(1.7)$ \\
\hline $\begin{array}{l}\text { do you perceive more advantages of eating } \\
\text { more fruit? }\end{array}$ & $-0.1(1.7)$ & $0.4(1.5)$ & $0.1(1.7) \mathrm{FSP}>\mathrm{EP}^{*}$ \\
\hline $\begin{array}{l}\text { do you perceive more advantages of eating } \\
\text { more vegetables? }\end{array}$ & $0.0(1.7)$ & $0.5(1.6)$ & $0.2(1.7)$ \\
\hline $\begin{array}{l}\text { do you have a better notion how to eat } \\
\text { healthy? }\end{array}$ & $-0.3(1.5)$ & $0.1(1.5)$ & $-0.3(1.7) \mathrm{FSP}>\mathrm{EP} * *$ \\
\hline
\end{tabular}

( $\mathrm{LP}=$ Labeling program; FSP= Food supply program; $\mathrm{EP}=$ Educational program)

$* \mathrm{p}<.05$

$* * \mathrm{p}=.01$ 
Chapter 3

Table 3 Mean total fat, fruit, and vegetable intake at baseline ( $t 1)$ and posttest ( $t 2)$ (mean(sd))

\begin{tabular}{|c|c|c|c|c|c|}
\hline Total $n=1013$ & & $\begin{array}{l}\mathrm{LP} \\
(\mathrm{n}=215)\end{array}$ & $\begin{array}{l}\text { FSP } \\
(n=290)\end{array}$ & $\begin{array}{l}\mathrm{EP} \\
(n=293)\end{array}$ & $\begin{array}{l}\mathrm{NP} \\
(\mathrm{n}=215)\end{array}$ \\
\hline $\begin{array}{l}\text { Fat } \\
\text { (fat points per day) }\end{array}$ & $\begin{array}{l}\mathrm{t} 1 \\
\mathrm{t} 2\end{array}$ & $\begin{array}{l}17.7(6.3) \\
17.3(6.2)\end{array}$ & $\begin{array}{l}17.1(5.7) \\
16.8(5.7)\end{array}$ & $\begin{array}{l}17.5(6.2) \\
17.6(6.0)\end{array}$ & $\begin{array}{l}17.7(6.1) \\
17.7(6.2)\end{array}$ \\
\hline $\begin{array}{l}\text { Fruit } \\
\text { (servings per day) }\end{array}$ & $\begin{array}{l}\mathrm{t} 1 \\
\mathrm{t} 2\end{array}$ & $\begin{array}{l}2.1(1.7) \\
2.2(1.6)\end{array}$ & $\begin{array}{l}2.0(1.6) \\
2.1(1.6)\end{array}$ & $\begin{array}{l}2.0(1.5) \\
2.1(1.6)\end{array}$ & $\begin{array}{l}2.1(1.8) \\
2.0(1.6)\end{array}$ \\
\hline $\begin{array}{l}\text { Vegetables } \\
\text { (grams per day) }\end{array}$ & $\begin{array}{l}\mathrm{t} 1 \\
\mathrm{t} 2\end{array}$ & $\begin{array}{l}170.1(92.6) \\
156.4(87.0)\end{array}$ & $\begin{array}{l}155.3(89.5) \\
148.3(80.4)\end{array}$ & $\begin{array}{l}168.0(86.7) \\
157.6(85.9)\end{array}$ & $\begin{array}{l}144.6(82.6) \\
142.9(83.5)\end{array}$ \\
\hline
\end{tabular}

$(\mathrm{LP}=$ Labeling program; FSP $=$ Food supply program; $\mathrm{EP}=$ Educational program; $\mathrm{NP}=$ No program $)$

no significant differences

Table 4 Mean total fat, fruit, and vegetable intake at baseline ( $t 1)$ and posttest ( $t 2)$ per condition (mean) (using worksites as units of analysis with equal weighting)

\begin{tabular}{|c|c|c|c|c|c|}
\hline \multicolumn{2}{|l|}{ Total $n=17$} & \multirow{2}{*}{$\begin{array}{l}\begin{array}{l}\mathrm{LP} \\
(\mathrm{n}=4)\end{array} \\
17.8 \\
17.4\end{array}$} & \multirow{2}{*}{$\begin{array}{l}\begin{array}{l}\text { FSP } \\
(\mathrm{n}=4)\end{array} \\
17.2 \\
16.9\end{array}$} & \multirow{2}{*}{$\begin{array}{l}\begin{array}{l}\mathrm{EP} \\
(\mathrm{n}=5)\end{array} \\
17.4 \\
17.5\end{array}$} & \multirow{2}{*}{$\begin{array}{l}\begin{array}{l}\mathrm{NP} \\
(\mathrm{n}=4)\end{array} \\
17.8 \\
17.8\end{array}$} \\
\hline $\begin{array}{l}\text { Fat } \\
\text { (fat points per day) }\end{array}$ & $\begin{array}{l}\mathrm{t} 1 \\
\mathrm{t} 2\end{array}$ & & & & \\
\hline $\begin{array}{l}\text { Fruit } \\
\text { (servings per day) }\end{array}$ & $\begin{array}{l}\mathrm{t} 1 \\
\mathrm{t} 2\end{array}$ & $\begin{array}{l}2.1 \\
2.3\end{array}$ & $\begin{array}{l}2.0 \\
2.1\end{array}$ & $\begin{array}{l}2.1 \\
2.2\end{array}$ & $\begin{array}{l}2.1 \\
2.0\end{array}$ \\
\hline $\begin{array}{l}\text { Vegetables } \\
\text { (grams per day) }\end{array}$ & $\begin{array}{l}\mathrm{t} 1 \\
\mathrm{t} 2\end{array}$ & $\begin{array}{l}166.2 \\
153.3\end{array}$ & $\begin{array}{l}157.9 \\
151.7\end{array}$ & $\begin{array}{l}163.7 \\
155.8\end{array}$ & $\begin{array}{l}145.1 \\
143.6\end{array}$ \\
\hline
\end{tabular}

$(\mathrm{LP}=$ Labeling program; $\mathrm{FSP}=$ Food supply program; $\mathrm{EP}=$ Educational program; $\mathrm{NP}=$ No program $)$ no significant differences 


\section{Effectiveness in worksite cafeterias}

\section{Total fat, fruit, and vegetable intake}

Mean total fat scores and fruit and vegetable consumption at baseline and one month after the start of the intervention are shown in Table 3. Mean fat and fruit consumption stayed more or less the same in the environmental programs, while vegetable consumption decreased among all groups. Regression analysis with persons as unit of analysis revealed no significant differences with respect to posttest, correcting for baseline consumption and other covariates (educational level, BMI and shopping behavior), between environmental interventions and the EP and NP respectively (all pvalues $\geq .12$ ). These analyses were repeated with consumption scores on $\mathrm{t} 3$ (six months after start of the intervention) as dependent variable ( $n=621)$. Figures 3,4 and 5 respectively show mean fat, fruit, and vegetable intake per day, at baseline and the two posttests ( $\mathrm{t} 2$ and $\mathrm{t} 3$ ) per condition for these 621 respondents. No significant differences were found between environmental interventions and the EP and NP respectively (all pvalues 2.16 ). Table 4 shows mean total fat scores and fruit and vegetable consumption at baseline and posttest ( $\mathrm{t} 2$ ) per condition, using worksites as unit of analysis. Scores are very similar to the individual scores presented in Table 3. Regression analysis with worksites as unit of analysis revealed no significant differences between research groups with respect to posttest scores, correcting for baseline scores (all p-values $\geq .08$ ).

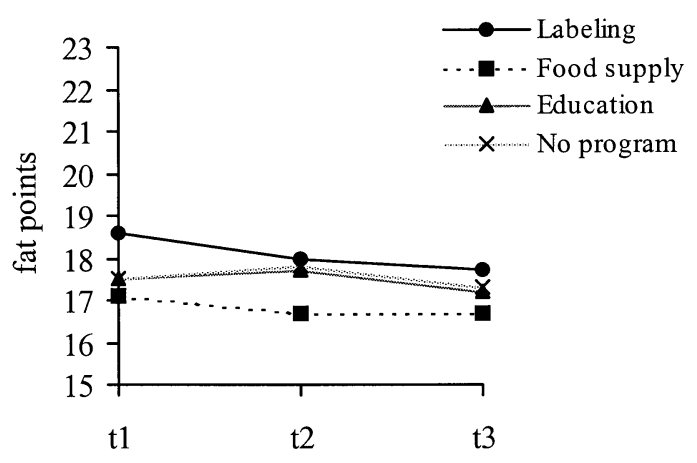

Figure 3 Mean fat intake per day at baseline ( $t 1)$ and posttests ( $t 2$ and $t 3$ ) per condition 


\section{Chapter 3}

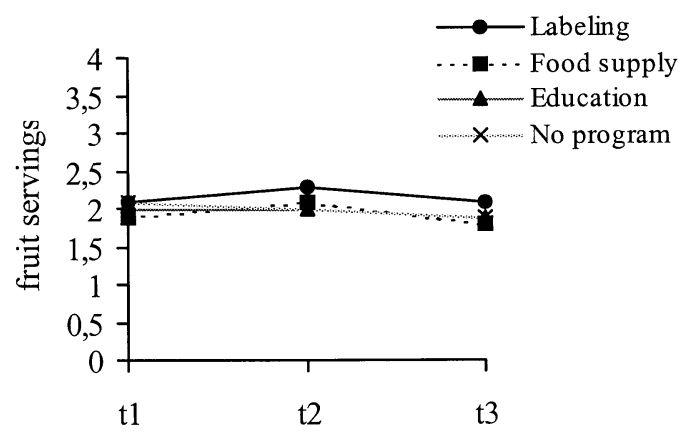

Figure 4 Mean fruit intake per day at baseline ( $t 1)$ and posttests ( $t 2$ and $t 3)$ per condition

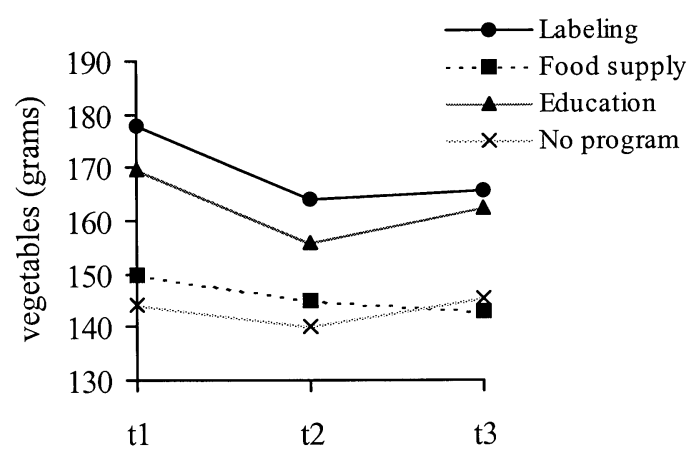

Figure 5 Mean vegetable intake per day at baseline ( $t 1$ ) and posttests ( $t 2$ and $t 3$ ) per condition 


\section{Effectiveness in worksite cafeterias}

It is possible that many respondents did not experience a need to change their fat, fruit and vegetable consumption, since many of them thought that their consumption levels were not very high (fat) or low (fruit and vegetables) to begin with. Of all respondents, $19 \%(\mathrm{n}=194)$ indicated at baseline that their own fat consumption was (very) high ('aware' people). For fruit intake, 39.8\% $(\mathrm{n}=403)$ indicated at baseline that their intake was (very) low, for vegetable intake $18.8 \%(\mathrm{n}=190)$. This classification only takes into account the subjective estimation of consumption levels (as distinct from the classification for misconception of own consumption levels, where both the subjective and the more objective estimation deriving from the fat frequency questionnaire was taken into account). It could be that the interventions especially were effective for this specific group of 'aware' respondents who thought they were eating a high fat diet or a diet low in fruit or vegetables. To test this hypothesis, we tested the presence of interaction between baseline awareness (yes/no) and treatment condition (LP, FSP, EP, NP) on posttest consumption, using pretest consumption as covariate (two-way ANOVA with covariate). For these interaction analysis, an alpha of .05 was used. For fat consumption, the omnibus test using all four treatment conditions showed no interaction ( $\mathrm{p}=.18$ ). Pairwise comparisons between FSP and EP; FSP and NP; and EP and NP failed to show interaction as well (p-values .75, .41 and .49 respectively). However, a pairwise comparison between LP and EP showed a trend toward interaction $(\mathrm{p}=.09)$, while a pairwise comparison between LP and NP showed a significant interaction effect $(\mathrm{p}=.04)$. For fruit intake, as well as for vegetable intake, no interaction between baseline awareness (yes/no) and treatment condition (LP, FSP, EP, NP) on posttest consumption, using pretest consumption as covariate, could be demonstrated (all p-values fruit intake $\geq .60$, all $\mathrm{p}$-values vegetable intake $\geq .63$ ). Based on these results, the initial analysis of treatment effect on posttest fat consumption, corrected for pretest fat consumption, educational level, BMI and shopping behavior was repeated within each of the two subgroups, unaware and aware respondents. Figures 6 and 7 show mean fat intake per day, at baseline and posttest (t2) per condition for the unaware and aware group. For unaware respondents, no significant treatment effects were found ( $\mathrm{p}$-values 2.13 ). In the aware group, a significant beneficial treatment effect was found for the LP compared to the NP $(\mathrm{p}<.05)$ (number of fat points in the LP decreased from 19.9 at $\mathrm{t} 1$ to 18.4 at $\mathrm{t} 2$, compared to 19.0 at $\mathrm{t} 1$ and 19.7 at $\mathrm{t} 2$ for the NP), but not for the other comparisons (LP vs EP p=.08, all other 
p-values 2.54$)$. The analyses for the aware group were repeated with worksites as unit of analysis, with consumption at baseline included as the only covariate in the model. A significant beneficial treatment effect was found for the LP compared to both the NP $(\mathrm{p}<.01)$ and the EP $(\mathrm{p}<.05)$.

The same procedure to test for interaction of treatment with (subjective) awareness was also carried out with respect to consumption levels at $\mathrm{t} 3$ (six months after the start of the intervention) $(n=621)$. For fat and fruit intake, no significant interactions were found (all $\mathrm{p}$-values fat intake $\geq .25$, all $\mathrm{p}$-values fruit intake $\geq .37$ ). For vegetable consumption, the omnibus test using all four treatment conditions showed a trend toward interaction $(\mathrm{p}=.07)$. Pairwise comparisons revealed a significant interaction effect comparing LP and EP ( $p=.01)$, but not for all the other comparisons ( $p$-values z.12). Figures 8 and 9 show mean vegetable intake at baseline and the second posttest ( $\mathrm{t} 3)$, for the LP and EP group, for the unaware and the aware respondents respectively. Regression analysis revealed a significantly higher intake of vegetables at $\mathrm{t} 3$ of aware respondents in the EP compared to aware respondents in the LP, corrected for baseline consumption, educational level, BMI and shopping behavior $(\mathrm{p}<.01)$. This difference remained significant using aggregated analysis (only covariate consumption level at baseline) $(\mathrm{p}<.01)$. For the unaware respondents, no significant differences were found between research groups.

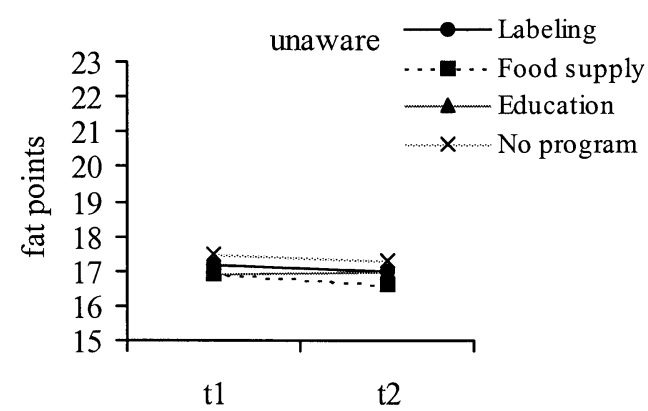

Figure 6 Mean fat intake per day at baseline (t1) and posttest (t2) per condition for unaware respondents 
Effectiveness in worksite cafeterias

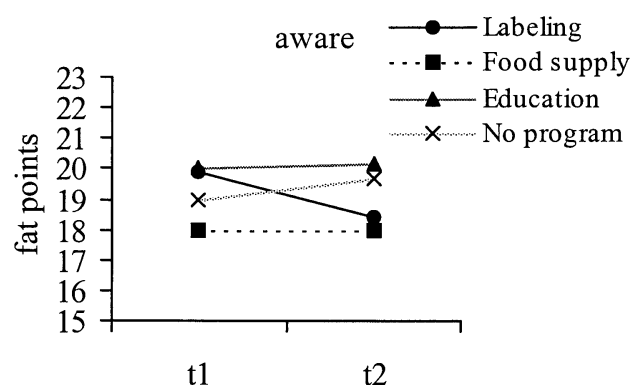

Figure 7 Mean fat intake per day at baseline ( $t 1$ ) and posttest (t2) per condition for aware respondents

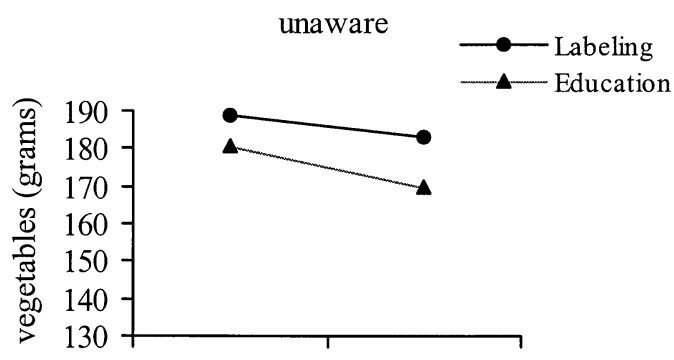

$\mathrm{t} 1$

t3

Figure 8 Mean vegetable intake per day at baseline ( $t 1)$ and posttest ( $t 3)$ for unaware respondents in the $L P$ and $E P$

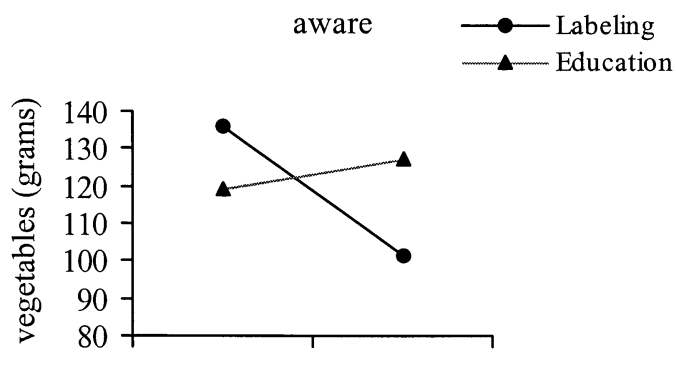

$\mathrm{t} 1$

t3

Figure 9 Mean vegetable intake per day at baseline ( $t 1)$ and posttest ( $t 3)$ for aware respondents in the $L P$ and $E P$ 
Chapter 3

Table 5 Mean fat, fruit, and vegetable intake during lunch in the cafeteria at baseline ( $t 1)$ and posttest (t2) (mean(sd))

\begin{tabular}{|c|c|c|c|c|c|}
\hline Total $n=941$ & & $\begin{array}{l}\mathrm{LP} \\
(\mathrm{n}=202)\end{array}$ & $\begin{array}{l}\text { FSP } \\
(n=265)\end{array}$ & $\begin{array}{l}\mathrm{EP} \\
(n=275)\end{array}$ & $\begin{array}{l}\mathrm{NP} \\
(\mathrm{n}=199)\end{array}$ \\
\hline $\begin{array}{l}\text { Fat } \\
\text { (grams per lunch) }\end{array}$ & $\begin{array}{l}\mathrm{t} 1 \\
\mathrm{t} 2\end{array}$ & $\begin{array}{l}21.9(13.1) \\
21.5(15.2)\end{array}$ & $\begin{array}{l}20.4(14.9) \\
19.7(12.4)\end{array}$ & $\begin{array}{l}20.3(15.6) \\
20.9(13.4)\end{array}$ & $\begin{array}{l}20.6(12.0) \\
21.6(12.3)\end{array}$ \\
\hline $\begin{array}{l}\text { Fruit } \\
\text { (grams per lunch) }\end{array}$ & $\begin{array}{l}\mathrm{t} 1 \\
\mathrm{t} 2\end{array}$ & $\begin{array}{l}79.8(99.1) \\
87.9(106.5)\end{array}$ & $\begin{array}{l}58.2(93.0) \\
76.6(101.4)\end{array}$ & $\begin{array}{l}71.8(102.9) \\
84.5(103.5)\end{array}$ & $\begin{array}{l}78.5(91.6) \\
80.7(116.1)\end{array}$ \\
\hline $\begin{array}{l}\text { Vegetables } \\
\text { (grams per lunch) }\end{array}$ & $\begin{array}{l}\mathrm{t} 1 \\
\mathrm{t} 2\end{array}$ & $\begin{array}{l}20.1(44.8) \\
14.9(23.7)\end{array}$ & $\begin{array}{l}19.6(33.2) \\
20.8(31.9)\end{array}$ & $\begin{array}{l}20.0(28.2) \\
19.6(28.7)\end{array}$ & $\begin{array}{l}17.2(27.8) \\
18.1(25.6)\end{array}$ \\
\hline
\end{tabular}

$(\mathrm{LP}=$ Labeling program; FSP= Food supply program; $\mathrm{EP}=$ Educational program; $\mathrm{NP}=$ No program $)$

no significant differences

\section{Fat, fruit, and vegetable intake during lunch in the worksite cafeteria}

Table 5 shows fat, fruit, and vegetable consumption during lunch in the cafeteria. Most respondents (97\% at $\mathrm{t} 1$ and $98 \%$ at $\mathrm{t} 2$ ) ate a cold lunch in the cafeteria, possibly completed with soup or a snack. Three percent and $2 \%$ ate a hot meal, respectively. This did not differ between the conditions. For the calculation of the fat, fruit and vegetable consumption during lunch, only those subjects who ate a cold lunch at both t1 and $\mathrm{t} 2$ were included. Final analyses were conducted in SPSS. Fat consumption during lunch stayed the same between $\mathrm{t} 1$ and $\mathrm{t} 2$, and at $\mathrm{t} 2$ did not differ significantly between the environmental programs and the EP or NP. Fruit consumption increased slightly in the LP and somewhat stronger in the EP and FSP, while fruit consumption in the control group stayed the same. Mean vegetable consumption during lunch decreased in the LP, and did not change in the other groups. However, no significant differences were found between groups with respect to fat, fruit and vegetable consumption at $\mathrm{t} 2$, corrected for consumption at $\mathrm{t} 1$ and the covariates included in the model (educational level, BMI, shopping behavior) (all p-values z.12, .35, .09 respectively for fat, fruit and vegetable intake). For fat, fruit and vegetable intake during lunch in the cafeteria, interaction analyses between (subjective) awareness of own consumption levels and study arm on behavior change were performed using the same method as outlined for total fat, fruit and vegetable intake. No significant 
Effectiveness in worksite cafeterias

interactions were found (all p-values $\geq .13, .75, .08$ respectively for fat, fruit and vegetable intake).

\section{Behavioral determinants}

Table 6 show mean scores on behavioral determinants of eating less fat and more fruit and vegetables at baseline and posttest ( $\mathrm{t} 2$ ). Scores on attitude, modeling and selfefficacy were already positive at baseline, while scores on social support and intention were negative. This applies to all three nutrition behaviors: fat, fruit and vegetable consumption. Regression analysis revealed no significant differences between treatment arms with respect to scores on attitudes, social support, and intention at $t 2$, corrected for baseline scores, educational level, BMI and shopping behavior. A significant difference $(\mathrm{p}<.01)$ was found between the LP and NP for modeling regarding fat consumption $(\mathrm{LP}<\mathrm{NP})$. However, this difference was not significant using worksites as unit of analysis ( $\mathrm{p}=.22$ ). Furthermore, respondents in the LP and FSP had higher scores at $\mathrm{t} 2$ on self-efficacy toward eating more fruit compared to the EP $(\mathrm{p}<.01)$. Compared to the NP, the LP and FSP showed a trend toward higher scores on self-efficacy regarding eating more fruit $(\mathrm{p}<.05)$. Repetition of these analyses with the aggregated data revealed no significant treatment effects with respect to self-efficacy scores at $\mathrm{t} 2$, corrected for baseline scores. However, a trend toward treatment effects could be observed for LP and FSP compared to EP ( $\mathrm{p}=.03$ and $\mathrm{p}=.06$ respectively) and of the LP compared to the NP $(\mathrm{p}=.07)$.

For the behavioral determinants listed in Table 6, interaction analyses were performed to test for interactions between (subjective) awareness and study arm on posttest scores of the behavioral determinants. For attitude, modeling, social support and self- efficacy, the omnibus tests using all four treatment conditions showed no interaction with regard to all three nutrition behaviors (all p-values 2.12 ). For intention, the omnibus test with regard to fat and fruit intake did not show interaction effects either (p-values .63 and .87 respectively), while for vegetable intake a significant interaction was found $(\mathrm{p}=.05)$. Pairwise comparisons revealed a significant interaction with respect to attitude toward eating less fat, comparing the LP and NP ( $\mathrm{p}=.04)$. Furthermore, a significant interaction was found comparing the FSP and EP regarding 
Table 6 Mean scores on behavioral determinants at baseline (t1) and posttest (t2) (mean(sd))

\begin{tabular}{|c|c|c|c|c|c|c|c|}
\hline Total $n=1013$ & & & LP & FSP & & $\mathrm{NP}$ & \\
\hline \multirow[t]{3}{*}{$\begin{array}{r}\text { Attitude } \\
(-3+3)\end{array}$} & Fat & $\begin{array}{l}\mathrm{t} 1 \\
\mathrm{t} 2\end{array}$ & $\begin{array}{l}1.8(1.2) \\
1.7(1.4)\end{array}$ & $\begin{array}{l}1.8(1.2) \\
1.8(1.4)\end{array}$ & $\begin{array}{l}1.7(1.4) \\
1.6(1.2)\end{array}$ & $\begin{array}{l}1.7(1.2) \\
1.7(1.3)\end{array}$ & \\
\hline & Fruit & $\begin{array}{l}\mathrm{t} 1 \\
\mathrm{t} 2\end{array}$ & $\begin{array}{l}2.0(0.9) \\
2.1(0.9)\end{array}$ & $\begin{array}{l}2.1(1.0) \\
2.1(0.9)\end{array}$ & $\begin{array}{l}2.0(1.0) \\
2.1(0.8)\end{array}$ & $\begin{array}{l}2.1(0.9) \\
2.0(1.0)\end{array}$ & \\
\hline & Vegetables & $\begin{array}{l}\mathrm{t} 1 \\
\mathrm{t} 2\end{array}$ & $\begin{array}{l}2.0(1.0) \\
2.0(1.0)\end{array}$ & $\begin{array}{l}2.1(1.0) \\
2.1(0.9)\end{array}$ & $\begin{array}{l}2.1(0.9) \\
2.0(0.9)\end{array}$ & $\begin{array}{l}2.1(1.0) \\
2.1(0.9)\end{array}$ & \\
\hline \multirow[t]{2}{*}{$\begin{array}{l}\text { Social } \\
\text { influence; } \\
\text { modeling } \\
(-3+3)\end{array}$} & Fruit & $\begin{array}{l}\mathrm{t} 1 \\
\mathrm{t} 2\end{array}$ & $\begin{array}{l}0.9(1.2) \\
0.7(1.4)\end{array}$ & $\begin{array}{l}0.4(1.3) \\
0.6(1.4)\end{array}$ & $\begin{array}{l}0.7(1.4) \\
0.7(1.3)\end{array}$ & $\begin{array}{l}0.7(1.4) \\
0.8(1.3) \\
0.3(1.7) \\
0.3(1.6)\end{array}$ & $\begin{array}{l}\mathrm{LP}<\mathrm{EP}^{*} \\
\mathrm{LP}<\mathrm{NP}^{* *}\end{array}$ \\
\hline & Vegetables & $\begin{array}{l}\mathrm{t} 1 \\
\mathrm{t} 2\end{array}$ & $\begin{array}{l}0.6(1.4) \\
0.6(1.3)\end{array}$ & $\begin{array}{l}0.7(1.3) \\
0.5(1.3)\end{array}$ & $\begin{array}{l}0.6(1.3) \\
0.5(1.2)\end{array}$ & $\begin{array}{l}0.6(1.4) \\
0.6(1.3)\end{array}$ & $\mathrm{FSP}<\mathrm{NP}^{*}$ \\
\hline \multirow[t]{2}{*}{$\begin{array}{l}\text { Social } \\
\text { influence; } \\
\text { social } \\
\text { support } \\
(-3+3)\end{array}$} & Fruit & $\begin{array}{l}\mathrm{t} 1 \\
\mathrm{t} 2\end{array}$ & $\begin{array}{l}-0.2(2.1) \\
-0.1(1.8) \\
-0.1(1.9) \\
-0.1(1.9)\end{array}$ & $\begin{array}{r}-0.2(1.9) \\
-0.2(1.9) \\
0.0(2.0) \\
-0.1(1.9)\end{array}$ & $\begin{array}{r}-0.1(1.9) \\
-0.3(1.9) \\
0.0(1.9) \\
-0.1(1.8)\end{array}$ & $\begin{array}{l}-0.1(2.0) \\
-0.1(1.9) \\
-0.2(2.0) \\
-0.2(1.8)\end{array}$ & \\
\hline & Vegetables & $\begin{array}{l}\mathrm{t} 1 \\
\mathrm{t} 2\end{array}$ & $\begin{array}{l}-0.1(1.8) \\
-0.1(1.7)\end{array}$ & $\begin{array}{l}-0.2(1.8) \\
-0.3(1.8)\end{array}$ & $\begin{array}{l}-0.2(1.8) \\
-0.2(1.7)\end{array}$ & $\begin{array}{l}-0.2(1.8) \\
-0.2(1.7)\end{array}$ & \\
\hline \multirow[t]{3}{*}{$\begin{array}{l}\text { Self- } \\
\text { efficacy } \\
(-3+3)\end{array}$} & Fat & $\begin{array}{l}\mathrm{t} 1 \\
\mathrm{t} 2\end{array}$ & $\begin{array}{l}1.1(1.6) \\
1.0(1.5)\end{array}$ & $\begin{array}{l}0.8(1.7) \\
0.8(1.7)\end{array}$ & $\begin{array}{l}1.0(1.6) \\
0.9(1.5)\end{array}$ & $\begin{array}{l}1.1(1.6) \\
1.2(1.5)\end{array}$ & $\begin{array}{l}\mathrm{LP}<\mathrm{NP} * \\
\mathrm{FSP}<\mathrm{NP} * \\
\mathrm{EP}<\mathrm{NP} *\end{array}$ \\
\hline & Fruit & $\begin{array}{l}\mathrm{t} 1 \\
\mathrm{t} 2\end{array}$ & $\begin{array}{l}1.6(1.4) \\
1.7(1.3)\end{array}$ & $\begin{array}{l}1.5(1.4) \\
1.6(1.4)\end{array}$ & $\begin{array}{l}1.5(1.5) \\
1.3(1.3)\end{array}$ & $\begin{array}{l}1.5(1.5) \\
1.4(1.4)\end{array}$ & $\begin{array}{l}\mathrm{LP}>\mathrm{EP}^{* *} \\
\mathrm{FSP}>\mathrm{EP}^{* *} \\
\mathrm{LP}>\mathrm{NP} *\end{array}$ \\
\hline & Vegetables & $\begin{array}{l}\mathrm{t} 1 \\
\mathrm{t} 2\end{array}$ & $\begin{array}{l}1.3(1.5) \\
1.2(1.4)\end{array}$ & $\begin{array}{l}1.4(1.5) \\
1.3(1.4)\end{array}$ & $\begin{array}{l}1.4(1.4) \\
1.2(1.4)\end{array}$ & $\begin{array}{l}1.4(1.5) \\
1.2(1.4)\end{array}$ & FSP $>N^{*}$ \\
\hline \multirow[t]{3}{*}{$\begin{array}{l}\text { Intention } \\
(3+3)\end{array}$} & Fat & $\begin{array}{l}\mathrm{t} 1 \\
\mathrm{t} 2\end{array}$ & $\begin{array}{l}-0.9(1.8) \\
-0.7(1.8)\end{array}$ & $\begin{array}{l}-0.8(1.8) \\
-0.4(1.8)\end{array}$ & $\begin{array}{l}-0.9(1.7) \\
-0.8(1.6)\end{array}$ & $\begin{array}{l}-0.9(1.7) \\
-0.7(1.7)\end{array}$ & \\
\hline & Fruit & $\begin{array}{l}\mathrm{t} 1 \\
\mathrm{t} 2\end{array}$ & $\begin{array}{l}-0.6(1.7) \\
-0.6(1.7)\end{array}$ & $\begin{array}{l}-0.4(1.7) \\
-0.5(1.6)\end{array}$ & $\begin{array}{l}-0.5(1.6) \\
-0.5(1.6)\end{array}$ & $\begin{array}{l}-0.4(1.7) \\
-0.5(1.6)\end{array}$ & \\
\hline & Vegetables & $\begin{array}{l}\mathrm{t} 1 \\
\mathrm{t} 2\end{array}$ & $\begin{array}{l}-0.8(1.6) \\
-0.8(1.5)\end{array}$ & $\begin{array}{l}-0.9(1.6) \\
-0.9(1.6)\end{array}$ & $\begin{array}{l}-0.9(1.5) \\
-0.7(1.6)\end{array}$ & $\begin{array}{l}-0.9(1.7) \\
-0.7(1.6)\end{array}$ & \\
\hline
\end{tabular}

$(\mathrm{LP}=$ Labeling program; $\mathrm{FSP}=$ Food supply program; $\mathrm{EP}=$ Educational program; $\mathrm{NP}=$ No program $)$

* $\mathrm{p}<.05 ; * * \mathrm{p}<.01$ (using individuals as unit of analysis) 
Effectiveness in worksite cafeterias

self-efficacy toward eating more vegetables $(p=.03)$. Pairwise comparisons for intention to eat more vegetables revealed a significant interaction effect comparing the FSP and NP $(\mathrm{p}<.01)$. For all the other comparisons, no significant interaction effects were found. Based on these results, the initial analysis of treatment effect on posttest attitude toward eating less fat, and self-efficacy and intention toward eating more vegetables, corrected for pretest scores, educational level, BMI and shopping behavior was repeated within each of the two subgroups, unaware and aware respondents. Scores on these variables for the unaware and aware respondents are listed in Table 7. At $\mathrm{t} 2$, respondents in the FSP scored significantly lower on intention to eat more vegetables compared to respondents in the NP condition $(\mathrm{p}<.01)$. This analysis was repeated with worksites as unit of analysis and baseline score as the only covariate. This difference between FSP and NP did not remain significant using an alpha of .01 ( $p=.03)$. Also, a trend could be observed that respondents in the FSP scored significantly higher on selfefficacy toward eating more vegetables $(\mathrm{p}<.05)$. However, aggregated analysis did not show this trend $(\mathrm{p} \geq .48)$.

Table 8 shows the percentage misconception of own consumption levels at baseline (t1) and posttest (t2). About half of the respondents in all research groups underestimated their fat consumption level and overestimated their vegetable consumption. About a quarter of all respondents overestimated their fruit consumption. Regression analysis did not show a significant difference between research groups with respect to the percentage of respondents that overestimated their fruit and vegetable consumption at t2 (all p-values fruit consumption $\geq .09$, all $\mathrm{p}$-values vegetable consumption $\geq .80$ ). At $\mathrm{t} 2$, significant less respondents in the LP and FSP underestimated their fat consumption compared to respondents in the EP, corrected for baseline score, educational level, BMI and shopping behavior. Regression analysis with worksites as unit of analysis, corrected for baseline score, confirmed these results ( $\mathrm{p}$-values $\leq .01$ ). 
Chapter 3

Table 7 Mean scores on behavioral determinants at baseline ( $t 1)$ and posttest ( $t 2)$ for unaware and aware respondents (mean(sd))

\begin{tabular}{|c|c|c|c|c|c|c|}
\hline Total $n=1013$ & & $\begin{array}{l}\mathrm{LP} \\
\mathrm{n}=215\end{array}$ & $\begin{array}{l}\mathrm{FSP} \\
\mathrm{n}=290\end{array}$ & $\begin{array}{l}\mathrm{EP} \\
\mathrm{n}=293\end{array}$ & $\begin{array}{l}\mathrm{NP} \\
\mathrm{n}=215\end{array}$ & \\
\hline \multicolumn{7}{|l|}{$\begin{array}{l}\text { Unaware respondents } \\
(\mathrm{n}=819, \text { fat intake }) \\
(\mathrm{n}=823, \text { vegetable intake })\end{array}$} \\
\hline $\begin{array}{l}\text { Attitude fat } \\
(-3+3)\end{array}$ & $\begin{array}{l}\mathrm{t} 1 \\
\mathrm{t} 2\end{array}$ & $\begin{array}{l}1.8(1.2) \\
1.8(1.4)\end{array}$ & $\begin{array}{l}1.8(1.3) \\
1.8(1.3)\end{array}$ & $\begin{array}{l}1.7(1.4) \\
1.7(1.2)\end{array}$ & $\begin{array}{l}1.8(1.1) \\
1.7(1.4)\end{array}$ & \\
\hline $\begin{array}{l}\text { Intention vegetables } \\
(-3+3)\end{array}$ & $\begin{array}{l}\mathrm{t} 1 \\
\mathrm{t} 2\end{array}$ & $\begin{array}{l}-1.0(1.6) \\
-1.0(1.6)\end{array}$ & $\begin{array}{l}-1.1(1.3) \\
-1.0(1.5)\end{array}$ & $\begin{array}{l}-1.0(1.5) \\
-0.8(1.6)\end{array}$ & $\begin{array}{l}-1.1(1.6) \\
-0.9(1.5)\end{array}$ & \\
\hline $\begin{array}{l}\text { Self-efficacy vegetables } \\
(-3+3)\end{array}$ & $\begin{array}{l}\mathrm{t} 1 \\
\mathrm{t} 2\end{array}$ & $\begin{array}{l}1.5(1.4) \\
1.4(1.4)\end{array}$ & $\begin{array}{l}1.4(1.4) \\
1.3(1.3)\end{array}$ & $\begin{array}{l}-1.1(1.6) \\
-0.9(1.5)\end{array}$ & $\begin{array}{l}1.7(1.4) \\
1.4(1.4)\end{array}$ & \\
\hline \multicolumn{7}{|l|}{$\begin{array}{l}\text { Aware respondents } \\
(\mathrm{n}=194, \text { fat intake }) \\
(\mathrm{n}=190, \text { vegetable intake })\end{array}$} \\
\hline $\begin{array}{l}\text { Attitude fat } \\
(-3+3)\end{array}$ & $\begin{array}{l}\mathrm{t} 1 \\
\mathrm{t} 2\end{array}$ & $\begin{array}{l}1.8(1.1) \\
1.4(1.5)\end{array}$ & $\begin{array}{l}1.9(1.2) \\
1.6(1.6)\end{array}$ & $\begin{array}{l}1.6(1.5) \\
1.6(1.3)\end{array}$ & $\begin{array}{l}1.5(1.5) \\
1.8(1.1)\end{array}$ & \\
\hline $\begin{array}{l}\text { Intention vegetables } \\
(-3+3)\end{array}$ & $\begin{array}{l}\mathrm{t} 1 \\
\mathrm{t} 2\end{array}$ & $\begin{array}{l}-0.2(1.5) \\
-0.1(1.6)\end{array}$ & $\begin{array}{r}0.0(1.6) \\
-0.4(1.7)\end{array}$ & $\begin{array}{l}-0.5(1.4) \\
-0.2(1.6)\end{array}$ & $\begin{array}{r}-0.4(1.8) \\
0.2(1.8)\end{array}$ & $\mathrm{FSP}<\mathrm{NP}^{* *}$ \\
\hline $\begin{array}{l}\text { Self-efficacy vegetables } \\
(-3+3)\end{array}$ & $\begin{array}{l}\mathrm{t} 1 \\
\mathrm{t} 2\end{array}$ & $\begin{array}{l}0.5(1.7) \\
0.6(1.5)\end{array}$ & $\begin{array}{l}1.1(1.6) \\
1.2(1.5)\end{array}$ & $\begin{array}{l}0.9(1.5) \\
0.6(1.4)\end{array}$ & $\begin{array}{l}0.5(1.6) \\
0.4(1.4)\end{array}$ & $\mathrm{FSP}>\mathrm{NP} *$ \\
\hline
\end{tabular}

( $\mathrm{LP}=$ Labeling program; FSP= Food supply program; $\mathrm{EP}=$ Educational program; $\mathrm{NP}=$ No program)

$* \mathrm{p}<.05 ; * * \mathrm{p} \leq .01$ (using individuals as unit of analysis) 
Effectiveness in worksite cafeterias

Table 8 Percentage misconception of own consumption levels at baseline (t1) and posttest (t2)

\begin{tabular}{|c|c|c|c|c|c|c|}
\hline Total $n=1013$ & & $\begin{array}{l}\mathrm{LP} \\
\mathrm{n}=215\end{array}$ & $\begin{array}{l}\mathrm{FSP} \\
\mathrm{n}=290\end{array}$ & $\begin{array}{l}\mathrm{EP} \\
\mathrm{n}=293\end{array}$ & $\begin{array}{l}\mathrm{NP} \\
\mathrm{n}=215\end{array}$ & \\
\hline \multicolumn{7}{|l|}{ Misconceptions fat } \\
\hline$\%$ realistic & $\mathrm{t} 1$ & 40.0 & 35.9 & 41.2 & 32.4 & \\
\hline$\%$ overestimating & $\mathrm{t} 1$ & 11.2 & 11.7 & 7.8 & 11.1 & \\
\hline$\%$ underestimating & $\mathrm{t} 1$ & 48.8 & 52.4 & 51.0 & 56.5 & \\
\hline$\%$ realistic & $\mathrm{t} 2$ & 41.4 & 43.1 & 32.0 & 34.3 & \\
\hline$\%$ overestimating & $\mathrm{t} 2$ & 13.5 & 10.7 & 9.5 & 9.7 & \\
\hline$\%$ underestimating & $\mathrm{t} 2$ & 45.1 & 46.2 & 58.5 & 56.0 & $\begin{array}{l}\mathrm{LP}<\mathrm{EP}^{* *} \\
\mathrm{FSP}<\mathrm{EP}^{* *}\end{array}$ \\
\hline \multicolumn{7}{|l|}{ Misconceptions fruit } \\
\hline$\%$ realistic & $\mathrm{t} 1$ & 65.6 & 62.1 & 58.5 & 59.3 & \\
\hline$\%$ overestimating & $\mathrm{t} 1$ & 23.7 & 19.7 & 25.2 & 24.1 & \\
\hline$\%$ underestimating & $\mathrm{t} 1$ & 10.7 & 18.3 & 16.3 & 16.7 & \\
\hline$\%$ realistic & $\mathrm{t} 2$ & 61.4 & 59.0 & 60.2 & 59.3 & \\
\hline$\%$ overestimating & $\mathrm{t} 2$ & 24.2 & 23.1 & 22.1 & 27.3 & \\
\hline$\%$ underestimating & $\mathrm{t} 2$ & 14.4 & 17.9 & 17.7 & 13.4 & \\
\hline \multicolumn{7}{|l|}{$\begin{array}{l}\text { Misconceptions } \\
\text { vegetables }\end{array}$} \\
\hline$\%$ realistic & $\mathrm{t} 1$ & 40.0 & 41.0 & 40.1 & 37.5 & \\
\hline$\%$ overestimating & $\mathrm{t} 1$ & 51.7 & 56.2 & 53.1 & 59.3 & \\
\hline$\%$ underestimating & $\mathrm{t} 1$ & 8.4 & 2.8 & 6.8 & 3.2 & \\
\hline$\%$ realistic & $\mathrm{t} 2$ & 35.3 & 35.2 & 34.4 & 31.5 & \\
\hline$\%$ overestimating & $\mathrm{t} 2$ & 60.5 & 62.8 & 60.9 & 65.3 & \\
\hline$\%$ underestimating & $\mathrm{t} 2$ & 4.2 & 2.1 & 4.8 & 3.2 & \\
\hline
\end{tabular}

(LP= Labeling program; FSP= Food supply program; $\mathrm{EP}=$ Educational program; $\mathrm{NP}=$ No program)

$* * \mathrm{p}<.01$ 
Table 9 Sales proportions (\%) of low-fat products per product group (mean (sd))

\begin{tabular}{|c|c|c|c|c|c|c|c|}
\hline & & $\begin{array}{l}\text { Milk } \\
(\mathrm{n}=16)\end{array}$ & $\begin{array}{l}\text { Butter } \\
(n=12)\end{array}$ & $\begin{array}{l}\text { Cheese } \\
(n=12)\end{array}$ & $\begin{array}{l}\text { Meat prod. } \\
(n=15)\end{array}$ & $\begin{array}{l}\text { Desserts } \\
(\mathrm{n}=16)\end{array}$ & \\
\hline \multirow{6}{*}{ LP } & $\begin{array}{l}\text { pre- } \\
\text { intervention }\end{array}$ & $94.8(3.2)$ & $61.5(5.5)$ & $8.9(3.2)$ & $54.8(18.5)$ & $28.6(12.6)$ & \\
\hline & week 1 & $95.0(3.9)$ & $50.8(15.9)$ & $10.0(3.7)$ & $52.7(21.9)$ & $42.1(18.3)$ & \\
\hline & week 2 & $96.1(3.5)$ & $55.0(12.0)$ & $25.2(24.1)$ & $55.1(23.1)$ & $45.8(9.5)$ & \\
\hline & week 3 & $94.9(4.0)$ & $55.0(12.6)$ & $17.5(3.1)$ & $51.0(24.7)$ & $45.0(10.7)$ & \\
\hline & week 4 & $95.3(4.2)$ & $56.1(13.9)$ & $22.6(12.8)$ & $51.8(24.7)$ & $44.9(6.7)$ & \\
\hline & intervention & $95.3(3.8)$ & $54.2(13.5)$ & $18.8(6.0)$ & $52.7(22.9)$ & $44.4(10.2)$ & $\begin{array}{l}\mathrm{LP}>\mathrm{EP}^{* *} \\
\mathrm{LP}>\mathrm{NP} *\end{array}$ \\
\hline \multirow{6}{*}{ FSP } & $\begin{array}{l}\text { pre- } \\
\text { intervention }\end{array}$ & $92.5(6.6)$ & $58.4(25.4)$ & $26.2(26.7)$ & $38.6(19.0)$ & $37.2(14.1)$ & \\
\hline & week 1 & $92.2(5.9)$ & $54.1(29.3)$ & $30.6(26.9)$ & $43.6(14.5)$ & $42.8(15.2)$ & \\
\hline & week 2 & $91.6(6.6)$ & $58.3(27.7)$ & $28.6(27.3)$ & $45.9(17.5)$ & $35.0(12.8)$ & \\
\hline & week 3 & $92.1(6.1)$ & $58.9(26.1)$ & $31.9(25.9)$ & $52.0(15.8)$ & $39.6(13.9)$ & \\
\hline & week 4 & $92.2(6.4)$ & $61.8(21.4)$ & $32.0(24.3)$ & $47.0(18.7)$ & $46.6(23.5)$ & \\
\hline & intervention & $92.0(6.2)$ & $58.3(26.1)$ & $30.8(25.9)$ & $47.1(16.5)$ & $41.0(8.7)$ & \\
\hline \multirow{6}{*}{ EP } & $\begin{array}{l}\text { pre- } \\
\text { intervention }\end{array}$ & $93.7(5.2)$ & $53.8(2.4)$ & $16.7(7.2)$ & $40.4(4.2)$ & $21.0(4.8)$ & \\
\hline & week 1 & $91.7(7.2)$ & $57.4(2.5)$ & $14.1(5.8)$ & $44.5(10.2)$ & $23.2(5.4)$ & \\
\hline & week 2 & $92.0(7.0)$ & $65.1(23.4)$ & $16.2(5.6)$ & $51.1(8.9)$ & $23.8(7.5)$ & \\
\hline & week 3 & $92.8(6.5)$ & $71.2(21.1)$ & $16.7(6.5)$ & $46.2(13.9)$ & $24.7(6.9)$ & \\
\hline & week 4 & $91.9(6.9)$ & $70.8(20.6)$ & $18.2(5.4)$ & $61.7(21.2)$ & $26.9(12.5)$ & \\
\hline & intervention & $92.1(6.9)$ & $66.1(15.4)$ & $16.3(5.8)$ & $50.9(11.4)$ & $24.7(7.1)$ & \\
\hline \multirow{6}{*}{$\mathrm{NP}$} & $\begin{array}{l}\text { pre- } \\
\text { intervention }\end{array}$ & $94.2(7.7)$ & $70.4(29.7)$ & $42.3(45.5)$ & $66.1(34.9)$ & $44.2(40.5)$ & \\
\hline & week 1 & $94.6(6.5)$ & $68.5(30.7)$ & $34.6(48.5)$ & $69.5(36.6)$ & $43.5(34.5)$ & \\
\hline & week 2 & $94.8(6.1)$ & $69.0(29.8)$ & $34.4(49.0)$ & $67.8(34.2)$ & $45.3(34.5)$ & \\
\hline & week 3 & $94.6(6.5)$ & $71.1(26.9)$ & $34.4(50.3)$ & $72.7(29.4)$ & $46.1(33.9)$ & \\
\hline & week 4 & $90.3(14.3)$ & $65.7(26.9)$ & $34.7(50.1)$ & $67.7(26.8)$ & $46.8(32.2)$ & \\
\hline & intervention & $93.6(8.2)$ & $69.9(28.6)$ & $34.5(49.5)$ & $69.4(31.6)$ & $45.4(33.4)$ & \\
\hline \multicolumn{5}{|c|}{$\begin{array}{l}* \mathrm{p}<.05 ; * * \mathrm{p}<.01 \\
\text { Proportion of low-fat products on total sales in product group } \\
\text { Pre-intervention= pre-intervention period (mean of three measures) } \\
\text { Intervention= intervention period (mean of week } 1 \text { through } 4 \text { ) }\end{array}$} & $\begin{array}{l}\mathrm{LP}=\text { Labeling } \\
\mathrm{FSP}=\text { Food sL } \\
\mathrm{EP}=\text { Educatio } \\
\mathrm{NP}=\text { No prog }\end{array}$ & $\begin{array}{l}\text { program } \\
\text { pply program } \\
\text { al program } \\
\text { am }\end{array}$ & \\
\hline
\end{tabular}


Effectiveness in worksite cafeterias

\section{Sales data}

Table 9 shows sales proportions of low-fat products per product group. For milk, no difference between the pre-intervention and intervention period was found. For butter, the LP showed a decrease of proportional sales of the low fat alternative, the butter sales of FSP and NP stayed stable, while in the EP sales of low-fat butters compared to highfat butters increased. Both the environmental programs showed an increase in proportion of low-fat cheese sales, with a stronger increase in the LP. Proportional sales data for lean meat products increased in the FSP and EP. For desserts, an increase of the proportion of sold low fat desserts was noticed in the LP, proportional sales of low fat desserts also increased in the FSP and EP. Comparisons of the environmental programs with the EP and NP on post-intervention sales data (mean weeks 1-4), corrected for preintervention sales data, revealed a significantly better effect of the LP compared to the EP and NP regarding desserts (LP vs EP, $\mathrm{p}<.01$; LP vs NP, $\mathrm{p}<.05$ ). For the other products, no significant differences were found.

\section{Discussion}

The aim of this study was to assess the effectiveness of two environmental interventions. No significant effects were found between the environmental programs and the educational or control condition on total fat, fruit, and vegetable intake one month or six months after the start of the intervention. Also, no significant effects were found on intake during lunch in the worksite cafeteria. The decrease in all research groups on vegetable intake was possibly caused by seasonal effects. The baseline measure was in September, while the posttest was in early December. No convincing evidence of treatment by awareness interaction was found for fruit and vegetable intake. Regarding total fat intake, the data showed a treatment effect of the LP for respondents who believe they eat a high fat diet. However, this interaction of treatment by awareness was no longer present at $\mathrm{t} 3$. For intake during lunch at the cafeteria at $\mathrm{t} 2$, no interaction effects were demonstrated at all. No significant effects were found between the environmental programs and the educational or control condition on nearly all behavioral determinants. A treatment effect of the LP and FSP was found for the number of people underestimating their fat intake. However this was only significant compared to the EP and not to the NP. Separate analyses for some behavioral 


\section{Chapter 3}

determinants for aware and unaware respondents neither showed convincing evidence for treatment effects. To summarize, for the whole study group no convincing effects of the interventions could be demonstrated regarding all three nutrition behaviors. Data indicate that a program including labeling of low fat alternatives, might be effective on the short term for people who believe they have a high fat intake.

Sales data confirm, for the most part, the results of the questionnaires. A main effect of the LP was found only for desserts. For some other products a trend in the positive direction could be observed. For example, the sales of low-fat cheese products doubled in the LP and also increased in the FSP. There was a ceiling effect for all research groups for the data on milk, with pre-intervention scores higher than $90 \%$ to begin with. Because of the limited number of worksite cafeterias included in this study, it is difficult to detect possible significant effects on sales data. The collection of sales data was problematic for some products, and therefore some products could not be included in the analysis.

Although around $90 \%$ of the respondents claimed to have seen something of the intervention programs, considerable fewer respondents reported seeing the labeling or the new, healthy products ( $46 \%$ and $26 \%$ respectively). Labels might have been too inconspicious to get enough attention. Because the assortment of worksite cafeterias were changing continuously, it is not too surprising that only $26 \%$ of the respondents in the FSP noticed new, healthy products. This does not necessarily mean that no behavioral change can be achieved. However, it might have had a minimal influence.

Jeffery et al. (1994) found an effect of extending fruit and salad offerings. They also decreased the price of fruit and salads. It might be that a simultaneous price reduction is necessary to achieve an effect of the environmental interventions. The study by Wilbur et al. (1981) also showed an effect, but in this case the extension with lower-calorie items concerned vending machines instead of the offerings in the cafeteria. Although not all labeling studies have shown effects (e.g. Mayer et al., 1987), most studies have (Dubbert et al., 1984; Levin, 1996; Schmitz \& Fielding, 1986; Sorenson et al., 1992). Dubbert et al., (1984) found an effect on sales data for labeling fruit and vegetables but not on the consumption of entrees, nor on the total caloric content of meals. In our 


\section{Effectiveness in worksite cafeterias}

study, the sales data of fruit and vegetables contained too many missing data points to analyze. Hence, a possible effect of labeling on sales data for fruit and vegetables could not be assessed. Schmitz \& Fielding (1986) found an effect of labeling on total intake of calories, but not on fat intake during lunch in the cafeteria. So, it may be that visitors in worksite cafeterias are more interested in and susceptible to changes in the caloriccontent of products rather than in the fat content of products, as we focused on in our study. In the study by Levin (1996), only entrees were labeled, and a positive effect of the labeling was found. In the study we conducted, no entrees were labeled. For the labeling we chose the product groups most frequently sold in Dutch worksite cafeterias. Also, it was difficult for the worksite cafeterias to provide standard recipes for their entrees, which made it impossible to compute the fat content of the entrees. Consequently, labeling entrees was not possible.

Previously reported evaluation studies of environmental interventions suffered from methodological weaknesses (see also Glanz \& Mullis, 1998): not all studies used a control condition and most studies only measured program effects on consumption in the cafeteria. In this way, the influence of the environmental program on total diet is not clear: will people also eat more low-fat alternatives at home? Does the labeled food item replace another item eaten at the cafeteria or at home or is it added to usual intake? Our study tried to take into account these omissions. This may have accounted for the apparent lack of impact in this trial. In future research regarding intervention programs using environmental elements, attention should be drawn to the visibility and attractiveness of the labels and possible combinations with price-reduction strategies. Furthermore, the labeling might focus not only on fat content, but also on caloric value. 


\section{Chapter 4}

\section{The effectiveness of nutrition education and labeling in Dutch supermarkets ${ }^{5}$}

${ }^{5}$ Submitted for publication as: Steenhuis, I.H.M., Assema, P. van, Reubsaet, A., Breukelen, G.J.P. van, Glanz, K., Kok, G.J. The short-term effectiveness of nutrition education and labeling in Dutch supermarkets. 


\begin{abstract}
Nutrition education and labeling may help consumers to meet the guidelines for a healthy diet. This article presents data on the effectiveness of nutrition education and a nutrition labeling program in Dutch supermarkets. The aim of the intervention was to reduce fat intake. The educational program consisted of information about healthy nutrition, primarily through brochures, recipe cards, a self help manual and posters. In the education plus labeling program, low fat products in nine food product categories were labeled. The goal of the educational program was to help shoppers adopt lower-fat eating habits, and the goal of the labeling program was to make healthy choices visible and easy to recognizable. This study compared the effects of a nutrition education program with and without labeling to a control condition, among 2,203 consumers in thirteen Dutch supermarkets. The design consisted of a randomized pretest-posttest experimental control group design, with three conditions: the educational program without labeling, the educational program with labeling, and a no intervention control group. Total fat intake of clients, consumption of certain high-fat food products, and determinants of eating less fat were measured by a questionnaire. A mixed effect regression model was used for the analysis. No significant effects were found for the educational intervention, alone or with the labeling component, on fat intake or consumption of targeted products. There was a trend toward consumption of lower-fat butter/margarine and cheese in the education with labeling group. In this study, nutrition education and labeling of low fat food products did not prove to be effective strategies for achieving changes in dietary behavior.
\end{abstract}


Effectiveness in supermarkets

\section{Introduction}

High saturated fat intake is associated with an increased risk of coronary heart disease (Willett, 1994). Also, total fat intake contributes to overweight and obesity (Larsson, 1990). Official dietary guidelines in many industrialized countries emphasize reducing fat intake. The Dutch Guidelines for Healthy Nutrition recommend a dietary fat intake of no more than $20-40 \%$ of total calories for people with a normal body weight, while for people with overweight a dietary fat intake of $20-30 / 35 \%$ of total calories is recommended. Furthermore, it is recommended to reduce the intake of saturated fat to a maximum of $10 \%$ of total calories (Health Council of the Netherlands, 2001). At the time this study was conducted, the guidelines were somewhat different: a dietary fat intake of no more than $30-35 \%$ of total calories was recommended, and an intake of saturated fat of no more than $10 \%$ of total calories (Dutch Nutrition Council, 1986, 1991). Actual fat intake of the Dutch population in 1998 was $35.9 \%$ of total calories and the intake of saturated fat $14.2 \%$ (Netherlands Bureau for Food and Nutrition, 1998). Therefore, in the Netherlands as in other countries, effective methods for achieving large scale dietary changes are needed.

The supermarket is especially suitable for behavioral change programs because people frequently and regularly shop in a supermarket. Furthermore, many purchasing decisions are made in the supermarket (Glanz et al., 1995). Several studies of labeling programs conducted in supermarkets have already been reported, and most provided labeling in combination with an educational program. Interventions have used various educational adjuncts to labeling, including small signs placed on shelves or packages with information about one item (i.e. Hunt et al., 1990; Kristal et al., 1997; Lang et al., 2000, Probart, 1993), and larger signs above aisles listing information about more than one item (Muller, 1984, 1985; Russo et al., 1986). In some programs the labels listed nutrient values of food items (i.e. Light et al., 1989; Muller, 1984, 1985), while others showed that a food item is 'high-fiber' or 'low-fat', without specific nutrient information (i.e. Glascoff et al., 1985; Schucker et. al, 1992). Plain colored labels or labels with the project logo or a slogan have also been reported (i.e. Achabal et al., 1987; Kristal et al., 1997; Lang et al., 2000). 


\section{Chapter 4}

Most studies found significant effects on the sales of labeled food items as a result of the labeling (Levy et al., 1985; Muller, 1984, 1985; Mullis \& Pirie, 1988; Olson et al., 1982; Patterson et al., 1992; Schucker et al., 1992). However, no effects on sales data were reported by some studies (Achabal et al., 1987; Ernst et al., 1986; Jeffery et al., 1982; Kristal et al., 1997). Russo et al. found positive effects on sales data of labeling featuring only one negative nutrient (sugar), and no effects on sales data of labels listing several nutrient values. Three studies that did not collect sales data, found self-reported changes in food choices as a result of the program among 35\% or more of a random sample of customers (Glascoff et al., 1985; Hunt et al., 1990; Mullis et al., 1993). To date, only one program including labeling in Dutch supermarkets has been reported (Vaandrager et al., 1993). Four different recipes were promoted to customers. The location of the ingredients was highlighted by colored shelf labels. A significant increase in the consumption of one of the key ingredients of the recipe was found.

Up to now, most studies investigated labeling programs carried out in combination with educational elements such as brochures or posters, but did not compare them with a program with only educational elements. Thus, it is not possible to determine the specific contribution of the labeling intervention. The purpose of this study is to assess the effect of nutrition education with and without shelf labeling, on reduced fat intake, in Dutch supermarkets.

\section{Intervention}

A labeling program and an educational program were developed, specifically to be used in the supermarket environment. Both programs were based on the outcomes of a preliminary study analyzing conditions for program development and implementation (Steenhuis et al., 2001) and on process evaluation data of a similar study conducted in worksite cafeterias (Steenhuis et al., submitted(a)). The intervention programs were pretested among managers of supermarkets and consumers. Based on the pretest results, parts of the intervention were refined. The duration of the programs was two months. After these two months, supermarkets could extend the program by repeating it, or repeating parts of it, up to six months. 


\section{Effectiveness in supermarkets}

\section{Educational Program}

The educational program targeted determinants of eating less fat, including awareness, attitude, social influence, self-efficacy and skills. Information was provided at various points in time, and during the program the information was tied to different stages of readiness for behavior change (Prochaska \& DiClemente, 1992). Thus, at the beginning of the program information was aimed toward increasing awareness of own consumption behavior and changing attitudes towards eating less fat and more fruit and vegetables in a positive direction. After that, the program focused more on increasing self-efficacy and teaching skills for healthy eating behavior. The educational program consisted of several elements, some of which were basic and standard, and others that were optional for the supermarkets. The basic elements were posters with information about the program, a brochure about healthy eating handed out at the check-out, recipe cards with at one side a healthy recipe and at the other side information about healthy nutrition, and a self help manual. People could obtain a free copy of the self help manual by filling out a coupon which was included in the brochure. The goal of the self help manual was to guide people through the different stages of change. The first section included a self-test to measure fat intake and improve awareness of users' fat consumption. Next, the manual gave information about the advantages of eating less fat. For people who wanted to change their dietary behavior, there were practical tips such as how to cook a low fat meal and how to read nutrient information in the supermarket. There were also healthy recipes and a list with high- and low-fat foods. Finally, several tips on how to sustain healthful dietary behavior were offered. Optional elements in the educational program were badges for store personnel, a healthy nutrition contest in the supermarket, and order-separator 'bars' at the cash register with the program logo and slogan ("eat less fat").

\section{Labeling Program}

The goal of the labeling program was to make healthy choices visible and easy recognizable. Low-fat products in nine food product categories were identified with a shelve label. Information on the label consisted of the program logo, the name of the item and the indication that the product was a good low-fat choice. Because earlier studies did not allow conclusions about the best type of label, the design of the labels and the information of the labels was chosen based on the results of the preliminary 


\section{Chapter 4}

study (Steenhuis et al., 2001). The food product categories were butter/margarine, milk, cheese, meat, meat products, desserts, sauces, cookies and crisps/salted biscuits. All these categories contribute significantly to the total fat consumption of the Dutch population (Netherlands Bureau for Food and Nutrition, 1998). The labeling was explained to the consumers with posters and leaflets. Specific criteria were developed for which items should be labeled and which should not. The criteria were based on the Dutch Guidelines on Healthy Nutrition (Dutch Nutrition Council, 1986).

\section{Methods}

\section{Design}

The study used a three group, randomized pretest-posttest experimental design. Thirteen supermarkets were recruited. The main inclusion criteria were a minimum number of 700 clients a day and no labeling program conducted in the last two years. After recruitment, the supermarkets were randomly assigned to one of the three experimental conditions: a no intervention control condition (C), an educational program without labeling $(\mathrm{E})$, or an educational program extended with labeling program $(\mathrm{E}+\mathrm{L})$. This design makes it possible to assess the effects of the intervention that includes education and labeling in comparison to a no-intervention condition as well as to a program that only includes educational elements.

\section{Sample and measures}

A cohort of regular clients of the supermarket were asked to fill out a questionnaire one month before, two months after, and six months after the start of the intervention. For the baseline measurement, respondents were recruited in the supermarket. In total, 6,420 questionnaires were distributed (420-500 per supermarket). The second questionnaire was distributed by mail to persons who had completed the first survey, and the third questionnaire to persons who also had completed the second survey.

The questionnaires measured total fat intake with a short food frequency list, validated in earlier research (van Assema et al., 1992; van Assema et al., 2001). In this list, fat consumption is expressed in 'fat-points'. One fat point is about 4 grams of fat. The list consists of 35 questions covering 19 (categories of) food items. The food items were 


\section{Effectiveness in supermarkets}

selected based on their contribution to the fat intake of the Dutch population (Netherlands Bureau for Food and Nutrition, 1992). Socio-demographic variables were also measured, as well as BMI (body mass index), household size, cooking for the household regularly or not, following a diet or being a vegetarian. Furthermore, psychosocial determinants of eating less fat were measured. Included psycho-social determinants were attitudes, social influence, self-efficacy and intention, following the 'Attitude-Social influence-Self-efficacy model' (ASE model) (de Vries et al., 1988; Kok et al., 1991). An attitude represents a person's general feeling (favorable or unfavorable) towards the behavior concerned. Social influence refers to the influence of others, and can be directly (expectations of significant others), or indirectly (what others do). Selfefficacy refers to a person's expectation regarding his capability to realize a behavior. Attitudes, social influence, and self-efficacy predict the intention to perform the behavior, which in turn predicts the behavior itself. Attitudes were in this study measured with one item on a 'good-bad' scale. Two aspects of social influence were measured: social support and modeling of colleagues. Self-efficacy was measured with one item. These variables were measured on a 7-point scale. Intention was measured by asking if respondents were planning to eat less fat within the next month (yes or no). In addition, possible misconceptions about own consumption levels were measured, since in recent years this has been identified as another important factor determining dietary behavior (Brug et al., 1994).

Possible misconceptions about own fat consumption were computed by combining scores on fat intake derived from the food frequency questionnaire with an item about the amount of fat a respondent indicated he or she was eating. Respondents were classified in three groups: realistic about their own consumption, underestimating their own consumption and overestimating their own consumption. In the posttest questionnaire, respondents were also asked about their opinions and reactions toward the nutrition program in their supermarket. This was measured on seven point scales. Data of the third questionnaire were only used to compute total fat intake.

Questionnaire data were used to assess the effect of interventions on total dietary fat intake and on determinants of eating less fat. Data from the questionnaires can also give some insight into the effects of the interventions on single product categories. For some 


\section{Chapter 4}

products, respondents were asked which type they normally used (e.g. low, semi or full fat milk). These data are available for butter/margarine, milk, cheese and desserts. For other product categories respondents were asked to indicate if they ate certain labeled products during the last month. These products were low fat salad dressing, ketchup/curry sauce, pretzels, Japanese salty biscuits, honey cake and low fat cookies.

Sales data were collected to provide a second type of outcome measure. Absolute sales figures for 67 products which met the criteria for labeling were collected four weeks before, and during the intervention period, at each supermarket. One popular brand per product was selected for monitoring. However, both the collection of the sales data and the analysis ran into numerous problems. Problems with data collection included the inability of three supermarkets to provide sales data, and that some supermarkets provided wholesale rather than retail sales data. Because only one brand per product was included in the data collection, assessment of sales in a product group was usually incomplete. Also, the proportional sales of labeled products within a whole product group (e.g. the percentage of low fat milk within the total sales of milk) could not be computed. Absolute sales numbers were analyzed for some products, but fluctuated too much to detect a possible intervention effect. Due to these problems with the sales data, the data could not be used to evaluate the interventions, and are not further presented in this article. As noted above, questionnaire data provided some information on changes in consumption of specific product groups.

\section{Analysis}

Total fat consumption scores were computed in SPSS (SPSS, 1999). Because the data are clustered, a random-effects regression model was used for the initial analysis. Random-effects regression allow data within clusters (i.e supermarkets) to be correlated by assuming a random cluster (supermarket) effect (Hedeker et al., 1994). This socalled 'intraclass correlation' is estimated along with the regression parameters, and affects the estimates and standard errors of the regression parameters (Hedeker et al., 1994). Ignoring this clustering usually leads to underestimation of standard errors and consequently to type I errors of testing and too narrow confidence intervals. The software packages MIXREG and MIXOR were used to perform the multi-level analysis (Hedeker \& Gibbons, 1996). However, the multilevel analysis with MIXOR/MIXREG 


\section{Effectiveness in supermarkets}

ran into numerical estimation problems, probably due to a zero intraclass correlation and/or small number of supermarkets. If the intraclass correlation is zero (which could be the case in view of the fact that running a few analyses with MLwiN (Goldstein et al., 1998) always yielded an estimated intraclass correlation of 0 ), an ordinary regression analysis with persons as unit of analysis and ignoring their nesting within supermarkets is correct. However, it is also known that an estimated intraclass correlation of 0 can also be due to a small sample size at the highest level, i.c. a small number of supermarkets. If the intraclass correlation is not zero, even if it is very small, this ordinary analysis is invalid and will underestimate the SEs of the intervention effects. In that case, an aggregated analysis with supermarkets as unit of analysis (using the average of all persons within that supermarket as observation) is a valid method to evaluate our intervention effects, albeit less powerful than multilevel analysis due to varying sample sizes per supermarket and the fact that only very few covariates can be included into this analysis (Moerbeek, 2000). In short, multi-level analysis is the best method to analyze the data, but since this analysis could not be performed, two alternative methods were considered: analysis with the individuals as unit of analysis and analysis with supermarkets as unit of analysis (aggregated analysis). The analysis with individuals as unit of analysis is too liberal and in fact even invalid, unless the intraclass correlation is zero (0). The aggregated analysis is a bit conservative, but at least valid whether the intraclass correlation is zero or not. In this article, both types of analysis (individuals and supermarkets as unit of analysis) were performed and presented. However, since the fact that analysis with individuals as unit of analysis is valid only if the intraclass correlation is zero, most importance should be attached to the aggregated analysis.

An initial non-response analysis was conducted, with individuals as unit of analysis. A regression model including the independent variables age, sex, educational level, fat intake at baseline, BMI, household size, cooking regularly, following a diet, being a vegetarian and study arm was used for an initial non-response analysis. To assess each outcome variable, comparisons were made between the educational with labeling program vs. the educational program and control condition. A regression model including score at baseline and study arm as independent variables was used to test for differences in fat consumption, product consumption, and determinants of eating less 


\section{Chapter 4}

fat. For study arm, dummy variables were used with control (C) and education only (E) as reference category. In the analysis with supermarkets as unit of analysis, ANCOVA was used with the baseline average of all persons sampled within that supermarket as covariate and the posttest average of the persons sampled as dependent variable. In view of the small number of supermarkets no other covariates were included into the model, assuming that most of their effects will already be reflected in the baseline average. SPSS was used to run the analysis. For the main outcome, fat intake, an alpha of .05 was used for the aggregated analysis. For the analysis with individuals as unit of analysis, an alpha of .01 was used. To avoid Type I errors due to multiple testing outcomes, an alpha of .01 was used for all the other outcomes, for both the analysis on individual and aggregated level.

\section{Results}

\section{Response rates and attrition}

Total response at baseline ( $\mathrm{t} 1$ ) was $48.4 \%(\mathrm{n}=3,106)$, and ranged from $47.1 \%$ to $49.8 \%$ for the three study conditions (See figure 1). Of the baseline questionnaires received, 29 were excluded from analysis due to more than $50 \%$ missing items. The mail distribution of questionnaires at $\mathrm{t} 2$ was complicated by problems with the postal delivery, so that 140 questionnaires in the $\mathrm{E}+\mathrm{L}$ condition were not delivered. Consequently, the total number of questionnaires distributed at $\mathrm{t} 2$ was 2,927. Overall response at $\mathrm{t} 2$ was $79.5 \%$ $(n=2,327)$ (see also Figure 1). At $\mathrm{t} 2$, seven questionnaires were excluded, again because of too much missing data. Another 117 respondents were excluded from analysis because they did not shop regularly in the supermarket $(n=91)$ or were younger than 18 years $(\mathrm{n}=26)$. In total, complete data ( $\mathrm{t} 1$ and $\mathrm{t} 2)$ from 2,203 respondents were used in the analysis. Of these 2,203 respondents, $82.9 \%$ also completed the third questionnaire $(n=1,827)$. Data of these respondents were used for the analysis of the effects on fat intake after six months. Dropout numbers at 12 did not differ significantly between the research groups. In the dropout analysis $(n=2,953)$, age, gender and level of education were significant predictors of attrition $(p<.005)$. Mean age of dropouts was 43 years and mean age of completers was 46 years. 


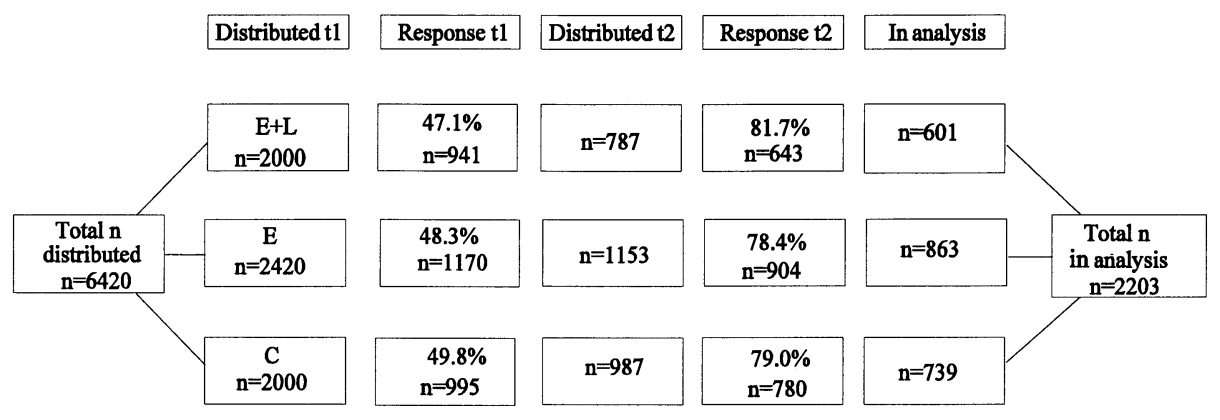

$(\mathrm{E}+\mathrm{L}=$ Education + labeling; $\mathrm{E}=$ Education; $\mathrm{C}=\mathrm{Control})$

Figure 1 Number of respondents and response

More men than women dropped out (30\% of all men, $24 \%$ of all women) as did more respondents with a low education level (31\% of respondents with a low education, $24 \%$ with middle education and $24 \%$ with a high education). Baseline fat intake was not a significant predictor of dropout.

\section{Description of the sample}

The mean age of respondents was 46 years. The majority of the respondents were female ( $80 \%$ female, $20 \%$ male), and had a medium level of education $(21 \%$ low, $61 \%$ medium, $18 \%$ high). Mean BMI of the study population was 24.3 . A large majority of the respondents lived together with others (87\%), and cooked regularly (91\%). Only a few respondents were following a diet $(8 \%)$ or were vegetarian $(4 \%)$. There were no significant differences between groups regarding these variables or fat intake.

\section{Awareness of and reactions to the interventions}

Table 1 shows reported awareness, or 'reach,' of the intervention. Almost half of the respondents had seen at least something of the nutrition programs in the supermarket. Nearly a quarter of the respondents in the $\mathrm{E}+\mathrm{L}$ program reported seeing the labels. The brochures, posters and recipe cards were seen by $20 \%-30 \%$ of the respondents, while the healthy nutrition contest was seen by fewer respondents. More than half of the 


\section{Chapter 4}

respondents who had seen the brochures, recipe cards or contest, read them, took them home or took part in the contest. Analysis with individuals as unit of analysis showed that significantly more respondents in the $\mathrm{E}+\mathrm{L}$ program saw the recipe cards $(\mathrm{p}<.01)$. However, this difference was not significant in the aggregated analysis $(\mathrm{p}=.30)$. For the other variables in Table 1, no significant differences were found between the two programs (all p-values 2.07 ). Table 2 shows reactions to the programs of respondents who were aware of at least something of the nutrition programs. Respondents in both conditions had a positive general opinion about the programs. More than half of the respondents reported that they had looked at their own fat consumption level as a result of the intervention, and almost half of the respondents reported their intention to follow one or more suggestions given in the program. No significant differences were found between the two intervention programs regarding the variables listed in Table 2, either with persons or with supermarkets as units of analysis (all p-values 2.09 ).

Table 1 Reach of the intervention (basic elements) for persons and supermarkets as unit of analysis (\%)

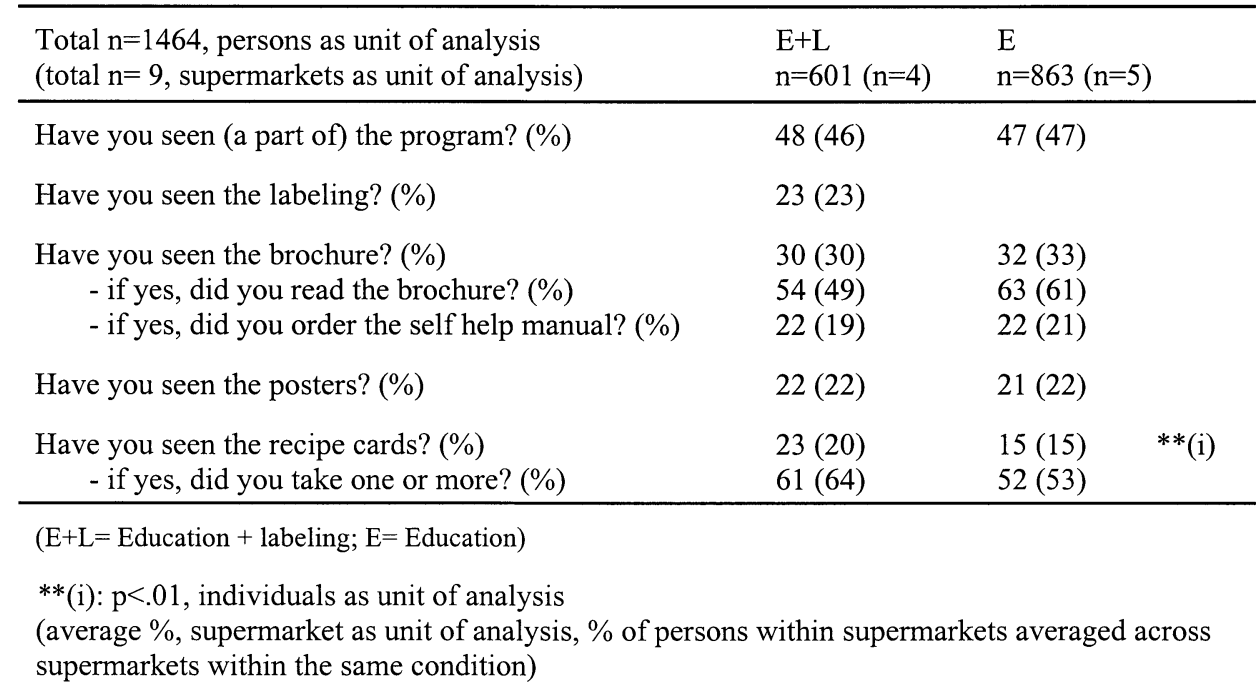




\section{Effectiveness in supermarkets}

Table 2 Respondents' reactions to the programs for persons (mean(SD)) and supermarkets (mean) as unit of analysis

\begin{tabular}{|c|c|c|}
\hline $\begin{array}{l}\text { Total } n=691 \text {, persons as unit of analysis } \\
\text { (total } n=9 \text {, supermarkets as unit of analysis) }\end{array}$ & $\begin{array}{l}\mathrm{E}+\mathrm{L} \\
\mathrm{n}=287 \\
(\mathrm{n}=4)\end{array}$ & $\begin{array}{l}\mathrm{E} \\
\mathrm{n}=404 \\
(\mathrm{n}=5)\end{array}$ \\
\hline \multicolumn{3}{|l|}{ Range -3 (very negative) +3 (very positive) } \\
\hline What is your general opinion about the program? & $\begin{array}{l}1.5(1.2) \\
(1.5)\end{array}$ & $\begin{array}{l}1.3(1.4) \\
(1.5)\end{array}$ \\
\hline How interesting was the information? & $\begin{array}{l}1.1(1.4) \\
(1.0)\end{array}$ & $\begin{array}{l}1.0(1.4) \\
(0.9)\end{array}$ \\
\hline $\begin{array}{l}\text { What did you think about the appearance of the } \\
\text { information? }\end{array}$ & $\begin{array}{l}0.7(1.4) \\
(0.7)\end{array}$ & $\begin{array}{l}0.7(1.4) \\
(0.7)\end{array}$ \\
\hline \multicolumn{3}{|l|}{ Range -3 (very negative) +3 (very positive) } \\
\hline \multicolumn{3}{|l|}{ As a result of the program ... } \\
\hline $\begin{array}{l}\text {... do you have more knowledge about healthy } \\
\text { nutrition? }\end{array}$ & $\begin{array}{l}0.3(1.7) \\
(0.2)\end{array}$ & $\begin{array}{l}0.2(1.7) \\
(0.2)\end{array}$ \\
\hline ... do you have a better notion how to eat healthy? & $\begin{array}{l}0.4(1.7) \\
(0.4)\end{array}$ & $\begin{array}{l}0.5(1.6) \\
(0.5)\end{array}$ \\
\hline $\begin{array}{l}\text { have you looked at your fat consumption? } \\
\text { (\% yes) }\end{array}$ & $\begin{array}{c}52 \\
(53)\end{array}$ & $\begin{array}{c}60 \\
(60)\end{array}$ \\
\hline $\begin{array}{l}\text { do you have the intention to follow one or } \\
\text { more advices? ( } \% \text { yes) }\end{array}$ & $\begin{array}{l}40 \\
(37)\end{array}$ & $\begin{array}{l}45 \\
(45)\end{array}$ \\
\hline
\end{tabular}

$(\mathrm{E}+\mathrm{L}=$ Education + labeling; $\mathrm{E}=$ Education $)$

(no significant differences between groups)

Table 3 Mean (SD) fat intake at baseline ( $t 1)$ and posttest ( $t 2)$ with individuals as unit of analysis

\begin{tabular}{lllll}
\hline Total $\mathrm{n}=2203$ & & $\mathrm{E}+\mathrm{L}$ & $\mathrm{E}$ & $\mathrm{C}$ \\
& & $\mathrm{n}=601$ & $\mathrm{n}=863$ & $\mathrm{n}=739$ \\
\hline Fat intake & $\mathrm{t} 1$ & $20.0(6.0)$ & $20.4(6.0)$ & $19.9(5.7)$ \\
(fat points per day) & $\mathrm{t} 2$ & $19.6(6.0)$ & $20.0(5.9)$ & $19.6(5.7)$ \\
\hline
\end{tabular}

$(\mathrm{E}+\mathrm{L}=$ Education + labeling; $\mathrm{E}=$ Education $\mathrm{C}=\mathrm{Control})$

(no significant differences between groups) 
Chapter 4

Table 4 Mean fat intake at baseline ( $t 1)$ and posttest ( $t 2)$ per supermarket, and mean per condition (using supermarkets as units of analysis with equal weighting)

\begin{tabular}{|c|c|c|c|c|c|}
\hline Total $n=13$ & $\begin{array}{l}\text { Fat intake } t 1 \\
\text { (fat points } \\
\text { per day) }\end{array}$ & $\begin{array}{l}\text { Fat intake } t 2 \\
\text { (fat points } \\
\text { per day) }\end{array}$ & Condition & $\begin{array}{l}\text { Fat intake per } \\
\text { condition } t 1 \\
\text { (fat points per } \\
\text { day) }\end{array}$ & $\begin{array}{l}\text { Fat intake per } \\
\text { condition } \mathrm{t} 2 \\
\text { (fat points per } \\
\text { day) }\end{array}$ \\
\hline $\begin{array}{l}\text { Supermarket } 1 \\
(\mathrm{n}=67)\end{array}$ & $20.5(6.3)$ & $20.1(6.0)$ & $\mathrm{E}+\mathrm{L}$ & & \\
\hline $\begin{array}{l}\text { Supermarket } 2 \\
(\mathrm{n}=169)\end{array}$ & $20.0(5.6)$ & $19.9(6.3)$ & $\mathrm{E}+\mathrm{L}$ & 20.1 & 19.7 \\
\hline $\begin{array}{l}\text { Supermarket } 3 \\
(n=164)\end{array}$ & $19.9(6.3)$ & $19.5(5.9)$ & $\mathrm{E}+\mathrm{L}$ & & \\
\hline $\begin{array}{l}\text { Supermarket } 4 \\
(\mathrm{n}=201)\end{array}$ & $19.9(6.1)$ & $19.2(5.7)$ & $\mathrm{E}+\mathrm{L}$ & & \\
\hline $\begin{array}{l}\text { Supermarket } 5 \\
(n=171)\end{array}$ & $20.7(5.9)$ & $20.4(5.8)$ & $\mathrm{E}$ & & \\
\hline $\begin{array}{l}\text { Supermarket } 6 \\
(\mathrm{n}=135)\end{array}$ & $19.9(6.6)$ & $20.0(6.4)$ & $\mathrm{E}$ & & \\
\hline $\begin{array}{l}\text { Supermarket } 7 \\
(n=166)\end{array}$ & $20.2(5.6)$ & $19.8(5.7)$ & $\mathrm{E}$ & 20.3 & 20.0 \\
\hline $\begin{array}{l}\text { Supermarket } 8 \\
(\mathrm{n}=213)\end{array}$ & $21.3(5.5)$ & $20.7(5.7)$ & $\mathrm{E}$ & & \\
\hline $\begin{array}{l}\text { Supermarket } 9 \\
(\mathrm{n}=178)\end{array}$ & $19.5(6.3)$ & $19.0(5.8)$ & $\mathrm{E}$ & & \\
\hline $\begin{array}{l}\text { Supermarket10 } \\
(\mathrm{n}=186)\end{array}$ & $19.4(5.5)$ & $19.5(5.5)$ & $\mathrm{C}$ & & \\
\hline $\begin{array}{l}\text { Supermarket11 } \\
(\mathrm{n}=182)\end{array}$ & $20.0(5.6)$ & $19.6(5.4)$ & $\mathrm{C}$ & 19.9 & 19.6 \\
\hline $\begin{array}{l}\text { Supermarket12 } \\
(\mathrm{n}=160)\end{array}$ & $19.3(5.5)$ & $18.8(5.5)$ & $\mathrm{C}$ & & \\
\hline $\begin{array}{l}\text { Supermarket13 } \\
(\mathrm{n}=211)\end{array}$ & $20.7(6.1)$ & $20.4(6.2)$ & $\mathrm{C}$ & & \\
\hline
\end{tabular}

$(\mathrm{E}+\mathrm{L}=$ Education + labeling; $\mathrm{E}=$ Education; $\mathrm{C}=\mathrm{Control})$

(no significant differences between groups) 
Effectiveness in supermarkets

\section{Total fat intake}

Mean total fat scores at baseline and two months after the start of the intervention are presented in Table 3 (individual as unit of analysis) and 4 (supermarket as unit of analysis). Mean fat consumption decreased 0.4 fat points in the $\mathrm{E}+\mathrm{L}$ program and 0.3 points in the educational only condition and control group $(n=13)$. Regression analyses with the individual as unit of analysis revealed no significant differences between the programs with respect to posttest ( $\mathrm{t} 2$ ), correcting for baseline consumption ( $\mathrm{p}$-values 2.53). ANCOVA analyses with the supermarket as unit of analysis did not show a significant difference between the programs either with respect to posttest, correcting for baseline consumption (all p-values 2.64 ). These analyses were repeated with fat scores on $\mathrm{t} 3$ (six months after start of the intervention) as dependent variable $(n=1,827$; $n=13$ ). Figure 2 shows mean fat intake at baseline and the two posttests ( $t 2$ and $t 3$ ) per condition, with supermarkets as units of analysis. Mean fat intake at $\mathrm{t} 3$ was $19.4(\mathrm{E}+\mathrm{L})$, 20.0 (E) and 19.3 (C), with individuals as unit of analysis. Both the analyses, with individuals and supermarkets as unit of analysis, did not show a significant difference between the programs with respect to fat intake at $\mathrm{t} 3$ (all p-values $\geq .28$ ).

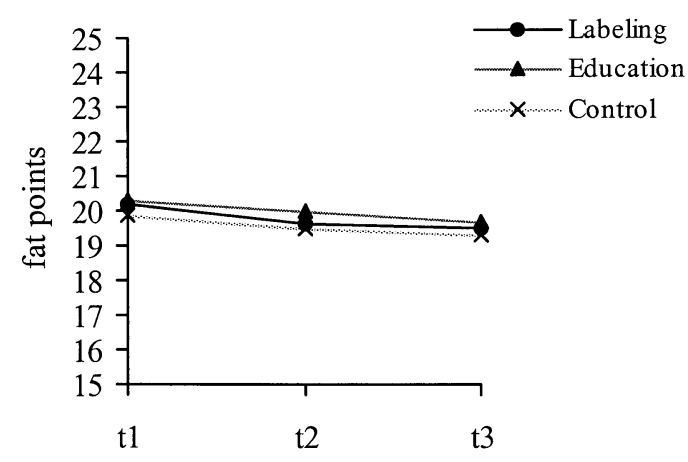

Figure 2 Mean fat intake at baseline ( $t 1)$ and posttests $(t 2+t 3)$ per condition (using supermarkets as units of analysis with equal weighting) 
It is possible that many respondents did not experience a need to change their fat consumption, since many of them thought that their fat consumption was not very high to begin with. Of all respondents, $15 \%(n=330)$ indicated at baseline that their own fat consumption was (very) high ('aware' people). This classification only takes into account the subjective estimation of fat consumption levels (as distinct from the classification for misconception of own consumption levels, where both the subjective and the more objective estimation deriving from the fat frequency questionnaire was taken into account). It could be that the $\mathrm{E}+\mathrm{L}$ intervention especially was effective for this specific group of aware respondents. To test this hypothesis, we tested the presence of interaction between baseline awareness (yes/no) and treatment condition $(\mathrm{E}+\mathrm{L}, \mathrm{E}, \mathrm{C})$ on posttest fat consumption, using pretest fat consumption as covariate and supermarkets as unit of analysis. More specifically, we first computed within each supermarket:

- as outcome the mean difference in posttest fat consumption between unaware and aware persons,

- as covariate the mean difference in pretest fat consumption between unaware and aware persons.

We next ran ANCOVA with supermarkets as units of analysis, treatment condition as fixed factor, and the outcome and covariate as defined above. Interaction between (subjective) awareness and treatment shows up as a treatment effect on the outcome as defined above. In fact, this method is equivalent to a 'split-plot ANOVA' with treatment as a between-subject (or between-supermarket) factor and awareness as a within-subject (within-supermarket) factor. While the omnibus test using all three treatment conditions showed no interaction $(\mathrm{p}=.25)$, and a pairwise comparison between $\mathrm{E}$ and $\mathrm{E}+\mathrm{L}$ failed to show interaction as well $(\mathrm{p}=.75)$, pairwise comparisons between $\mathrm{E}+\mathrm{L}$ and $\mathrm{C}$ and between $\mathrm{E}$ and $\mathrm{C}$ showed a very weak trend toward interaction $(\mathrm{p}=.11$ and $\mathrm{p}=.16$ respectively). Figures 3 and 4 summarize the pre- and posttest mean fat consumptions per treatment for unaware and aware persons respectively. These figures also indicate a possible effect of the educational component of the treatments for aware persons. Therefore, the initial analysis of treatment effect on posttest fat consumption, corrected 


\section{Effectiveness in supermarkets}

for pretest fat consumption, with supermarkets as unit of analysis, was repeated within each of the two subgroups, unaware and aware persons. No significant treatment effects were found either in the unaware subgroup (all p-values 2.51 ) or in the aware subgroup (all p-values 2.07). The same procedure to test for interaction of treatment with awareness was also carried out with respect to fat consumption at $\mathrm{t} 3$ (six months after the start of the intervention) (unaware $n=255,14 \%$, aware $n=1,572,86 \%$ ). Although no significant interactions were found, there was a trend towards interaction for the $\mathrm{E}+\mathrm{L}$ condition compared to the $\mathrm{E}$ condition $(\mathrm{p}=.06)$. Figure 5 and 6 show mean fat intake at baseline (t1) and posttests (t2 and $\mathrm{t} 3$ ) per condition, for unaware and aware people. For unaware people, the data show a decrease of $0.7,0.5$ and 0.6 fat points between posttest at $\mathrm{t} 3$ and baseline in respectively the $\mathrm{E}+\mathrm{L}$ condition, the $\mathrm{E}$ condition and the control condition. For the aware group, the decrease between $\mathrm{t} 3$ and $\mathrm{t} 1$ was 0.6 fat points in the $\mathrm{E}+\mathrm{L}$ condition and in the control condition, and 1.6 fat points in the $\mathrm{E}$ condition. For both the unaware and the aware group, ANCOVA analyses with the supermarket as unit of analysis did not show a significant difference between the programs with respect to posttest ( $\mathrm{t} 3$ ), correcting for baseline consumption (all p-values unaware group $\geq .25$; aware group $\geq .14)$.

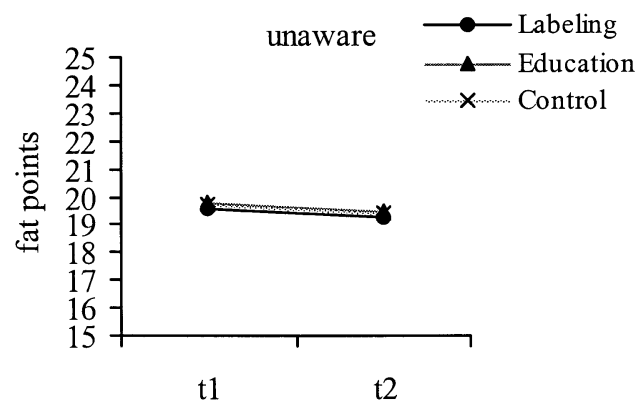

Figure 3 Mean fat intake at baseline ( $t 1$ ) and posttest ( $t 2$ ) per condition for unaware people (using supermarkets as units of analysis with equal weighting) 


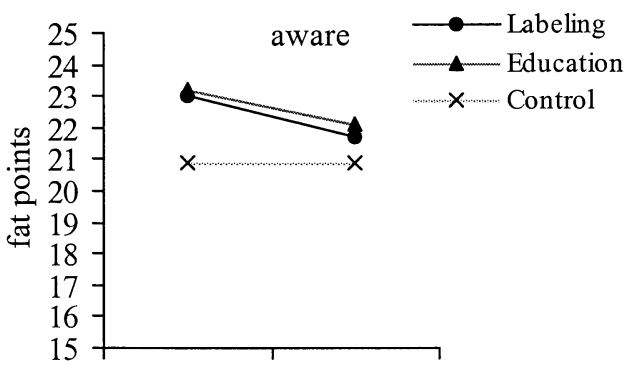

t1

t2

Figure 4 Mean fat intake at baseline (t1) and posttest (t2) per condition for aware people (using supermarkets as units of analysis with equal weighting)

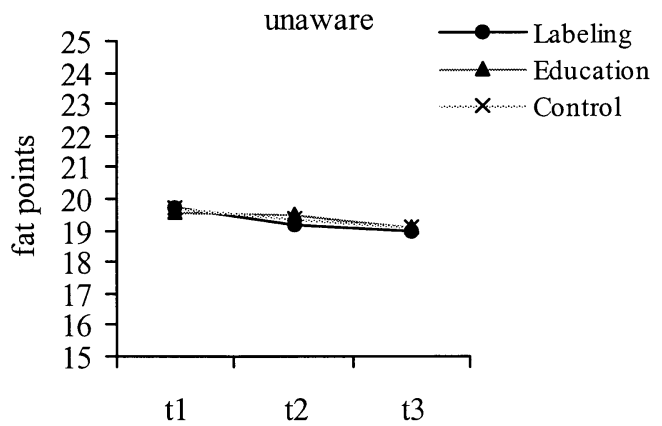

Figure 5 Mean fat intake at baseline ( $t 1)$ and posttests ( $t 2$ and $t 3$ ) per condition for unaware people (using supermarkets as units of analysis with equal weighting)

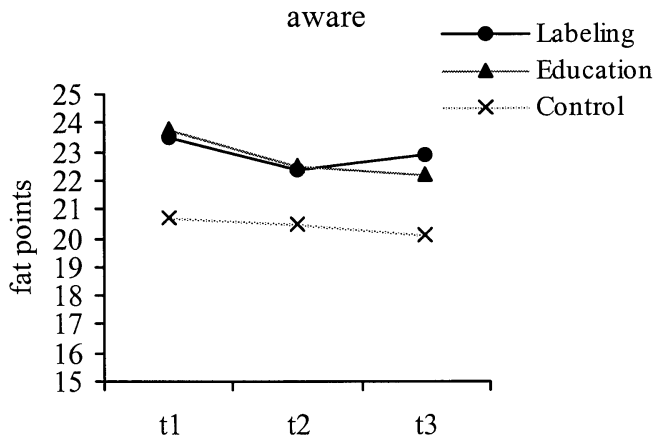

Figure 6 Mean fat intake at baseline ( $t 1)$ and posttests $(t 2+t 3)$ per condition for aware people (using supermarkets as units of analysis with equal weighting) 
Effectiveness in supermarkets

Table 5 Percentage respondents that consumed labeled type of product with persons as unit of analysis (and average \% using supermarkets as unit of analysis)

\begin{tabular}{|c|c|c|c|}
\hline $\begin{array}{l}\text { Total } n=2203 \text {, persons as unit of } \\
\text { analysis } \\
\text { (total } n=13 \text {, supermarkets as unit of } \\
\text { analysis) }\end{array}$ & $\begin{array}{l}E+L \\
n=601 \\
(n=4)\end{array}$ & $\begin{array}{l}E \\
n=863 \\
(n=5)\end{array}$ & $\begin{array}{l}\mathrm{C} \\
\mathrm{n}=739 \\
(\mathrm{n}=4)\end{array}$ \\
\hline $\begin{array}{l}\text { Butter/margarine } \\
\% \text { low fat }\end{array}$ & $\begin{array}{l}59.6(59.1) \\
64.1(63.8) \\
+4.5(+4.7)\end{array}$ & $\begin{array}{l}65.8(65.5) \\
65.9(65.7) \\
+0.1(+0.2)\end{array}$ & $\begin{array}{r}63.2(63.4) \\
63.2(63.5) \\
0.0(+0.1)\end{array}$ \\
\hline $\begin{array}{l}\text { Milk } \\
\text { \% low/semi fat }\end{array}$ & $\begin{array}{l}84.4(84.7) \\
90.5(90.9) \\
+6.1(+6.2)\end{array}$ & $\begin{array}{l}89.3(89.0) \\
94.1(93.8) \\
+4.8(+4.8)\end{array}$ & $\begin{array}{l}87.6(87.7) \\
92.8(92.8) \\
+5.2(+5.1)\end{array}$ \\
\hline $\begin{array}{l}\text { Cheese } \\
\% 20+\text { or } 30+\end{array}$ & $\begin{array}{l}16.8(18.2) \\
19.6(21.0) \\
+2.8(+2.8)\end{array}$ & $\begin{array}{l}19.2(19.3) \\
19.1(19.1) \\
-0.1(-0.2)\end{array}$ & $\begin{array}{r}19.2(16.8) \\
19.2(19.2) \\
0.0(+2.4)\end{array}$ \\
\hline $\begin{array}{l}\text { Desserts } \\
\% \text { low/semi fat }\end{array}$ & $\begin{array}{l}85.7(85.0) \\
78.5(78.7) \\
-7.2(-6.3)\end{array}$ & $\begin{array}{l}90.6(90.7) \\
84.0(84.0) \\
-6.6(-6.7)\end{array}$ & $\begin{array}{l}89.9(90.1) \\
80.6(80.6) \\
-9.3(-9.5)\end{array}$ \\
\hline
\end{tabular}

$(\mathrm{E}+\mathrm{L}=$ Education + labeling; $\mathrm{E}=$ Education; $\mathrm{C}=\mathrm{Control})$

(no significant differences between groups)

\section{Product consumption}

Table 5 shows the proportion of respondents who consumed the labeled type of products at baseline and post-intervention for four product categories. For butter/margarine and cheese, in the $\mathrm{E}+\mathrm{L}$ condition a slight increase in the percentage of respondents who consumed the low fat variety was found, while the percentages in the other conditions remained stable. For milk, an increase for the labeled types were found in all conditions, while for desserts a decrease was found in all conditions. Differences between the conditions on posttest data, correcting for baseline data, were nonsignificant (all p-values $\geq .19$ ). 
Chapter 4

Table 6 Percentage respondents that consumed labeled product during last month with persons as unit of analysis (and average \% using supermarkets as unit of analysis)

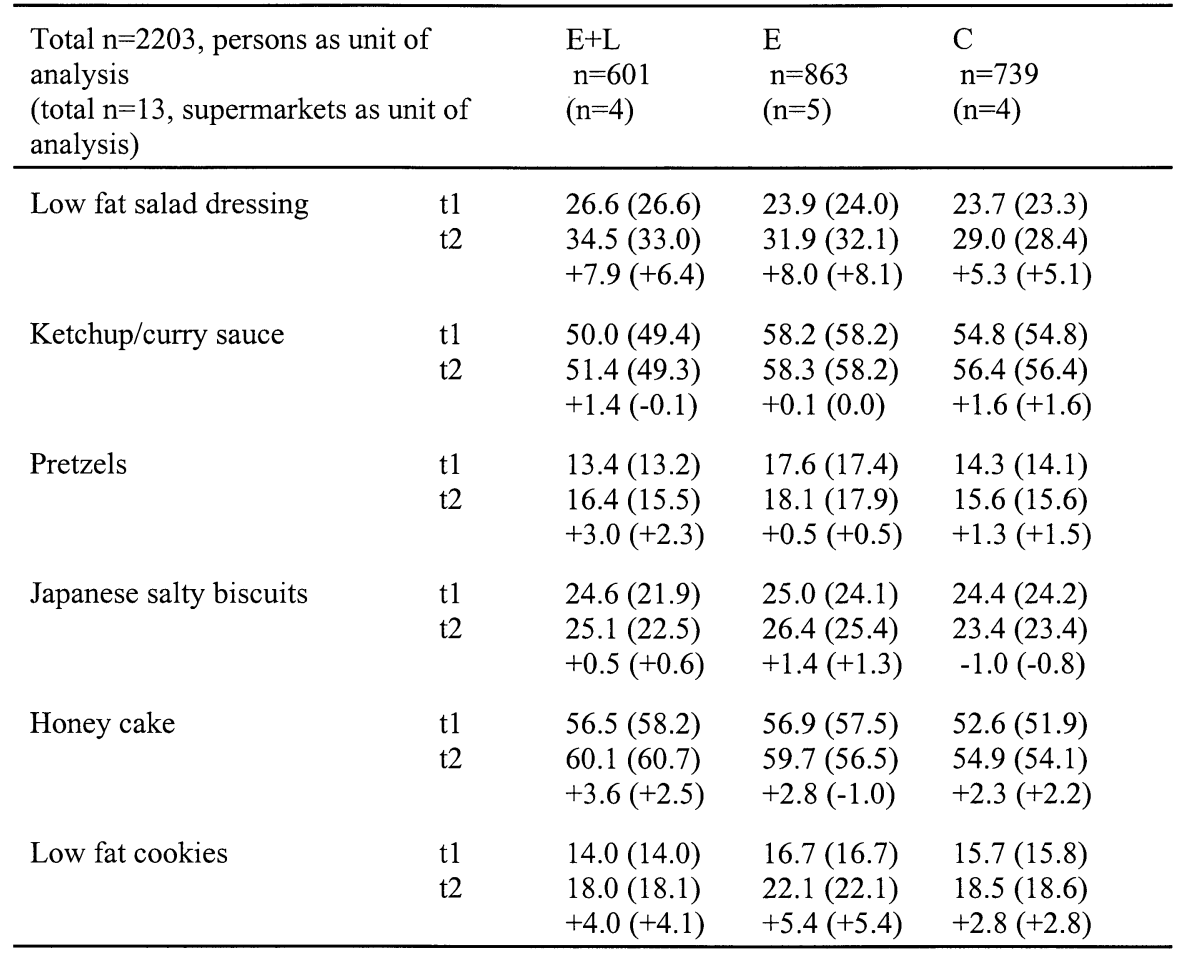

$(\mathrm{E}+\mathrm{L}=$ Education + labeling; $\mathrm{E}=$ Education; $\mathrm{C}=\mathrm{Control})$

(no significant differences between groups)

Table 6 shows percentages of respondents who consumed certain labeled products during the last month. The percentage of respondents who consumed low fat salad dressing increased in all conditions. More consumers ate low fat cookies at posttest, and this increase was the greatest in the educational program. Comparisons between the conditions on posttest data revealed no significant differences between the conditions, correcting for baseline data, with both persons and supermarkets as unit of analysis (all p-values 2.08$)$. 


\section{Effectiveness in supermarkets}

For all variables in Table 5 and 6, interaction analyses between (subjective) awareness of own fat consumption level and study arm on behavior change (i.e. consumption of certain products) were performed with the aggregated data. ANCOVA-analysis with condition as factor, score at $\mathrm{t} 2$ of the aware respondents minus the score at $\mathrm{t} 2$ of the unaware respondents as dependent variable and the same score at $\mathrm{t} 1$ as covariate was used to perform the analyses. No significant interactions were found.

\section{Behavioral determinants}

Table 7 shows scores on determinants of eating less fat at baseline (t1) and posttest (t2), for both persons as unit of analysis and supermarkets as unit of analysis. Scores on attitude, social influence and self-efficacy were already positive at baseline (except for scores on social support). The scores on attitudes, social influences and self-efficacy stayed more or less the same between baseline and posttest. No significant differences were found between research groups on posttest scores, corrected for baseline scores, with both individuals and supermarkets as unit of analysis (all p-values 2.15 ). The intention to eat less fat increased slightly in all groups, but least in the control group. The analysis with individuals as unit of analysis showed that in the $\mathrm{E}$ condition significantly more respondents than in the control condition at $\mathrm{t} 2 \mathrm{had}$ the intention to eat less fat within the next month, correcting for baseline scores $(\mathrm{p}<.01)$. However, in the analysis with supermarkets as unit of analysis this difference did not remain significant $(p=.53)$. Regarding misconceptions of own consumption levels, more than half of the respondents in all research groups underestimated their fat consumption level. At posttest, the number of respondents underestimating their fat consumption decreased with approximately $5 \%$ in the $\mathrm{E}+\mathrm{L}$ condition, while the percentage of respondents underestimating their fat consumption in the other conditions remained more or less the same. Analysis at both the individual level and the aggregated level did not show a significant difference between research groups with respect to the percentage of underestimators (all p-values individual analysis $\geq .07$, all p-values aggregated analysis 2.11). For attitude, social influence, self-efficacy and intention, ANCOVA analyses were performed to test for interactions between (subjective) awareness and study arm on posttest scores of the behavioral determinants, following the same statistical procedure as outlined for total fat consumption. No significant interactions were found. 
Table 7 Scores on determinants of eating less fat at baseline (t1) and posttest (t2) with persons as unit of analysis (mean(SD) or \%) and for supermarkets as unit of analysis (mean or \%)

\begin{tabular}{|c|c|c|c|c|c|}
\hline \multicolumn{2}{|c|}{$\begin{array}{l}\text { Total } n=2203 \text {, persons as unit } \\
\text { of analysis } \\
\text { (total } n=13 \text {, supermarkets as } \\
\text { unit of analysis) }\end{array}$} & \multirow{2}{*}{ 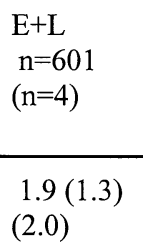 } & \multirow{2}{*}{ 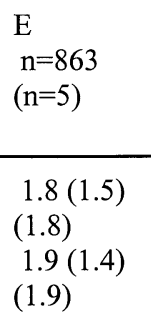 } & \multicolumn{2}{|l|}{$\begin{array}{l}\mathrm{C} \\
\mathrm{n}=739 \\
(\mathrm{n}=4)\end{array}$} \\
\hline $\begin{array}{l}\text { Attitude } \\
(-3+3)\end{array}$ & $\begin{array}{l}\mathrm{t} 1 \\
\mathrm{t} 2\end{array}$ & & & $\begin{array}{l}1.8(1.4) \\
(1.8) \\
1.9(1.4) \\
(1.9)\end{array}$ & \\
\hline $\begin{array}{l}\text { Social influence; } \\
\text { modeling } \\
(-3+3)\end{array}$ & $\mathrm{t} 1$ & $\begin{array}{l}0.7(1.4) \\
(0.7) \\
0.8(1.5) \\
(0.8)\end{array}$ & $\begin{array}{l}0.5(1.4) \\
(0.5) \\
0.6(1.4) \\
(0.6)\end{array}$ & $\begin{array}{l}0.6(1.4) \\
(0.6) \\
0.7(1.5) \\
(0.6)\end{array}$ & \\
\hline $\begin{array}{l}\text { Social influence; } \\
\text { social support } \\
(-3+3)\end{array}$ & $\mathrm{t} 1$ & $\begin{array}{l}-0.5(2.0) \\
(-0.4) \\
-0.5(2.1) \\
(-0.4)\end{array}$ & $\begin{array}{l}-0.5(2.0) \\
(-0.5) \\
-0.5(2.1) \\
(-0.5)\end{array}$ & $\begin{array}{l}-0.6(2.1) \\
(-0.6) \\
-0.5(2.0) \\
(-0.5)\end{array}$ & \\
\hline $\begin{array}{l}\text { Self-efficacy } \\
(-3+3)\end{array}$ & $\mathrm{t} 1$ & $\begin{array}{l}0.6(1.9) \\
(0.7) \\
0.7(1.9) \\
(0.7)\end{array}$ & $\begin{array}{l}0.5(1.9) \\
(0.5) \\
0.5(1.9) \\
(0.5)\end{array}$ & $\begin{array}{l}0.7(1.8) \\
(0.7) \\
0.7(1.8) \\
(0.7)\end{array}$ & \\
\hline $\begin{array}{l}\text { Intention } \\
\% \text { yes }\end{array}$ & $\begin{array}{l}\mathrm{t} 1 \\
\mathrm{t} 2\end{array}$ & $\begin{array}{l}33.9 \\
(35.7) \\
36.5 \\
(37.5)\end{array}$ & $\begin{array}{l}37.9 \\
(38.4) \\
40.8 \\
(41.4)\end{array}$ & $\begin{array}{l}33.1 \\
(33.5) \\
33.6 \\
(34.0)\end{array}$ & $(* * \mathrm{E}>\mathrm{C}(\mathrm{i}))$ \\
\hline \multicolumn{6}{|l|}{ Misconceptions } \\
\hline$\%$ overestimating & $\mathrm{t} 1$ & $\begin{array}{l}(38.3) \\
2.1 \\
(2.5)\end{array}$ & $\begin{array}{l}(40.4) \\
3.1 \\
(3.3)\end{array}$ & $\begin{array}{l}(40.0) \\
4.9 \\
(5.2)\end{array}$ & \\
\hline$\%$ underestimating & $\mathrm{t} 1$ & $\begin{array}{l}58.6 \\
(59.2)\end{array}$ & $\begin{array}{c}56.9 \\
(56.3)\end{array}$ & $\begin{array}{c}55.6 \\
(54.9)\end{array}$ & \\
\hline$\%$ realistic & $\mathrm{t} 2$ & $\begin{array}{l}45.1 \\
(45.4)\end{array}$ & $\begin{array}{c}40.4 \\
(40.4)\end{array}$ & $\begin{array}{c}42.2 \\
(42.6)\end{array}$ & \\
\hline$\%$ overestimating & $\mathrm{t} 2$ & $\begin{array}{l}1.3 \\
(1.1)\end{array}$ & $\begin{array}{l}2.5 \\
(2.6)\end{array}$ & $\begin{array}{l}2.7 \\
(3.0)\end{array}$ & \\
\hline$\%$ underestimating & $\mathrm{t} 2$ & $\begin{array}{l}53.6 \\
(53.6)\end{array}$ & $\begin{array}{c}57.0 \\
(56.9)\end{array}$ & $\begin{array}{c}54.9 \\
(54.5)\end{array}$ & \\
\hline
\end{tabular}

$(\mathrm{E}+\mathrm{L}=$ Education + labeling; $\mathrm{E}=$ Education; $\mathrm{C}=\mathrm{Control})$

$* * \mathrm{p}<.01$

(i) with individuals as unit of analysis 
Effectiveness in supermarkets

\section{Discussion}

The goal of this study was to assess the effectiveness of a supermarket-based nutrition education program, with and without labeling, for reducing fat intake. No significant difference was found on total fat intake between the educational program, the education plus labeling program, and the control group. Most studies conducted thusfar into the effectiveness of supermarket-based intervention programs with labeling, measured effects on purchases or consumption of targeted food items. By doing that, the influence on total fat intake remained unclear (e.g. will people also eat more low fat alternatives at home, does the labeled food item replace another item or is it added to usual intake). Therefore, our study did measure effects on total fat intake. Although no effects on total fat intake were found, it still could be that people ate more of the labeled products, but that this did not make a significant overall difference because they were also eating other, high fat, products. However, even on consumption data of some individual labeled products no significant effects of the education plus labeling program were found. The educational program seemed to have a slight but non-significant effect on intention to eat less fat, while the educational plus labeling program showed a (nonsignificant) trend towards less people underestimating their fat intake. For all other determinants, no effects were found of either one of the experimental programs. No convincing evidence of treatment by awareness interaction was found. This may be due to type II errors, that is, low statistical power caused by the small number of supermarkets and the highly skewed distribution of awareness (only $15 \%$ was aware). On the other hand, testing for interaction with an omnibus test and pairwise comparisons on a primary outcome (fat), plus on several product categories, plus on several ASE variables, strongly inflates the risk of type I errors. Interaction of treatment with awareness, if present, could therefore not be demonstrated in the present study.

Unfortunately, these findings could not be verified by sales data. Although we attempted to use sales data as a measurement, the data could not be analyzed due to numerous practical problems. In the literature, monitoring sales data are described as a good, but time-consuming method to assess the effectiveness of health promotion campaigns (Närhinen, 2000). Proportional sales data are seen as more reliable because they are much more stable than direct sales numbers (Närhinen et al., 1998). In our 


\section{Chapter 4}

study it was practically impossible to collect all the data necessary to compute proportional sales. Collecting the sales numbers of all brands of all products in all nine targeted product categories would have been too time-consuming. An added complication was that the supermarkets in the study were from eight different supermarket chains, which all had different computer systems for sales data. We intentionally included supermarkets from different chains in our study, in order to have a representative sample of all supermarkets in the Netherlands. Perhaps, future computer systems for sales data will be more advanced, and it will be easier to collect and process a large amount of sales data.

There are several possible explanations for the lack of effects of the intervention programs. Half of the respondents claimed to have seen (a part of) the program, and only a quarter of the respondents in the labeling program claimed to have seen the labels. Despite the advantages of the supermarket as a setting for nutrition education (possibility of frequent exposure and being a point-of-choice setting), the supermarket is also a highly competitive environment. This makes it very difficult to get attention for nutrition education, and makes exposure to and awareness of the nutrition education message problematic (Ernst et al., 1986; Glanz et al., 1992; Probart, 1993). Customers at the supermarket were informed about the labeling through posters and leaflets. Despite this, only a quarter of the respondents in the supermarkets with the labeling program were aware of the labeling. It might have had a positive influence if the labeling was promoted more intensively, for instance also through advertisements by the supermarkets. One program that emphasized nutrition labeling in the 1980's, the 'Special Diet Alert' program in the USA, was promoted through radio and television commercials as well as printed materials (Schucker et al., 1992). Using audio messages in the supermarkets might also draw more attention to the labeling. However, in the preliminary study (Steenhuis et al., 2001), supermarket managers indicated they were not willing to use this medium for health promotion messages.

It is also possible that a different type of labeling would have been more effective. Muller (1985) found an effect on sales of nutrition labeling based on comparisons across brands of breakfast cereals. We did not distinguish between brands in our study. All brands of a certain product type were labeled, because supermarket managers 


\section{Effectiveness in supermarkets}

indicated in the preliminary study that brand specific labeling was unacceptable for them and the manufacturers and the wholesale dealers (Steenhuis et al., 2001). It could be that consumers did not want to choose a labeled product above a non labeled other type of product, but that they would choose a labeled brand of a product above a none labeled brand of the same type of product. Levy et al. (1985) also evaluated a brandspecific labeling program. They found an effect for three of the five products that were included in the study. Ernst et al. (1986) on the other hand, did not find an effect of their labeling intervention which was not brand-specific. The authors indicated the lack of brand-specification as a possible explanation for the ineffectiveness of the intervention.

Another factor in relation to the type of labeling might have been the information on the labels. Perhaps, people would have responded more to labels with specific nutrient value information such as grams of fat instead of the indication low-fat. Studies which have been conducted in the past report mixed findings with nutrient value information on labels (i.e. Achabal et al., 1987; Russo et al, 1986). It seems that mentioning negative nutrients (e.g. sodium, sugar, fat) is more effective than mentioning positive nutrients on labels (e.g. vitamins) (Achabal et al., 1987; Russo et al., 1986).

Combining the labeling with price reduction strategies might also help to make the labeling more effective (Närhinen, 2000). However, to date, no studies in supermarket settings have examined this. Shannon et al. (1990) combined the labeling with a game approach. Customers could collect special markers and, when they had a certain number of markers, participate in a lottery. Extra markers could be obtained by buying labeled food items. Results indicated only a slight shift in food purchasing patterns toward the preferable alternative but that customers were highly aware of the game. The gameapproach is recommended by Shannon et al. (1990) to use as a promotional activity when introducing a labeling program. Furthermore, the authors argued that a more immediate reward system would have been more effective.

In conclusion, several studies conducted in the past to assess the effectiveness of labeling programs found positive effects, at least for some products (Levy et al., 1985; Muller, 1984, 1985; Mullis \& Pirie, 1988; Olson et al., 1982; Patterson et al., 1992; Schucker et al., 1992). There are also a number of studies that found no effects of 


\section{Chapter 4}

labeling (Achabal et al., 1987; Ernst et al., 1986; Jeffery et al., 1982; Glanz et al., 1992). However, in most of the studies conducted it was not possible to determine the separate effects of labeling, since the labeling component was combined with other program elements that were not evaluated separately. We attempted to evaluate the separate effects of labeling in our study. No effects were found based on data derived from questionnaires completed by customers. Possibilities and effects of brand-specific labeling and combinations with price reduction strategies should be further investigated. 


\section{Chapter 5}

Process evaluation of two environmental nutrition programs and an educational nutrition program conducted at supermarkets and worksite cafeterias in the Netherlands ${ }^{6}$

${ }^{6}$ Submitted for publication as: Steenhuis, I.H.M., Assema, P. van, Reubsaet, A., Kok, G.J. Process evaluation of two environmental nutrition programs and an educational nutrition program at supermarkets and worksite cafeterias in the Netherlands. 


\section{Abstract}

This article describes the process evaluation of a nutrition education program and two environmental programs. The programs were aimed at reducing fat intake and increasing fruit and vegetable consumption, and were implemented at supermarkets and worksite cafeterias. The effectiveness of the programs was studied by means of two randomized controlled trials. It appeared that the programs had no effect on consumers' fat, fruit or vegetable intake. Consequently, the more specific purpose of this study was to identify potential explanations for the ineffectiveness of the programs. The nutrition education program consisted of several elements, such as posters, brochures and a self help guide. The environmental programs included labeling of healthy food products and increasing the range of healthy foods on offer. Semi-structured interviews were conducted with twenty-one managers of supermarkets and worksite cafeterias where the programs were implemented. The results indicated that their general impression of the programs was positive. Although program materials were not always entirely compatible with the different supermarkets and worksite cafeterias, the degree of implementation of the various program elements was satisfactory. This study suggests several explanations for the ineffectiveness of the programs. According to the managers, the programs (or parts of them) were not striking enough, the labeling would have been more effective if it had discriminated between different brands of a product, and the number of new, healthy products was too small compared to the total range of foods on offer. The results of this study can be used to help design and check future behavioral change programs for use at supermarkets or worksite cafeterias. 


\section{Introduction}

Dietary factors have been found to be important in the prevention of cancer and coronary heart disease, for example the consumption of fat, fruit and vegetables (Willet, 1994). For years now, the official Dutch Guidelines for Healthy Nutrition have recommended reducing one's dietary fat intake (Dutch Nutrition Council, 1986; Dutch Nutrition Council, 1991; Health Council of the Netherlands, 2001). The Netherlands Bureau for Food and Nutrition also recommends to eat ample amounts of fruits and vegetables (Netherlands Bureau for Food and Nutrition, 1992). However, there is still a discrepancy between these guidelines and the actual intake of the Dutch population (Netherlands Bureau for Food and Nutrition, 1998).

Nutrition education methods combined with environmental interventions may help consumers meet the guidelines for a healthy diet. Environmental interventions can be defined as "all those strategies that do not require individuals to self-select into a defined educational program". Furthermore, they can be defined as strategies that reduce barriers or increase opportunities for healthy choices, i.e. by creating more healthy choices, making them more accessible (convenient to find and not too expensive), and establishing policies that require healthy options to be available or which limit the number of less healthy ones (Glanz, 1993). Environmental interventions aimed at changing dietary habits include nutritional labeling, regulation of health claims, shelf labeling in supermarkets, changes in food preparation or the food on offer at places where food is prepared, served or sold, catering policies and pricing policies. These interventions are seen as promising strategies with which to change dietary habits (Contento et al., 1995; Glanz, 1993). However, their actual effectiveness is still unclear.

In order to gain a better understanding of the effectiveness of environmental interventions, we developed a nutrition education program combined with environmental components (labeling of healthy products and an increased range of healthy foods) aimed at reducing fat intake and increasing fruit and vegetable intake. The behavioral effects of the educational intervention alone and the educational intervention combined with the environmental intervention were assessed in experiments in two point-of-choice settings (supermarkets and worksite cafeterias) (see also Steenhuis et al., submitted(a); Steenhuis et al., submitted(b)). Seventeen worksite 
Chapter 5

cafeterias and thirteen supermarkets participated in the studies. Both studies used a randomized pretest-posttest experimental control group design. Besides a control condition with no program, the studies included a condition with a nutrition education program only and conditions with an educational program combined with an environmental component (labeling or an increased range of healthy foods). Process evaluation data collected from customers at the worksite cafeterias and supermarkets revealed that respondents in both settings had a positive opinion of the programs. Respondents at worksite cafeterias were a little more negative about certain aspects of the program. They reported, for example, that the program was of low personal relevance and that it did not lead to their gaining a greater knowledge of healthy nutrition. Respondents at the supermarkets reported that the programs had a positive effect on determinants for eating less fat and more fruit and vegetables. For example, more than half of the respondents reported that the intervention had led them to reconsider their own fat consumption level, and almost half of them reported their intention to follow one or more of the suggestions given in the program. However, no significant effects on consumption data were found for any of the programs in either study. Sales data collected at the worksite cafeterias revealed a significant effect of the labeling program where the consumption of desserts was concerned, but not for the other products.

A possible explanation for the ineffectiveness of the interventions was the low level of perceived personal relevance of the programs. Process evaluation data from both studies also showed that awareness of the program materials used at the worksites and supermarkets was not very high, especially awareness of the environmental program components. This means that the ineffectiveness of the interventions may also be caused by a lack of awareness of the various program components (Steenhuis et al., submitted(a); Steenhuis et al., submitted(b)).

This article will describe the process evaluation which was held with the managers of the supermarkets and worksite cafeterias where the interventions were implemented. Goal is also to identify other possible reasons for the ineffectiveness of the nutrition education program and the environmental components. 


\section{Description of intervention}

The interventions were developed on the basis of the results of a preliminary study of the conditions for adoption and implementation of nutrition programs at worksite cafeterias and supermarkets (Steenhuis et al., 2001). The results of this study indicated that programs for worksite cafeterias should not be too obtrusive or dominant, should not consume too much of the personnel's or customers' time, and should emphasize the positive aspects. Furthermore, labeling should only be used for healthy products and labels should be hygienic and easily comprehensible. In increasing the range of products available, it was important that prices should not increase, and only limited changes to the range were desirable. In general, the same factors were important for supermarkets. The importance of increasing profits and the need for program materials to be professionally and attractively produced were additional factors requiring consideration in supermarket programs. Where the labeling was concerned, one specific point for the supermarkets was that it was not possible to label too many products. Labeling should therefore be restricted to the most important product categories, and shelf labeling should be used instead of labeling each individual product. All these factors were taken into account in the development and design of the final interventions.

The intervention program ran for two months at the supermarkets and one month at the worksite cafeterias. Managers at both the supermarkets and cafeterias could extend the use of certain program elements, for example the labeling, up to six months. The nine supermarkets and thirteen worksites included in the study received either the nutrition education program with one of the two environmental components, or the education program alone. The range of food products available was only increased at the worksite cafeterias, since most supermarkets already offered an extensive range of healthy products. The content of the programs used at the supermarkets and worksite cafeterias was almost identical, but some of the program materials were designed differently. The intervention programs were pretested among managers of supermarkets and worksite cafeterias and consumers. On the basis of the pretest results, parts of the intervention were refined. The research team assisted with the implementation of the programs at the supermarkets and worksite cafeterias. Personnel were informed about the programs at a special meeting organized by the research team. A program manual was also available for all supermarkets and worksites participating in the study. During the intervention 


\section{Chapter 5}

period, the research team regularly visited the experimental sites to ensure optimal implementation of the programs. In the early stages of the study period, contact between the research team and the managers of the supermarkets and worksites was relatively frequent (weekly visits); contact was later reduced to monthly phone calls.

\section{Nutrition education program}

The nutrition education program targeted important determinants for eating less fat and more fruit and vegetables, including awareness of personal consumption levels, attitudes towards eating less fat and more fruit and vegetables, social influences on healthy eating habits, self-efficacy, and skills for selecting and preparing low-fat products/meals and eating 2 pieces of fruit and 200 grams of vegetables a day (see also Brug, 2000a). The program consisted of various elements. Of these, some were optional for the supermarkets and worksites participating in the study, while others were basic elements and therefore obligatory. For supermarkets, the basic elements were posters, brochures, recipe cards and a free self help manual which could be obtained by filling in a coupon included in the brochure. Optional elements included badges for supermarket personnel, 'Next Customer' bars on checkout conveyer belts bearing the program logo and slogan ("eat less fat") and a contest with questions about healthy nutrition. For worksites, the recipe cards were replaced by table-top information stands, and an article in the worksite newsletter was added to the optional elements.

\section{Labeling program}

The goal of the labeling was to make healthy choices visible and easily recognizable. Low-fat products in various food product categories, such as meat and meat products or milk and dairy products, were labeled with a shelf label (supermarkets), or a sign in front of the product (worksite cafeterias). The information on the label consisted of the program logo, the name of the item, and a statement that the product was a low-fat product. At the worksite cafeterias, fruit and vegetables were also labeled with a sign in front of the products. 


\section{Increased range of food products}

The range of low-fat products and of fruit and vegetables at worksite cafeterias was increased by at least four products, for example low-fat cheese or a low-fat snack. Attention was drawn to the new products by a sign placed in front of them, bearing the words "new and healthy".

\section{Research method}

\section{Procedures}

Semi-structured interviews were conducted with the managers of the supermarkets and worksite cafeterias where the intervention was implemented. The interviews were held two months (supermarkets) or one month (worksite cafeterias) after the start of the intervention. They lasted approximately 45 minutes. The supermarkets belonged to various regional or national chains, and some of them were franchises. The cafeterias included in the study belonged to large Dutch companies and government organizations with mainly white-collar workers. All thirteen catering managers of the experimental worksite cafeterias in the study were interviewed, and eight of the nine managers of the experimental supermarkets. One manager refused an interview because of time considerations. All but two of the interviews were recorded on tape and full transcripts were made. (Notes were taken during and immediately after the two interviews -with cafeteria managers- which were not recorded and these were used instead of transcripts.) The transcripts were divided up into small text units, which were coded and categorized by the researcher according to the list of interview topics. After the coding process, the text units were sorted per interview topic. Finally, summary reports were written on each topic. This 'cut-and paste' technique is described as a quick, costeffective and very useful method for analyzing transcripts (Stewart \& Shamdasani, 1991).

\section{Interview topics}

The interview questions concerned the implementation of the programs, managers' opinions on the various program elements and program organization, and the reactions of customers as perceived by the managers. The main interview topics are listed in Table 1. Identical interview schemes were used for the worksites and the supermarkets. 
In order to give respondents the maximum opportunity to express their opinion, all questions were open-ended. Depending on the answers given by the respondent, the interviewer asked further questions in order to obtain as much information as possible.

Table 1 Main interview topics

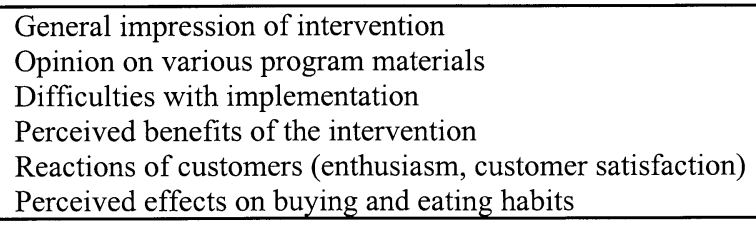

\section{Results}

\section{General impression}

In general, the supermarket and the cafeteria managers had a positive opinion of the intervention programs. The programs were described as clear, professional, informative, well-organized and with a good level of coherence between the various program elements. Almost all the supermarkets and cafeterias had extended the intervention up to six months, especially as regards the use of labels, the availability of brochures and the option to obtain the self help guide. Some of the supermarket mangers remarked that much of the information given in the programs was already familiar. Managers of the worksite cafeterias appreciated the fact that the program was not too obtrusive for customers. However, a few catering managers stated that the intervention could have been more striking (see remarks about program materials).

\section{Opinions on program materials}

Supermarket managers were satisfied with most of the program materials. According to one manager, the coupon for the self help manual in the brochure was not clear or striking enough. Most complaints were about the posters. Supermarket chains all have their own standard size for posters, and a standard display system for them. The posters for the programs did not always fit their specific system and they were also too small for most supermarkets. Managers also pointed out that the various posters resembled one another too much. The managers were enthusiastic about the recipe cards and the self help manual. They considered that the self help manual contained a lot of 
interesting, clearly worded information and that it was made of high-quality materials. The fact that customers did not have to pay for the self help manual was very important for the managers. The contest was also well received by the supermarkets. One supermarket considered that the prize that could be won was not big enough compared to other contests held at the supermarket. Almost all supermarkets used the 'Next Customer' bars in the first few weeks of the program. Some supermarkets considered that the bars were not heavy enough and that this gave rise to problems in use. Because of the intensive use made of the bars, the managers would have preferred them to be made of a more durable material. The buttons were only used for a very short period of time. Some supermarkets did not use the buttons at all. The main reason for this was that neither the managers nor the employees found it practical to wear them. Where labeling was concerned, managers reported the same problem as with the posters. All supermarket chains have their own type of shelving and shelf labeling system. Although the labeling program was adapted to the various systems as much as possible, the labeling system was not always $100 \%$ compatible with the supermarket's own system. Because of this, the labels on some shelves had to be replaced frequently and were not on the shelves all the time. In the case of fresh products, such as meat, it was not always possible to place the labels close to the specific products. Managers also remarked that the labeling was a major deviation from the store's own formula.

Worksite cafeteria managers also commented most on the posters. The posters were not big enough for some cafeterias. Again, the managers pointed out that the different posters resembled one another too much, and they suggested that the colors of the posters should be changed each week. Another remark regarding the posters had to do with the amount of text. Some respondents would have preferred less text and a more prominent place for the pictures on the posters. According to the catering managers, the different table-top information stands also resembled one another too much. Changing the colors each week might have prevented this.

Some managers would have liked table-top information stands constructed of more durable materials. The brochures and self help manual were well received by the respondents. Buttons were not used, or only for a short period of time. The labels used in the labeling program were easy to understand, but according to some respondents 


\section{Chapter 5}

were not striking enough. They could have been larger and also more striking. The same applied to the signs used in the program to increase the range of foods on offer.

\section{Difficulties with program implementation}

In some cases, the program interfered with other campaigns and advertisements at the supermarkets. The result was that personnel did not always have enough time to put the program materials on display. In addition, there was sometimes insufficient space in the store to display all the materials. However, these problems were solved during the course of the intervention period. Although all the managers mentioned the extra work involved in the program, they agreed that it was kept to a minimum and was not excessive. Another difficulty supermarket managers mentioned during the interviews was that after the first two weeks awareness of the program among both personnel and customers decreased. The availability of time and space was also mentioned by the worksite cafeteria managers. The programs did not take up a lot of time but in all cases they involved extra work on top of the heavy workload that cafeteria personnel already had. One manager felt that the intervention and the worksite cafeteria had conflicting interests: the goal of the program was to discourage people from eating a lot of snacks, whereas the cafeteria's greatest profits actually came from selling snacks. Cafeterias which wanted to increase their range of low-fat products had difficulty in obtaining them. Their regular suppliers and wholesalers could not always supply the new products, or provide them on a daily basis. In addition, catering managers did not have enough alternatives to choose from, especially where low-fat snacks were concerned. Some catering managers stated that because the range was already extensive, and customers already had a lot of choice, the extra products did not make any difference, and did not attract any attention. In some cases the labeling of snacks was problematical. The fat content of the snacks was sometimes unclear. Furthermore, the managers said that the labeling was the most time-consuming component of the intervention.

\section{Benefits}

Supermarket managers mentioned benefits of the programs both for themselves and for their customers. Where they themselves were concerned, numerous managers mentioned that the programs produced a more positive image for the store because it 


\section{Process evaluation}

suggested that they 'care' about their customers and provide additional service. Focusing on healthy nutrition is a way to promote their supermarket because they see healthy nutrition as an important issue nowadays. Another benefit for the supermarkets was the possibility of higher profits from selling more expensive, healthy products, or from selling a greater number of products, for example ingredients for the recipes promoted on the recipe cards. Benefits mentioned for customers included more information about healthy nutrition, the free self help manual (which was seen as a reward for the customers), and the variation the programs created in the daily routine of the store. The specific benefits of labeling were increased awareness and the fact that it made labeling easier to select healthy products. However, managers indicated that these benefits mainly applied to customers who were already interested in healthy nutrition, for example people on a diet.

Worksite cafeteria managers did not mention the possibility of greater profits as an important motive. Other than this exception, the other motives mentioned by the supermarket respondents also applied to the worksite cafeterias. The most important benefits for cafeterias, according to their managers, included a positive image for the cafeteria, the provision of a better service, and making people more conscious of their eating habits and the relationship between dietary factors and illness. In addition, worksite respondents mentioned a bonus for their customers' employer: healthy employees were seen as a benefit to the company.

\section{Reactions of customers}

Supermarket managers reported a large number of reactions from customers during the first few weeks of the intervention. Moreover, managers considered that the number of self help manuals and recipe cards taken by the customers and the number of customers participating in the contest were indicators that the program had an impact. Some managers felt that the program had contributed to customer satisfaction regarding the store, but others did not see any difference.

Worksite cafeteria managers did not report receiving many reactions at all. In most companies, the number of self help manuals purchased was not very large, and neither was the number of people participating in the contest. Cafeteria managers thought that 


\section{Chapter 5}

those who responded were already interested in healthy nutrition before the programs were introduced. One manager believed that the small number of responses had to do with the small amount of time people spend at the cafeteria.

\section{Perceived effects on buying and eating habits}

Most supermarket managers thought that the intervention had positive effects on the buying and eating habits of their customers. Some thought it only had positive effects on specific groups of customers, for example older people. Some managers also believed that although customers learned more about healthy nutrition, this did not alter their actual behavior. Where the specific effects of the labeling component were concerned, they did expect a positive influence on eating habits. According to the managers, labeling could have an influence on buying decisions, particularly when customers have to choose between different brands (with similar prices) of a product.

Most respondents at the worksite cafeterias did not think that people changed their eating habits as a result of the program. Again, some managers thought people learned more about their eating habits and were a little more conscious of them, but did not actually change that behavior. However, there were also respondents who noticed a change in the buying and eating habits at their cafeteria. At a few cafeterias, more vegetable salads were sold after the start of the intervention. Where the cafeterias with the labeling program were concerned, changes were noticed by the managers in sales of low-fat margarine and low-fat meat products. Where snacks were concerned, they only noticed an effect during the first week of labeling. After that, customers very quickly returned to their old habits.

At cafeterias where the range of dishes was increased, the new low-fat desserts sold well. The number of low-fat snacks sold depended on what other snacks were provided on a particular day. Depending on the level of 'competition' with other snacks, a low-fat snack might sell better or worse. One catering manager suggested that only replacing existing products by low-fat alternatives would help, as opposed to selling both the fat and the low-fat alternatives. Another manager mentioned that only a few low-fat products were added, meaning that this cannot be expected to make a major difference to total consumption. 


\section{Discussion}

One of the main goals of the process evaluation described in this article has been to identify possible reasons for the ineffectiveness of the nutrition education program and environmental programs which were developed for supermarkets and worksite cafeterias. Although the managers experienced some practical problems, the degree of implementation of the programs was quite good. In most cases, all the various program elements were implemented in the correct way. However, the labeling was not fully compatible with all the various shelving systems used by the supermarkets. Because of this, implementation of the labeling program was not optimal, which may have led to the labeling being ineffective. However, this applied only to a small proportion of the labels, and it therefore cannot be taken to be the decisive factor in the ineffectiveness of the labeling program. Besides the labels, other program elements, such as the posters, did not always fit in with the standard systems at the supermarkets and the worksite cafeterias. Implementation of the program to increase the range of foods on offer was complicated by the limited number of suitable products available. Products not only had to be low in fat, but also had to be supplied by the regular suppliers of the worksite cafeterias on a daily basis, which was not always possible. As a result, only a small number of new low-fat products and fruit and vegetable options were introduced at the cafeterias. Although most of the new products were well received by the customers, the increase in the range might have been too limited to influence the total consumption of fat, fruit and vegetables at the cafeteria, or even total daily consumption.

The managers confirmed the findings of previous effectiveness studies that the education and labeling programs at worksites were not striking enough to attract a great deal of attention from customers (see also Steenhuis et al., submitted(a); Steenhuis et al., submitted(b)). In accordance with the findings of the preliminary study, the managers pointed out that people rush through the cafeteria and do not wish to spend time on nutrition education (Steenhuis, 2001). The time required to use (part of) the intervention programs was kept to a minimum (for example by restricting the amount of information given on the labels) but it may still have been too much for some consumers. These factors may have contributed to the ineffectiveness of the programs. At supermarkets, the programs were more striking. Managers pointed out, however, that the supermarket is a highly competitive environment, with a lot of other advertisements 


\section{Chapter 5}

and campaigns vying for attention. This may have resulted in the programs receiving less attention and therefore in their being less effective. It has already been observed that the supermarket is a highly competitive environment and that this leads to problems when exposing people to nutrition education programs and making them aware of them (Ernst et al., 1986; Probart, 1993). Apart from the program materials not attracting a great deal of attention from customers, it could have been that additional program components were needed, especially to increase publicity of the programs and to promote the programs more extensively.

Although a few cafeteria managers thought that people did change their buying and eating habits at the cafeteria as a result of the intervention programs, most managers did not notice any effects on such behavior. This confirms the findings of the effect study at worksite cafeterias, where (except for increased sales of the desserts in the labeling program) no significant changes in sales data could be demonstrated. The supermarket managers did expect the interventions to have positive effects on buying and eating habits. However, no significant effects on eating habits were found in the effect study conducted at supermarkets. Nevertheless, it is possible that the measures in the evaluation studies occurred before the effects were evident. Another observation by the managers regarding the effects of the programs was that the program might have had effects on specific groups of customers regarding healthy nutrition. However, additional analysis of data from the effect studies did not reveal an effect for specific subgroups such as older people or people who were in a certain phase of behavioral change.

Supermarket managers suggested that labeling could influence people's choice more when choosing between various brands of the same product. Other research also shows that brand-specific labeling might be effective in changing eating habits (Levy, 1985; Muller, 1985). Thus, instead of labeling all brands of a certain type of product as we did in our study, brand-specific labeling could have been more effective. However, we did not use brand-specific labeling for two reasons. Firstly, managers were not very keen on the idea of discriminating between various brands of products because they were afraid of problems with the manufacturers and wholesalers. This fact decreases the chance of adoption and implementation of a labeling program which uses brand-specific labeling. Second, brand-specific labeling is only feasible when it concerns only a few products, 


\section{Process evaluation}

as was the case in the study by Muller (1985), for example. When more product groups are concerned, time considerations mean that it is not feasible to check every single brand of product in all product groups.

In conclusion, this study confirmed some of the explanations for the ineffectiveness of the nutrition education program and environmental components proposed in our earlier studies of the effects of the programs. The present study also identified some additional potential reasons for their ineffectiveness. It therefore provides useful information on the feasibility and effectiveness of such programs at supermarkets and worksite cafeterias. It also provides an insight into factors which should be taken into account when developing future nutrition programs to be used in these settings. Program materials should be designed in such a way that they are fully compatible with the various systems used at the supermarkets, and they should also be striking enough for customers. This is particularly relevant for the highly competitive supermarket environment. The programs should be promoted intensively. Furthermore, the relevant manufacturers and wholesalers supplying worksite cafeterias should be encouraged to increase their range of suitable low-fat products for sale there. Finally, the feasibility and possible effects of brand-specific labeling should be investigated further. 


\section{Chapter 6}

\section{'Eet Smakelijk, Eet Gezond'? Evaluation of a self help guide ${ }^{8}$}

${ }^{7}$ The title of the self help guide has been left in the original Dutch throughout this article. An exact translation is difficult as it would not reflect the play on words made possible by the Dutch language. The title translates approximately as 'Tasty Food, Healthy Food'.

${ }^{8}$ Published as: Steenhuis, I.H.M., Assema, P. van, Reubsaet, A. (2000). 'Eet smakelijk, eet gezond' evaluatie van een zelfhulpgids. Tijdschrift voor Gezondheidswetenschappen, 78, 412-418. 


\section{Abstract}

The self help guide 'Eet Smakelijk, Eet Gezond' aimed to reduce the (saturated) fat consumption and increase the fruit and vegetable consumption of its readers. The guide is based on theories on behavioral patterns and changes in behavioral patterns, and also on prior research carried out in the field of behavior regarding nutrition and information about nutrition. The guide was used in two educational programs, implemented in a number of worksite cafeterias and supermarkets. Alongside an evaluation of the educational program as a whole, separate evaluation work was carried out on the self help guide itself. The evaluation of the self help guide should facilitate the future improvement of the guide, and also give an impression of its effectiveness before it is introduced into health promotion and education on a larger scale. In addition to the extent of the use of the guide, users' opinions on the guide were also assessed, as were the effects of having read the guide. This research shows that the guide was well-used and rated positively by those who read it. The guide seems to have positive effects on fat, fruit and vegetable consumption, and the corresponding determinants of behavior. 


\section{Evaluation self help guide}

\section{Introduction}

Nutrition plays an important role in the prevention of diseases such as cancer and cardiovascular diseases. A diet high in (saturated) fat puts the individual concerned at a greater risk of developing these diseases. In contrast, a diet with a high level of fruit and vegetable consumption actually appears to offer some protection (Willett, 1994). Although research is still being carried out into the exact effects and the relationship between diet and the occurrence of diseases, the above principles have already been incorporated into the Guidelines on Good Nutrition, produced for and aimed at the general public (Dutch Nutrition Council, 1986). The Guidelines on Good Nutrition indicate that fat should not make up more than $30-35 \%$ of the daily energy intake (hereafter referred to as energy percent or en\%). In addition, the guidelines state that saturated fats should not exceed 10en\%. ${ }^{9}$ With regard to fruit and vegetable consumption, the guidelines recommend eating at least 200 grams of vegetables and two pieces of fruit per day.

In the Netherlands, the dietary patterns of the population are well documented. To date, there have been three food consumption surveys, in 1987-1988, 1992 and 1997-1998 (Breedveld \& Hulshof, 1998). The results of these surveys showed that total fat consumption has decreased over the years, from $39 \mathrm{en} \%$ fat in 1987 to $37 \mathrm{en} \%$ fat in 1992, and down to $36 \mathrm{en} \%$ fat in 1998. This is a positive development, but fat consumption still exceeds the recommended level. This is also true of saturated fat consumption levels. In 1998, the consumption of saturated fat amounted to $14 \mathrm{en} \%$ fat, significantly more than recommended. The level of fruit and vegetable consumption in the Netherlands is significantly less than the recommended quantities, and this level is still decreasing. In 1987, the average citizen still ate 108-148 grams of vegetables and 125 grams (approximately 1 piece) of fruit per day; in 1998, these quantities had decreased to 90-130 grams of vegetables and 105 grams of fruit per day (Breedveld \& Hulshof, 1998).

\footnotetext{
${ }^{9}$ These were the guidelines at the time this study was conducted and published. Recently, the guidelines on fat intake have changed. The official Dutch Guidelines for Healthy Nutrition now recommend a dietary fat intake of $20-40 \%$ of total calories for people with a normal body weight, while for people with overweight a dietary fat intake of $20-30 / 35 \%$ of total calories is recommended (Health Council of the Netherlands, 2001).
} 
Considering the differences between the recommended quantities of fat, fruit and vegetables and the actual consumption levels, it is important to develop educational interventions which aim to influence behavioral patterns. At the same time, when developing such intervention programs, it is important to make use of theories and research on behavioral change in the field of nutrition education. Only in this way can an optimally effective intervention program be developed (Contento et al., 1995). Once the interventions have been designed, they must first be tested and evaluated on a small scale. This article describes a self help guide aiming to reduce (saturated) fat consumption and to increase fruit and vegetable consumption. Once the composition and content of the guide have been explained, the results of the corresponding evaluation will be presented, followed by a discussion of whether the use of such a self help method represents a useful supplement to existing intervention materials.

\section{The 'Eet Smakelijk, Eet Gezond' guide}

\section{Theoretical background and prior research}

The 'Eet Smakelijk, Eet Gezond' guide consists of a number of sections covering, as far as possible, the different stages of behavioral change. For each stage, the most important determinants of behavior are examined in more depth. In Prochaska and DiClemente's transtheoretical model, the stages of behavioral change are elaborated further (Prochaska \& DiClemente, 1983; 1992). The stages in which an individual can find himself are: precontemplation, contemplation, preparation, action and maintenance. It is also possible that, instead of maintaining the new behavior, the individual may slip back into his/her old habits; from here, he/she can once again progress to one of the other stages of behavioral change (Prochaska \& DiClemente, 1985). Marlatt \& Gordon have developed a strategy for 'relapse prevention', regarding the subject of individuals falling back into old behavioral patterns, suffering a 'lapse' or a 'relapse', and the kind of action that can be taken (Marlatt \& Gordon, 1985). On the subject of fat, fruit and vegetable consumption, Lechner et al. (1998) have carried out research into the number of people in the Netherlands in each of the different stages of behavioral change. People in each stage need different information, knowledge and skills in order to progress to one of the next stages. For example, in the precontemplation and contemplation stages, it is chiefly attitude information that is required, in order to convince people of the 


\section{Evaluation self help guide}

advantages of the proposed new, healthy behavioral pattern. In contrast, in the preparation and action stages, there is a much greater need for the skills required in order to put the new behavioral pattern into good and effective practice (Brug et al., 1997a; Brug et al., 1997b; Prochaska \& DiClemente, 1992).

In the field of nutrition, various studies have been carried out on determinants. With regard both to the consumption of less fat and the consumption of more fruit and vegetables, it is evident that awareness of one's own consumption pattern is an important determinant. Research shows that many people are not aware of their own levels of consumption of fat, fruit and vegetables (Brug et al., 1998; Lechner et al., 1997). Around $41 \%$ do not consider their fat intake to be excessive, while the guidelines indicate that their fat intake is indeed above the recommended levels (Brug et al., 1998); $30 \%$ believe they eat enough vegetables (for fruit, the figure is $38 \%$ ) while in fact this is not the case (Lechner et al., 1997). Research into the causes of such misconceptions shows that the optimistic bias plays a key role: an individual thinks that he eats more healthily than most other people, and that his own diet is therefore not too bad (van Assema et al., 1996). With regards to attitudes towards the consumption of less fat, a number of different considerations appear to play a role: taste, health, price and convenience (Stafleu et al., 1991). Taste and health appear to be the most important factors where the consumption of fruit and vegetables is concerned. The attitude towards vegetable consumption is also determined by the idea people have of the amount of pesticides contained in them (Brug et al., 1995). In addition to awareness and attitude, social influence and self-efficacy (whether someone considers himself capable of reducing his fat intake or increasing his fruit and vegetable intake) can be important factors influencing dietary behavior. Social influence can consist of both social support or pressure and the social norms to which people think they must conform. Skills are particularly important where self-efficacy is concerned. In the case of diet, consideration should be given to skills such as using low-fat food preparation methods, or the skill of judging which foodstuffs are high or low in fat. Lastly, knowledge is also a factor which can influence diet. It is generally accepted that knowledge does not have direct influence on (dietary) behavior, but can indirectly influence behavior via other determinants. Knowledge of the amount of fat in foodstuffs can, for example, increase self-efficacy (van Assema et al., 1998). 
Chapter 6

\section{Structure and content}

As mentioned above, the guide is structured according to the different phases of behavioral change. The introduction of the guide indicates which sections are relevant for each phase of behavioral change. The 'Eet Smakelijk, Eet Gezond' guide begins by listing a number of frequent misconceptions (Brug et al., 1998; van Assema et al., 1996). In this way, an attempt is made to encourage the reader to reflect on his own fat, fruit and vegetable consumption, and thus to increase awareness of his consumption levels. To further stimulate consciousness of the reader's own consumption levels, the guide features a fat test and a fruit and vegetable test. Using a scoring system, the reader can work out whether or not his fat intake is too high, and which product groups represent major sources of fat. The fat test is based on a validated food frequency list which measures fat consumption (van Assema et al., 1992). The so-called 'writing down method' is used for the fruit and vegetable test. For this, the respondent records his fruit and vegetable consumption in detail for one or more days. His notes are then compared with the recommendation of 200 grams of vegetables and two pieces of fruit per day. Following the awareness stage, the guide endeavours to influence the reader's attitude in a positive manner. This is done by emphasising the importance of good nutrition in preventing diseases such as cardiovascular disease and cancer. More information is also given on other important considerations with regard to reduced fat intake and increased fruit and vegetable consumption, such as losing weight and the use of pesticides in cultivation. A later section of the guide comprises practical tips on how to reduce fat or increase fruit and vegetable consumption. In this way, the guide tries to raise the reader's self-efficacy. The tips suggest alternatives to fatty products, and lowerfat food-preparation methods are explained. There are also explanations of how to read and understand the nutritional value declaration (compulsory on all foodstuffs in the Netherlands). This is one of the recommendations that has emerged from research into the use of the nutritional value declaration in the Netherlands (Meuldijk et al., 1996). The guide also features a number of recipes demonstrating how simple it is to cook tasty, lower-fat food and meals comprising enough vegetables. Alongside the practical tips, attention is also given to maintaining the new behavior or habit. Relapseprevention theory tells us that particularly those in so-called high risk situations have a tendency to fall back into their old habits (Marlatt \& Gordon, 1986). For this reason, the guide also gives specific advice on how to maintain the change in situations where 


\section{Evaluation self help guide}

eating healthily is more difficult or where it is difficult to determine the menu, such as in the worksite cafeteria, or when eating with others. For the latter case, advice is given on how to deal with social pressure. Lastly, there are information boxes throughout the guide aiming to enhance knowledge on healthy eating. Explanations are given through this medium on, for example, cholesterol in the diet, and on the difference between saturated fat and unsaturated fat. Readers can test their knowledge on the amount of fat contained in foodstuffs by filling in the fat knowledge test. This test was validated in a prior study (Steenhuis et al., 1996). Also included in the guide is a list showing the amount of fat per consumption unit of several common foodstuffs. This list can be consulted to calculate one's own fat consumption and to get an idea of the amount of fat in various foodstuffs.

During its development, the guide was pre-tested, both by experts in the field of nutrition and (nutrition) education, and by potential users of the guide. During the pretesting stage, attention was paid to aspects like clarity, the personal relevance of the message, and reliability (Damoiseaux, 1993). In addition, the experts checked on the accuracy and completeness of the information.

\section{Methods}

The 'Eet Smakelijk, Eet Gezond' guide was used as part of two educational programs: one program for worksite cafeterias and one for supermarkets. Worksite cafeteria customers could request a free copy of the guide using a voucher. The voucher was included in a short leaflet on healthy eating, which was given out to customers. The guide was intended for people who, having read the leaflet, wanted to find out more about healthy eating, and also wanted to see how they could improve their own eating habits. The educational programs were implemented in 17 worksite cafeterias and 13 supermarkets throughout the Netherlands, and were evaluated using an experimental method. Companies and supermarkets were randomly either allocated a research group with an educational program, or a research group with a variation of the educational program or a control group. The companies selected were large companies, both commercial and non-commercial, with an office staff consisting predominantly of men with a relatively high level of education; these companies included an insurance 
Chapter 6

company, a bank and a tax office. The supermarkets varied from independent supermarkets to branches of national supermarket chains, situated in districts with a low, medium or high social-economic status.

Due to the fact that various different informative elements were included in the programs (for example food labeling, posters and leaflets, as well as the self help guide), the contribution of the separate elements could not be determined. Process evaluation data is certainly of particular importance in order to make any necessary improvements and in order to get an impression of the effectiveness of the individual elements. For this reason, the 'Eet Smakelijk, Eet Gezond' self help guide was evaluated separately using a short questionnaire.

A questionnaire was sent to a random sample of 100 guide-requesting customers of various worksite cafeterias, and to 90 guide-requesting customers of various supermarkets. Respondents were able to complete and return the questionnaire anonymously. Equal numbers of customers for each worksite cafeteria or supermarket were selected at random from the total group of diners or customers who had requested the guide. In addition to demographic variables, the questionnaire asked which sections of the guide had been read or used. Also included were questions measuring the extent to which people found the guide easy to understand, interesting, reliable, 'new' (in terms of the information provided), and appealing. Moreover, possible effects are measured, such as whether, having read the guide, people's knowledge of healthy eating had increased, whether they now saw more advantages in eating healthily, whether they now had a better idea of their own consumption pattern, whether they intended to eat less fat or more fruit and vegetables, and whether they were intending to follow up any tips given in the guide. Respondents answered using a 7-point scale. This was later translated into a scale ranging from -3 to +3 ; the higher the score, the more positive the opinion of the respondent regarding the variable concerned. Lastly, an evaluation of the guide was asked for, rated on a scale of 1 to 10 . The questionnaire was short (two sides of A4 paper) and took around five or ten minutes to fill in. The responses were processed using SPSS (1997). Averages and standard deviations were calculated from the different variables. In addition, using multivariate analyses (ANCOVA and logistical regression), any differences in use, appreciation and effect between 


\section{Evaluation self help guide}

respondents from different companies and supermarkets, and between men and women, were examined.

\section{Results}

On average, the self help guide was requested by $9 \%$ of worksite cafeteria customers (varying per company from $1 \%$ to $81 \%$ ), and by $6 \%$ of supermarket customers (varying from $2 \%$ to $16 \%$ ). Of those supermarket customers requesting the guide, the vast majority were female (87\%), with an average age of 46 . Equivalent data is not available on worksite cafeteria customers.

\section{Respondents}

The total response rate to the questionnaire was $42.1 \%(n=80)$. One questionnaire out of these 80 was not useable. Worksite cafeterias yielded a better response rate than the supermarkets (53\% versus 30\%). The average age of respondents was 43 (41 in worksite cafeterias, and 46 in the supermarkets). More than half the respondents were women $(60.8 \%)$. The percentages of male and female respondents varied significantly between those from worksite cafeterias $(47.2 \%$ women) and those from supermarkets (88.5\% women).

Approximately a third of the respondents $(32.1 \%)$ indicated when requesting the guide that they were already 'very much aware' of issues of healthy eating. Almost another third (28.3\%) indicated that they were 'quite aware', and almost a quarter $(24.5 \%)$ were 'partially aware' before requesting the guide. The rest (15.2\%) indicated that, before requesting the guide, they were 'unaware' or 'completely unaware' about healthy eating issues. Female respondents differed significantly from male respondents in this respect: women who requested the guide were already more aware about healthy eating. This still applied after correcting the figures for the locations of the respondents (supermarket or worksite cafeteria) $(\mathrm{p}<.05)$. 
Table 1 Usage of parts of the guide $(n=79)$

\begin{tabular}{lc}
\hline Section & \% of respondents that had read that section \\
\hline Fat test & 84.8 \\
Advantages of eating less fat & 86.1 \\
Fat knowledge test & 83.5 \\
Practical tips for eating less fat & 81.0 \\
Fruit and vegetable test & 83.5 \\
Advantages of eating more fruit and vegetables & 81.0 \\
Practical tips for eating more vegetables & 74.7 \\
Practical tips for eating more fruit & 73.4 \\
Tips for eating together with others & 59.5 \\
Tips on sweets and snacks & 78.5 \\
Tips at work & 67.1 \\
Tips on eating out & 58.2 \\
Tips for parties and birthdays & 60.8 \\
Recipes & 63.3 \\
List of products and their fat content & 81.0 \\
\hline
\end{tabular}

\section{Use of the guide}

A large majority of the respondents stated that they had read all sections of the guide (see Table 1). A large proportion of the respondents had filled in the tests. $71 \%$ of respondents filled in the fat test, $66 \%$ did the fat knowledge test, and $54 \%$ did the fruit and vegetable test. A small proportion of the respondents made the meals described in the recipes (15\%). More men than women filled in the fat test and the fat knowledge test, while more women than men read the recipes. All these differences were statistically significant $(\mathrm{p}<.05)$ after corrections according to the location (supermarket or worksite cafeteria) from which the respondents came. 
Table 2 Assessment of the guide $(n=79)$

\begin{tabular}{ll}
\hline Questions & Mean (SD) * \\
\hline Is the guide interesting? & $1.9(1.3)$ \\
Is the guide credible/believable? & $2.0(1.1)$ \\
Is the guide easy to understand? & $2.1(1.2)$ \\
To what extent was the information new for you? & $-0.4(1.7)$ \\
Does the guide look appealing? & $1.9(1.2)$ \\
\hline
\end{tabular}

* scores range from -3 (negative assessment) to 3 (positive)

\section{Process evaluation}

Table 2 shows the respondents' assessment of a number of process-related aspects. Respondents were positive in their rating of the guide regarding interest-value, credibility, clarity and appeal. The guide scored less highly as far as the amount of new information presented was concerned. Significantly more male than female respondents indicated that the information was new to them $(\mathrm{p}<.05)$. As far as the general appeal of the guide was concerned, there was a significant difference - even after adjustments for gender - between respondents who were customers at the worksite cafeterias and those who were supermarket customers. Supermarket customer respondents rated the appeal of the guide significantly more positively than the worksite cafeteria respondents $(p<.05)$. Respondents were asked to give the guide as a whole a mark on a scale of 1 to 10. The average mark given was 7.9 ( 7.9 from worksite cafeteria customers, 8.0 from supermarket customers).

\section{Self-reported effects on determinants}

The guide seems to have a positive effect on a number of determinants of dietary behavior (see Table 3). Respondents named the following as being positively influenced: awareness of one's own fat consumption; attitude towards both the consumption of less fat and the consumption of more fruit and vegetables; and having gained an idea of how to eat more healthily. Where attitudes are concerned, gender- 
Chapter 6

Table 3 Self-reported effects on determinants and behavior after having read the guide $(n=79)$

\begin{tabular}{ll}
\hline Determinant & Mean (SD)* \\
\hline $\begin{array}{l}\text { Knowledge: } \\
\text { - gained more knowledge about healthy eating }\end{array}$ & $0.7(1.7)$ \\
& \\
Awareness: & $1.4(1.5)$ \\
- more aware of own fat consumption & $0.9(1.7)$ \\
- more aware of own vegetable consumption & $0.9(1.7)$ \\
- more aware of own fruit consumption & \\
& \\
Attitude: & $1.2(1.8)$ \\
- can see more advantages in eating less fat & $1.4(1.8)$ \\
- can see more advantages in eating more fruit and vegetables & \\
& \\
Self-efficacy: & $1.3(1.7)$ \\
- more ideas on how to eat more healthily & $0.0(1.7)$ \\
- tips for high risk situations useful & \\
& \\
Intention: & $0.9(1.8)$ \\
- intention to follow up one or more tips & \\
Behavior: & \\
- going to eat less fat & $0.5(1.7)$ \\
- going to eat more vegetables & $0.5(1.7)$ \\
- going to eat more fruit & $0.4(1.8)$ \\
\hline
\end{tabular}

* scores from -3 (negative assessment) to 3 (positive)

related effects and location-related effects were both in evidence: having read the guide, significantly more men than women stated that they now saw more advantages in the consumption of less fat $(\mathrm{p}<.05)$. Additionally, more supermarket-respondents than worksite cafeteria-respondents indicated that they now saw more advantages in consuming less fat (with corrections made for gender; $\mathrm{p}<.05$ ). Significant differences between worksite cafeteria-respondents and supermarket-respondents were found concerning the determinants 'awareness of one's own consumption' and 'behavior' (see Table 4). This was true of awareness both of fat consumption and of fruit and vegetable consumption. For 'behavior', there was a significant difference between the 


\section{Evaluation self help guide}

consumption of less fat and the consumption of more fruit. For all these variables, the respondents from the supermarkets scored better than those from the worksite cafeterias, and the effects were the same after correction for gender. However, there was also a specific gender effect (see Table 4). Male respondents scored better on the variables 'awareness of own fat, fruit and vegetable consumption' and 'eating more fruit'.

\section{Discussion}

The response rate to the questionnaire was low, particularly among the supermarket customers (30\%). Respondents from the supermarkets did not differ much in age and gender from the other supermarket customers who requested the guide. However, the low response level may paint a more positive picture of the guide with regard to use, appreciation and the self-reported effects on determinants and behavior. It is possible that those who did not read or use the guide were less motivated to fill in and return the questionnaire. Those who had a positive assessment of the guide, and/or people who have taken action as a result of reading the guide, were probably more motivated to complete and return the questionnaire. Giving socially-desirable answers is another possible source of distortion of the results in a positive direction. However, the fact that people were able to return the questionnaire in complete anonymity reduces the significance of this source of bias.

The respondents had read by far the greater part of the guide. The various tests in the guide were also used by the majority of respondents. The recipes were less well used, but were read by the majority of respondents. Because of this, positive effects may still have occurred. Reading the guide may have given the respondents more insight into, for example, lower-fat methods of food preparation. The guide was assessed positively on various aspects, although the amount of information that was new to respondents was relatively small, especially for female respondents. This effect can be explained by the fact that a large proportion of the people who had requested the guide - females in particular - were already making a conscious effort to eat healthily, and therefore knew more about it than average. Methods should be sought to also raise interest in the guide among those who are making less of a conscious effort with regards to good nutrition. 


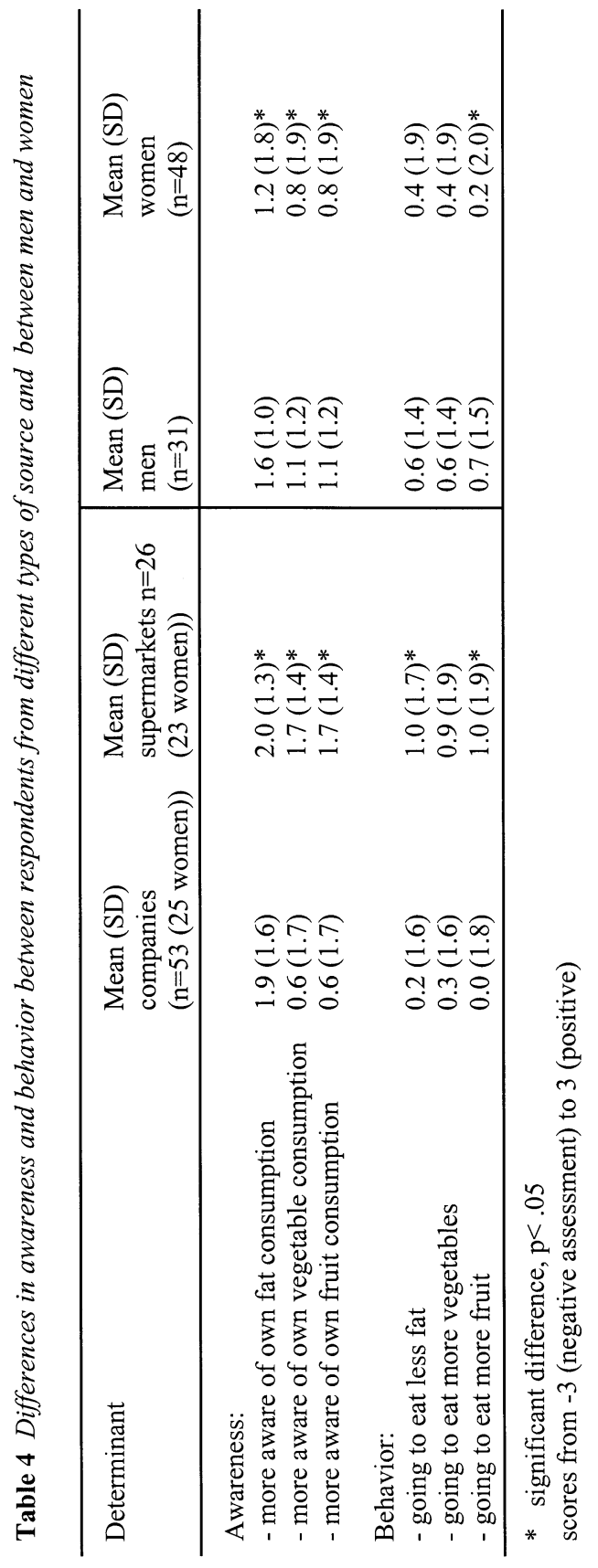




\section{Evaluation self help guide}

Although the effects of reading and using the guide are only measured to a limited degree in this study, using a relatively small sample of respondents - with these effects also being self-reported and therefore less reliable than, for example, using food frequency lists - the guide nevertheless appears to have had a positive influence on dietary behavior and the determinants of behavior. A difference has been demonstrated between respondents who were worksite cafeteria customers and those who were supermarket customers. The most important difference was that, once corrections had been made for gender differences, supermarket respondents scored better on awareness and behavior variables. As stated earlier, it is possibly a question of a higher response rate among those who, as a result of having read the guide, changed their behavior and gained motivation. The difference between male and female respondents, especially with regard to awareness variables, could be explained by the fact that the women who requested the guide were already aware of their own dietary pattern, while this was less so for the men.

The guide was evaluated positively, but in order to assess the value of it, an examination must be made of how the guide scores in relation to other comparable informative materials within (nutrition) education. 'Self help methods' in this case means methods by which the user of the educational material is lead, in an independent manner, step by step through the different phases of behavioral change. Within the framework of the "Healthy Bergeijk" community project, use was made of a self help method, namely a calender with a step by step plan to reduce fat consumption (Steenbakker et al., 1992). The evaluation showed that $90 \%$ of the respondents had read some or all of the calender, and that three-quarters of these had read more than half of it. Respondents were able to fill in a daily menu on the calender. Almost a quarter did so. The calender was given a mark of 7.8 on a scale of 1 to $10.40 \%$ of the respondents indicated that the pack had not given them any new information. Respondents indicated that the calender had increased their awareness of their own fat consumption, and $70 \%$ stated that they were actively intending to eat less fat. The results of the evaluation of the 'Eet Smakelijk, Eet Gezond' guide generally correspond with the results of the nutrition calender evaluation. More respondents filled in the tests in the 'Eet Smakelijk, Eet Gezond' guide than filled in the daily menu in the nutritional calender, probably because the latter involved a more active method. A considerable proportion of the 
respondents in the nutrition calender project also indicated that the information given was not new to them. However, respondents in both projects indicated that the educational material had had an impact on their determinants of behavior and on their actual behavior. A large share of the respondents also intended to act upon one or more of the tips given in the guide. Evidently, even familiar information can stimulate change by bringing attention to it again.

Aside from nutrition education, smoking prevention projects also make use of self help guides. In a series of three studies by Mudde et al. (1994), a self help guide to quitting smoking was evaluated. The construction was comparable to that of the 'Eet Smakelijk, Eet Gezond' guide. The guide deals with the different phases of behavioral change, and also devotes attention to the different determinants of behavior related to smoking. Attention was also paid to relapse prevention. The evaluation showed that, in this case too, the majority of the respondents had read at least half of the guide. The self help guide was rated by the three studies respectively with the marks $7.4,7.7$ and 8.0 on a scale of 1 to 10 . The guide had a positive effect regarding quitting smoking, although it was less effective than group programs. Another self help guide aiming to help people stop smoking was entitled 'Stoppen met roken...... dat bevalt beter'. ${ }^{10}$ This self help guide is based on the guide by Mudde et al. (1994), but is specifically aimed at pregnant women. This guide was also evaluated positively. Around $90 \%$ of the respondents in the evaluation survey had read at least part of the guide. The guide was rated highly for aspects such as credibility, clarity, interest value and appeal. The guide was graded at 7.4 on a scale of 1 to 10 (Bakker et al., submitted). The 'Eet Smakelijk, Eet Gezond' guide's score for reader's appreciation and use was comparable with that of the abovementioned self help guide to stopping smoking. The conclusion can be drawn that, just as in the cases of the other self help methods mentioned here, the 'Eet Smakelijk, Eet Gezond' guide was received positively by the respondents and appears to have had a positive effect. Self help methods therefore seem to be a valuable complement to existing materials. In the future, applications in different settings or within different educational methods could be considered, and directed at different target groups.

\footnotetext{
${ }^{10}$ This title uses a play on words. Two alternative translations would be 'Stopping smoking...... that feels better' or 'Stopping smoking... and a better delivery of your child'. 


\section{References}

Achabal, D.D., Bell, C.H., McIntyre, S.H., Tucker N. (1987). The effect of nutrition p-o-p signs on consumer attitudes and behavior. Journal of Retailing, 63, 9-24.

Albright, C.L., Flora, J.A., Fortmann, S.P. (1990). Restaurant menu labeling: impact of nutrition information on entree sales and patron attitudes. Health Education Quarterly, 17,157-167.

Almeida, M.D. de, Graca, P., Lappalainen, R., Giachetti, I., Kafatos, A., Remaut de Winter, A., Kearney, J.M. (1997). Sources used and trusted by nationally-representative adults in the European Union for information on healthy eating. European Journal of Clinical Nutrition, 51,S16-S22.

Anonymous. (1988). Wat eet Nederland, resultaten van de voedselconsumptiepeiling 1987-1988 (What does the Netherlands eat, results of the food consumption survey 1987-1988). Rijswijk: Ministerie van Welzijn, Volksgezondheid en Cultuur en Ministerie van Landbouw en Visserij.

Anonymous. (1993). Zo eet Nederland,1992, resultaten van de voedselconsumptiepeiling 1992 (This is how the Netherlands eats, results of the food consumption survey 1992). Den-Haag: Voorlichtingsbureau voor de Voeding.

Assema, P. van, Brug, H., Dolders, M., Kok, G., Steenhuis, I. (1996). Misconceptie van vetconsumptie: Een kwalitatief onderzoek naar oorzaken (Misconceptions about fat consumption: A qualitative survey of causes). Tijdschrift voor Gezondheidswetenschappen, 7, 347-355.

Assema, P. van, Brug, J., Kok, G., Brants, H. (1992). The reliability and validity of a Dutch questionnaire on fat consumption as a means to rank subjects according to individual fat intake. European Journal of Cancer Prevention, 1, 375-380.

Assema, P. van, Brug, J., Ronda, G., Steenhuis, I. (2001). The relative validity of a short Dutch questionnaire as a means to rank adults and adolescents to total and saturated fat intake. Journal of Human Nutrition and Dietetics, 14, 377-390.

Assema, P. van, Brug, J., Ronda, G., Steenhuis, I., Oenema, A. (in press). A short Dutch questionnaire to measure fruit and vegetable intake: relative validity among adults and adolescents. Nutrition and Health.

Assema, P. van, Kok, G.J., Hospers, H., Steenhuis, I. (1998). Gezondheidsvoorlichting en beïnvloeding van voedingsgedrag (Health education and influencing dietary behavior). In: Informatorium Voeding en Diëtetiek (Nutrition and dietetics), supplement 36, XIV-1-23. 


\section{References}

Bakker, M.J., de Vries, H., Dolan-Mullen, P., van Breukelen, G. (submitted). Smoking cessation by participants in a Dutch multi-media smoking cessation program for pregnant women and their partners.

Bandura, A. (1986). Social foundations of thought and action: A social cognitive theory. Englewood Cliffs NJ: Prentice Hall.

Bourdeaudhuij, I. de. (1997). Perceived family members' influence on introducing healthy food into the family. Health Education Research, 12, 77-90.

Benito, E. (1992). Overview of dietary recommendations on diet and cancer. In: Benito, E., Giacosa, A., Hill, M.J., eds. Public education on diet and cancer. Dordrecht (the Netherlands): Kluwer Academic Publishers, 3-12.

Bracht, N. (1990). Health Promotion at the community level. Sage, Thousand Oaks CA..

Bracht, N. (1999). Health Promotion at the community level: new advances. Sage, Thousand Oaks CA.

Brandt, P. van den, Dagnelie, P.C., Meyenfeldt, M.F. von. (1999). Voeding en kanker: Causale, beschermende en therapeutische aspecten (Nutrition and cancer: Causative, protective and therapeutic aspects). Nederlands Tijdschrift voor Geneeskunde, 143, 1414-1421.

Breedveld, B.C., Hulshof, K.F.A.M. (1998). De derde Voedselconsumptiepeiling: 'Hoe goed voedt de gemiddelde Nederlander zich?' (The third food consumption survey: 'How good does the average Dutchman eat?'). Voeding $N u, 1,11-15$.

Brug, J. (1997). The development and impact of computer-tailored nutrition education. Maastricht: Maastricht University.

Brug, J. (2000a). Primaire preventie: computergestuurde voedingsvoorlichting op maat (Primary prevention: Computer-tailored nutrition education). In: Brug, J., Schaalma, H., Kok, G., Meertens, R.M., Molen, H.T. van der, eds. Gezondheidsvoorlichting en gedragsverandering; Een planmatige aanpak (Health education and behavioral change; a planned approach). Assen: Van Gorcum/Open Universiteit Nederland.

Brug, J. (2000b). Koffie, kool en de mogelijkheden van voedingsvoorlichting (Coffee, cabbage and the potential of nutrition education). Inaugurale rede. Maastricht. 


\section{References}

Brug, J., Assema, P. van, Kok, G., Lenderink, T., Glanz, K. (1994). Self-rated dietary fat intake: Associations with objective assessment of fat, psychosocial factors, and intention to change. Journal of Nutrition Education, 26, 218-223.

Brug, J., Assema, P. van, Kok, G. (1998). Misconceptie van consumptie van vet, groente en fruit (Misconceptions about fat, fruit and vegetable consumption). Tijdschrift voor Gezondheidswetenschappen, 76, 17-23.

Brug, J., Campbell, M., Assema, P. van. (1999). The application and impact of computer-generated personalized nutrition education: A review of the literature. Patient Education and Counseling, 36, 145156.

Brug, J., Glanz, K., Kok, G. (1997a). The relationship between self-efficacy, attitudes, intake compared to others, consumption, and stages of change related to fruit and vegetables. American Journal of Health Promotion, 12, 25-30.

Brug, J., Hospers, H.J., Kok, G. (1997b). Differences in psychosocial factors and fat consumption between stages of change for fat reduction. Psychology and Health, 12, 719-727.

Brug, J., Lechner, L., de Vries, H. (1995). Psychosocial determinants of fruit and vegetable consumption. Appetite, 25, 285-96.

Contento, I., Balch, G.I., Bronner, I.L., Paige, D.M., Gross, S.M., Bisignani, L., Lytle, L.A., Maloney, S.K., White, S.L., Olson, C.M., Sharaga Swadener, S., Randell, J.S. (1995). The effectiveness of nutrition education and implications for nutrition education policy, programs, and research: a review of research. Journal of Nutrition Education, 27.

Damoiseaux, V. (1993). Het pretesten van voorlichtingsmateriaal (Pre-testing educational material). In: Damoiseaux, V., van der Molen, H.T., Kok, G.J. eds. Gezondheidsvoorlichting en gedragsverandering (Health education and behavioral change). Assen: Van Gorcum.

Dubbert, P.M., Johnson, W.G., Schlundt, D.G., Montague, N.W. (1984). The influence of caloric information on cafeteria food choices. Journal of Applied Behavioral Analysis, 17, 85-92.

Dutch Nutrition Council (1986). Adviesrichtlijnen goede voeding (Advice guidelines healthy nutrition). Voedingsraad, 's Gravenhage. 


\section{References}

Dutch Nutrition Council (1991). Nader advies inzake de richtlijn m.b.t. de vetconsumptie uit het advies Richtlijnen goede voeding 1986 (Further advice regarding the recommendations with regard to the fat consumption in the advisory Guidelines on healthy nutrition 1986). Voedingsraad, 's Gravenhage.

Engelberts, C. (1998). Het bedrijf als ideale plek voor voedingsvoorlichting (Companies as an ideal location for nutrition education). Voeding en Voorlichting, 9, 14-15.

Ernst, N.D., Wu, M., Frommer, P., Katz, E., Mathews, O., Moskowitz, J., Pinsky, L., Pohl, S., Schreiber, G.B., Sondik, E., Tenney, J., Wilbur, C., Zifferblatt, S. (1986). Nutrition education at the point of purchase: The foods for health project evaluated. Preventive Medicine, 15, 60-73.

Feskens, E.J.M. (1992). Nutritional factors and the etiology of non-insulin-dependent diabetes mellitus: an epidemiologic overview. World Review Nutrition and Dietetics, 69, 1-39.

Glanz, K. (1993). Environmental and policy approaches to cardiovascular disease prevention through nutrition. Paper presented at the workshop on environmental and policy approaches to cardiovascular disease prevention. Centers for Disease Control, Atlanta, GA.

Glanz, K., Brug, J., Assema, P. van. (1997a). Are awareness of dietary fat intake and actual fat consumption associated? - A Dutch-American comparison. European Journal of Clinical Nutrition, 51, 542-547.

Glanz, K., Hewitt, A.M., Rudd, J. (1992). Consumer behavior and nutrition education: An integrative review. Journal of Nutrition Education, 24, 267-277.

Glanz, K., Lankenau, B., Foerster, S., Temple, S., Mullis, R., Schmidt, T. (1997b). Environmental and policy approaches to cardiovascular disease prevention through nutrition: Opportunities for state and local action. Health Education Quarterly, 22, 512-527.

Glanz, K., Lewis, F.M., Rimer, B.K. (eds). (1990). Health behavior and health education: Theory, research and practice. San Francisco CA: Jossey-Bass.

Glanz, K., Mullis, R.M. (1988). Environmental interventions to promote healthy eating: A review of models, programs and evidence. Health Education Quarterly, 15, 395-315.

Glanz, K., Seewald-Klein, T. (1986). Nutrition at the worksite: an overview. Journal of Nutrition Education, 18, s1-s11. 


\section{References}

Glascoff, M.A., Taylor, S., Glascoff, D.W., Raff, L.G. (1985). A social marketing approach to reducing salt intake. Health Education, 17, 11-14.

Goldstein, H., Rabash, J., Plewis, I., Draper, D., Browne, W., Yang, M., Woodhouse, G., Healy, M. (1998). A user's guide to MLwiN. London: Institute of education.

Health Council of the Netherlands (2001). Voedingsnormen (Nutrition guidelines). Gezondheidsraad, Den Haag.

Hedeker, D., Gibbons, R.D., Flay, B.R. (1994). Random-effects regression models for clustered data with an example from smoking prevention research. Journal of Consulting and Clinical Psychology, $62,757-765$.

Hedeker, D., Gibbons, R.D. (1996). MIXREG: a computer program for mixed-effects regression analysis with autocorrelated errors. Computer Methods and Programs in Biomedicine, 49, 229-252.

Holdsworth, M., Haslam, C. (1998). A review of point-of-choice nutrition labelling schemes in the workplace, public eating places and universities. Journal of Human Nutrition and Dietetics, 11, 423445 .

Holla, J. (2001). De strijd om het maagaandeel (The struggle for a share of the stomach). In: Gorseling, S., Graafmans, W., Louwen, F., Temminghoff, M. (eds.) (2001). GFK Jaargids 2001: kerncijfers voor marketing-en beleidsplannen (Annual guide 2001: Key figures for marketing and policy planning). Utrecht.

Hunt, M.K., Lefebvre, R.C., Hixson, M.L., Banspach, S.W., Assaf, A.R., Carleton, R.A.. (1990). Pawtucket heart health program point-of-purchase nutrition education program in supermarkets. American Journal of Public Health, 80, 730-732.

Jeffery, R.W., French, S.A., Raether, C., Baxter, J.E. (1994). An environmental intervention to increase fruit and salad purchases in a cafeteria. Preventive Medicine, 23, 788-792.

Jeffery, R.W., Pirie, P.L., Rosenthal, B.S., Gerber, W.M., Murray, D.M. (1982). Nutrition education in supermarkets: An unsuccessful attempt to influence knowledge and product sales. Journal of Behavioral Medicine, 5, 189-200.

Joshipura, K.J., Ascherio, M.D., Manson, J.E., Stampfer, M.J., Rimm, E.B., Speizer, F.E., Hennekes, C.H., Spiegelman, D., Willett, W.C. (1999). Fruit and vegetable intake in relation to risk of ischemic stroke. Journal of the American Medical Association, 282, 1233-1239. 


\section{References}

Keijsers, J.F.E.M., Vaandrager, L. (eds.). (2000). Gezond Leven; Stand van zaken en voorstel voor programmering (Healthy living; State of the and program proposal). Den-Haag: ZorgOnderzoek Nederland.

Kok, G., Vries, H. de, Mudde, A., Strecher, V.J. (1991). Planned health education and the role of selfefficacy: Dutch research. Health Education Research, 6, 231-238.

Konings-Dalstra, J.A.A., Reitsma, J.B. (1999). Hart- en vaatziekten in Nederland 1999: Cijfers over ziekte en sterfte (Cardiovascular diseases in the Netherlands 1999: Figures on diseases and death). Den Haag: Nederlandse Hartstichting.

Kristal, A.R., Goldenhar, L., Muldoon, J., Morton, R.F. (1997). Evaluation of a supermarket intervention to increase consumption of fruits and vegetables. American Journal of Health Promotion, $11,422-425$.

Lang, J.E., Mercer, N., Tran, D., Mosca, L. (2000). Use of a supermarket shelf-labeling program to educate a predominately minority community about foods that promote heart health. Journal of the American Dietetic Association, 7, 804-809.

Larsson, B. (1990). Obesity, fat distribution and cardiovascular disease. In: Oomura, Y., Tarui, S., Inoue, S., Shimazu, T. (eds.). Progress in obesity research. London: John Libbeym.

Lechner, L., Brug, J., de Vries, H. (1997). Misconceptions of fruit and vegetable consumption: Differences between objective and subjective estimation of intake. Journal of Nutrition Education, 29, 313-320.

Lechner, L., Brug, J., de Vries, H., Assema, P. van, Mudde, A. (1998). Stages of change for fruit, vegetable and fat intake: consequences of misconception. Health Education Research, 13, 1-11.

Leer, E.M. van, Cleton, F.J., Leeuwen, F.E. van (eds). (1999). Signaleringsrapport kanker 1999 (Indicative cancer report). Amsterdam, Nederlandse Kankerbestrijding.

Lefebvre, C. (1986). A case history of nutritional information on menus. Journal of Foodservice Systems, 4, 153-158.

Levin, S. (1996). Pilot study of a cafeteria program relying primarily on symbols to promote healthy choices. Journal Nutrition Education, 28, 282-285.

Levy, A.S., Mathews, O., Stephenson, M., Tenney, J.E., Schucker, R.E. (1985). The impact of a nutrition education program on food purchases. Journal of Public Policy, 4, 1-16. 


\section{References}

Liu, S., Manson, J.E., Lee, I.M., Cole, S.R., Hennekes, C.H., Willett, W.C., Buring, J.E. (2000). Fruit and vegetable intake and risk of cardiovascular disease: the Women's Health Study. American Journal of Clinical Nutrition, 72, 922-928.

Light, L., Tenney, J., Portnoy, B., Kessler, L., Brown-Rodgers, A., Patterson, B., Mathews, O., Katz, E., Blair, J., King-Evans, S., Tuckermanty, E. (1989). Eat for health: a nutrition and cancer control supermarket intervention. Public Health Reports, 104, 443-450.

Maas, I.A.M., Gijsen, R., Lobbezoo, I.E., Poos, M.M.J.J.C. (eds). (1997). Volksgezondheid Toekomstverkenning 1997; I De gezondheidstoestand: een actualisering (Investigation of the future of public health 1997; I State of health: an actualisation). RIVM, Bilthoven: Elsevier/De Tijdstroom.

Marlatt, G.A., Gordon, J.R. (eds.). (1985). Relapse prevention. Maintenance strategies in the treatment of addictive behaviors. New York: The Guilford Press.

Marrieta, A.B., Welshimer, K.J., Anderson SL. (1999). Knowledge, attitudes, and behaviors of college students regarding the 1990 Nutrition Labeling Education Act food labels. Journal of the American Dietetic Association, 99, 445-449.

Mayer, J.A., Brown, T.P., Heins, J.M., Bishop, D.B. (1987). A multi-component intervention for modifying food selections in a worksite cafeteria. Journal of Nutrition Education, 19, 277-280.

Mayer, J.A., Dubbert, P.M., Elder, J.P. (1989). Promoting nutrition at the point of choice: A review. Health Education Quarterly, 16, 31-43.

Meuldijk, S., Assema P. van, Dis, I. van, Mudde, A. (1996). Helpfulness of nutritional value labels in choosing low-fat products. Journal of Nutrition Education, 28, 348-352.

Ministerie van VWS. (1998). Nederland: Goed gevoed; Nota gezondheid en voeding (The Netherlands: Well fed: Memorandum on health and nutrition). Tweede Kamer, vergaderjaar 19981999, 26 229, nrs 1-2. 's-Gravenhage: Sdu uitgevers.

Moerbeek, M. (2000). Design and analysis of multilevel intervention studies. Maastricht: Maastricht University.

Mudde, A., de Vries, H., Willemsen, M.C., Assema, P. van. (1994). Development and utilization of a self helpmanual for community smoking cessation interventions. In: Richmond, R. (ed.). Interventions for smokers: An international perspective. Sydney: Williams \& Wilkins. 
Muller, T.E. (1984). The use of nutrition composition data at the point of purchase. Journal of Nutrition Education, 16, 137-141.

Muller, T.E. (1985). Structural information factors which stimulate the use of nutrition information: A field experiment. Journal of Marketing Research, 22, 143-157.

Mullis RM, Pirie P. Lean meats make the grade: A collaborative nutrition intervention program. Journal of the American Dietetic Association 1988;88:191-195.

Närhinen, M., Nissinen, A., Puska, P. (1998). Sales data of a supermarket- a tool for monitoring nutrition interventions, Public Health Nutrition, 1, 101-107.

Närhinen, M. (2000). Healthier food choices in supermarkets. Kuopio University Library, Kuopio, Finland.

Ness, A.R., Powles, J.W. (1997). Fruit and vegetables, and cardiovascular disease: A review. International Journal of Epidemiology, 26, 1-13.

Netherlands Bureau for Food and Nutrition. (1992). Praktische Voedingsmiddelengids (Practical food stuff guide). Voedingscentrum, 's Gravenhage.

Netherlands Bureau for Food and Nutrition (Voedingscentrum). (1993). Zo eet Nederland 1992, resultaten van de voedselconsumptiepeiling 1992 (This is how the Netherlands eats, results of the food consumption survey 1992). Voedingscentrum, 's Gravenhage.

Netherlands Bureau for Food and Nutrition (Voedingscentrum). (1998). Zo eet Nederland, resultaten van de voedselconsumptiepeiling 1997-1998 (This is how the Netherlands eats: results of the food consumption survey 1997-1998). Voedingscentrum, 's Gravenhage.

Olson, C.M., Bisogni, C.A., Thonney, P.F. (1982). Evaluation of a supermarket nutrition education program, Journal of Nutrition Education, 4, 141-145.

Patterson, B.H., Kessler, L.G., Wax, Y., Bernstein, A., Light, L., Midthune, D.N., Portnoy, B., Tenney, J., Tuckermanty, E. (1992). Evaluation of a supermarket intervention. The NCI-Giant food eat for health study. Evaluation Review, 16, 464-490.

Peterson, G., Elder, J.P., Knisley, P.M., Colby, J.C., Beaudin, P., DeBlois, D., Carleton, R.A. (1986). Developing strategies for food vendor intervention: The first step. Journal of the American Dietetic Association, 86, 659-661. 


\section{References}

Probart, C.K. (1993). In-store consumer nutrition education utilizing student educators. Journal of Nutrition Education, 25, 25-28.

Prochaska, J.O., DiClemente, C.C. (1983). Stages and processes of self-change of smoking: toward an integrative model of change. Journal of Consulting Clinical Psychology, 51, 390-395.

Prochaska, J.O., DiClemente, C.C. (1992). Stages of change in the modification of problem behaviors. Progress in Behavior Modification, 28, 184-218.

Rogers, E.M. (1983). Diffusion of Innovations (3rd edition). New-York NY: The Free Press.

Ronda, G., Assema, P. van, Brug J. (submitted). The Dutch Heartbeat Limburg community intervention: evaluation design and baseline data.

Russo, J.E., Staelin, R., Nolan, C.A., Russell, G.J., Metcalf, B.L. (1986). Nutrition information in the supermarket. Journal of Consumer Research, 13, 48-17.

Ruwaard, D., Kramers, P.G.N. (eds). (1993). Volksgezondheid Toekomstverkenning; De gezondheidstoestand van de Nederlandse bevolking in de periode 1950-2010 (Investigation of the future of public health; I The state of health of the Dutch population in the period 1950-2010). RIVM, Den Haag: Sdu uitgeverij.

Schmitz, M.F., Fielding, J.E. (1986). Point-of-choice nutritional labeling: Evaluation in a worksite cafeteria. Journal of Nutrition Education, 18, s65-s68.

Schucker, R.E., Levy, A.S., Tenney, J.E., Mathews, O. (1992). Nutrition shelf-labeling and consumer purchase behavior. Journal of Nutrition Education, 24, 75-81.

Scott, J.A., Begley, A.M., Miller, M.R., Binns, C.W. (1991). Nutrition education in supermarkets: The lifestyle 2000 experience. Australian Journal of Public Health, 15, 49-55.

Scott, V., Worsley, A.F. (1994). Ticks, claims, tables and food groups: A comparison for nutrition labelling. Health Promotion International, 9, 27-37.

Seidell, J.C., Löwik, M.R.H. (1993). Exogene determinanten (Exogenous determinants). In: Ruwaard, D., Kramers, P.G.N. (eds). Volksgezondheid Toekomstverkenning; De gezondheidstoestand van de Nederlandse bevolking in de periode 1950-2010 (Investigation of the future of public health; The state of health of the Dutch population in the period 1950-2010). RIVM, Den Haag: Sdu uitgeverij. 


\section{References}

Shannon, B., Mullis, R.M., Pirie, P.L., Pheley, A.M. (1990). Promoting better nutrition in the grocery store using a game format: The shop smart game project. Journal of Nutrition Education, 4, 183-188.

SPSS Inc. (1997). SPSS for Windows, release 7.5.2. Chicago, IL.

SPSS Inc. (1999). Statistical Package for the Social Sciences, version 9.01. SPSS: Chicago, IL.

Sorenson, G., Morris, D.M., Hunt, M.K., Hebert, J.R., Harris, D.R., Stoddard, A., Ockene, J.K. (1992). Work-site nutrition intervention and employees' dietary habits: The Treatwell program. American Journal of Public Health, 6, 214-224.

Stafleu, A., Graaf, C. de, Staveren, W.A. van. (1991). A review of selected studies assessing socialpsychological determinants of fat and cholesterol intake. Food Quality and Preference, 3, 183-200.

Steenbakkers, M., Assema, P. van, Kok, G. (1992). Voedingsinformatiepakket 'Gezonder en minder vet eten': een methode voor voedingsvoorlichting aan het algemene publiek (The nutritional information pack "Being healthier and eating less fat": A nutrition education method for the general public). Tijdschrift Gezondheidsvoorlichting, 9, 14-16.

Steenhuis, I.H.M., Assema, P. van, Glanz, K. (2001). Strengthening environmental and educational nutrition programmes in worksite cafeterias and supermarkets in the Netherlands. Health Promotion International, 1, 21-31.

Steenhuis, I.H.M., Assema, P. van, Breukelen, G. van, Glanz, K., Kok, G.J., Vries, H. de. (submitted(a)). Short-term behavioral effects of educational and environmental interventions in Dutch worksite cafeterias.

Steenhuis, I.H.M., Assema, P. van, Reubsaet, A., Breukelen, G. van, Glanz, K., Kok, G.J. (submitted(b)). The short-term effectiveness of nutrition education and labeling in Dutch supermarkets.

Steenhuis, I.H.M., Brug, J., Assema, P. van, Imbos, T. (1996). The validation of a test to measure knowledge about the fat content of food products. Nutrition and Health, 10, 331-339.

Steenhuis, I., Sijpestein-Molenaar, F., Assema, P. van, Brug, J., Mela, D. (submitted(c)). Effecten van het gratis aanbieden van gezonde voedingsmiddelen in bedrijfsrestaurants (The effects of free provision of healthy food in worksite cafeterias.).

Steenhuis, I.H.M., Assema, P. van, Reubsaet, A. (2000). 'Eet smakelijk, eet gezond': Evaluatie van een zelfhulpgids ('Tasty food, healthy food': Evaluation of a self help guide'. Tijdschrift voor Gezondheidswetenschappen, 7, 412-418. 


\section{References}

Steinmetz, K.A., Potter, J.D. (1991). Vegetables, fruit, and cancer. I Epidemiology. Cancer causes and control, 2, 325-357.

Stewart, D., Shamdasani, P.M. (1991). Focusgroups; Theory and practice. Applied Social Research Methods Series, 20. Sage Publications, Newbury Park, CA.

U.S. Department of Agriculture, U.S. Department of Health and Human Services. (1990). Nutrition and your health: Dietary guidelines for Americans. Home and Garden Bulletin, no 232., U.S. Department of Agriculture, U.S. Department of Health and Human Services.

Vaandrager, L., Koelen, M., Os, M. van. (1993). Het SUPER-project deel III: Een overzicht van de voedingsvoorlichtingsactiviteiten in Eindhoven gedurende het tweede projectjaar (SUPER-project part III: An overview of nutrition education activities in Eindhoven during the second year of the project). Wageningen: vakgroep Voorlichtingskunde.

Vries, H. de, Backbier, E. (1994). Self-efficacy as important factor of quitting among pregnant women who smoke: The Ø-pattern. Preventive Medicine, 23, 167-174.

Vries, H. de, Dijkstra, M., Kuhlman, P. (1988). Self-efficacy: The third factor besides attitude and subjective norm as a predictor of behavioral intentions. Health Education Research,3, 273-282.

Wilbur, S.R., Zifferblat, S.M., Pinsky, J.L., Zifferblat, S. (1981). Healthy vending: A cooperative pilot research program to stimulate good health in the marketplace. Preventive Medicine, 10, 85-93.

Willett, W.C. (1994). Diet and Health: What should we eat? Science, 264, 532-537.

Willett, W.C. (2001). Diet and cancer: One view at the start of the millennium. Cancer Epidemiology, Biomarkers and Prevention, 10, 3-8.

Williams, C., Poulter, J. (1991). Formative evaluation of a workplace menu labelling scheme. Journal of Human Nutrition and Dietetics, 4, 251-262.

World Cancer Research Fund/American Institute for Cancer Research. (1997). Food nutrition and the prevention of cancer: A global perspective. Washington DC: The American Institute for Cancer Research. 


\section{Summary}

Dietary factors have been found to be important in the prevention of coronary heart diseases and cancer. In the Netherlands, a number of efforts have been made to reduce the risk of these diseases by attempting to reduce people's fat consumption and to increase their fruit and vegetable consumption. However, there is still a discrepancy between the recommended quantities and the actual reported food intake of the Dutch population. Environmental interventions may help consumers to meet the guidelines for a healthy diet. Environmental interventions reduce barriers or increase opportunities for healthy choices, i.e. they create more healthy choices, make them more accessible and establish policies that require healthy options to be available, or limit the number of less healthy options. In this thesis, two types of environmental interventions were studied, namely changes in the range of foods available and food labeling. The intervention involving changes in the range of foods available consisted of increasing the number of low-fat products and increasing the variety of fruits and vegetables on offer. In the labeling intervention, low-fat products were labeled with a shelf label (supermarkets) or a sign placed in front of them (worksite cafeterias). The two environmental interventions were combined with educational components such as brochures, recipe cards and a self help manual. The interventions were implemented at worksite cafeterias (changes in the range of foods available and food labeling) and supermarkets (food labeling) in the Netherlands.

The first objective of the studies described in this thesis was to assess the feasibility of the two environmental interventions aimed at changing dietary behavior at worksite cafeterias and supermarkets in the Netherlands. The second objective was to study their effectiveness.

The study described in chapter 2 was carried out to assess the feasibility and conditions for adoption and implementation of the environmental interventions in the two settings. Twenty semi-structured interviews were conducted with representatives of worksite cafeterias and supermarkets. Concepts taken from theories of diffusion were used as a framework for the study. The study showed that environmental interventions at worksite cafeterias and supermarkets are feasible, although some requirements regarding program design and implementation must be taken into account. Besides being positive 
and practicable for both staff and customers, programs need to meet a large number of practical requirements. In order to ensure that the programs are implemented correctly, implementation strategies should focus on the advantages of nutritional education programs perceived by worksite cafeterias and supermarkets (such as a positive influence on customer satisfaction) and on reducing the expected difficulties of conducting nutrition programs (such as the necessary time investment). The results of this study were used in developing the environmental and educational interventions described in chapter 3 and 4. The 'Attitude-Social influence-Self-efficacy model' formed the theoretical basis for the educational intervention. In addition, not all information was given at the same time, with the information provided during the program being attuned to the various different stages of behavioral change.

Chapter 3 describes the evaluation study which was conducted at worksite cafeterias. A pretest-posttest experimental control group design was used. Seventeen large worksite cafeterias and a total of 1,013 of their customers participated in the study. Data collection methods consisted of questionnaires filled out by cafeteria customers and sales data records. Although respondents at worksite cafeterias had a positive general opinion about the program, they also reported that the program was of low personal relevance and that they did not gain a greater knowledge of healthy nutrition as a result of it. No effects of the interventions were found on consumption data of the whole study population. A short-term treatment effect of the labeling program for fat was found for respondents who believed they ate a high fat diet. No convincing effects of the environmental interventions were found on behavioral determinants of eating less fat and more fruit and vegetables. Analysis of sales data revealed a significant effect of the labeling program on desserts, but not on the other products.

Chapter 4 reports on the effectiveness of a nutrition labeling program aimed at reducing fat intake and implemented at supermarkets. A pretest-posttest experimental control group design was also used for this study. Thirteen supermarkets and 2,203 of their customers were included in the study. The same data collection methods were used as for the worksite cafeterias. However, numerous problems in collecting the sales data meant that the sales data could ultimately not be used to assess the effectiveness of the interventions. Respondents at supermarkets also had a positive general opinion about 
the programs. Respondents who were aware of the program indicated that the programs had a positive effect on determinants for eating less fat. More than half of these respondents reported that they had looked at their own fat consumption level as a result of the intervention, and almost half reported their intention to follow one or more suggestions given in the program. However, this study once more failed to show significant effects on fat intake, consumption of targeted products, or behavioral determinants of eating less fat.

The qualitative study involving twenty-one managers of the intervention sites (reported in chapter 5), was carried out to gain further insight into the possible reasons for the ineffectiveness of the intervention programs. In addition to the explanations for the ineffectiveness of the programs proposed in the evaluation studies (for example the low perceived relevance of the programs), this study revealed (among other things) that the labeling might have had greater potential if it had discriminated between different brands of a product, and that the limited availability of low-fat alternatives suitable for sale at worksite cafeterias was a barrier to making major changes in the range of foods available there.

One of the nutritional education components, the self help manual, was evaluated separately using a questionnaire distributed to 79 consumers who requested the manual. The results of this study are presented in chapter 6 . The research shows that the guide was well used and rated positively by those who read it. The guide would appear to have had positive effects on fat, fruit and vegetable consumption and on the corresponding determinants for behavior.

It can be concluded that using environmental intervention components at Dutch worksite cafeterias and supermarkets is feasible. However, no evidence can be found for the effectiveness of intervention programs at worksite cafeterias, including changes in the range of foods available. Interventions including labeling at worksite cafeterias and supermarkets did not prove to be successful in changing dietary behavior either. 


\section{Samenvatting}

Eetgewoonten zijn van belang bij de preventie van hart- vaatziekten en kanker. Een verlaging van de vetconsumptie en een verhoging van de groente- en fruitconsumptie reduceren het risico op deze ziekten. In Nederland zijn diverse initiatieven ontplooid om de consumptie van vet, groente en fruit te beïnvloeden. Er bestaat echter nog steeds een discrepantie tussen de aanbevolen hoeveelheden ten aanzien van de consumptie van vet, groente en fruit en de daadwerkelijke consumptie van de Nederlandse bevolking. Omgevingsinterventies zouden er toe kunnen bijdragen dat de consumptie meer in overeenstemming komt met de aanbevelingen. Omgevingsinterventies kunnen barrières om gezonde keuzes te maken reduceren dan wel wegnemen, of kunnen de mogelijkheden om gezond gedrag uit te voeren vergroten. Dit kan door het aanbieden van meer gezonde keuzemogelijkheden, het gemakkelijker toegankelijk maken van gezonde keuzes of door het instellen van beleid dat de aanwezigheid van voldoende gezonde keuzemogelijkheden verplicht stelt of de aanwezigheid van ongezonde keuzes limiteert.

In dit proefschrift staan twee typen omgevingsinterventies centraal: uitbreiding van het aanbod van gezonde voedingsmiddelen en labeling. De eerste interventie betrof een uitbreiding van het aanbod in bedrijfsrestaurants met magere producten en groente en fruit. Bij de labelingsinterventie werden magere producten in bedrijfsrestaurants en supermarkten gelabeld met een schaplabel (supermarkten) of een label dat voor de desbetreffende producten stond/hing (bedrijfsrestaurants). De twee omgevingsinterventies werden gecombineerd met een algemeen voedingsvoorlichtingsprogramma met onder meer folders, receptenkaartjes en een zelfhulpgids om gezonde eetgewoonten te bevorderen.

De eerste doelstelling van de studies die in dit proefschrift beschreven staan, was om de haalbaarheid van de twee typen omgevingsinterventies in bedrijfsrestaurants en supermarkten te onderzoeken. De tweede doelstelling was om de effectiviteit van de omgevingsinterventies met betrekking tot het veranderen van eetgedrag vast te stellen. 
Het onderzoek dat in hoofdstuk 2 beschreven staat, is uitgevoerd om de haalbaarheid van het uitvoeren van de omgevingsinterventies in bedrijfsrestaurants en supermarkten te achterhalen en om te bepalen welke factoren succesvolle adoptie en implementatie van de interventies kunnen bevorderen. Er werden twintig semi-gestructureerde interviews gehouden met vertegenwoordigers van bedrijfsrestaurants en supermarkten. Het theoretisch kader van het onderzoek werd gevormd door concepten uit verschillende diffusie-theorieën. De resultaten van dit onderzoek laten zien dat het uitvoeren van dergelijke interventies zeker haalbaar is in Nederlandse bedrijfsrestaurants en supermarkten. Wel moet rekening worden gehouden met een aantal eisen ten aanzien van het interventie-ontwerp en de implementatie-strategieën. De programma's moeten positief van toon zijn, en gemakkelijk in gebruik voor zowel personeel van de bedrijfsrestaurants en supermarkten als voor hun klanten. Daarnaast moeten de programma-materialen aan veel praktische eisen voldoen (bijvoorbeeld om de hygiëne te waarborgen). Om adequate implementatie van de programma's te bevorderen, moeten de implementatie-strategieën zich onder meer focussen op het benadrukken van de voordelen van het uitvoeren van voedingsvoorlichtingsprogramma's in bedrijfsrestaurants en supermarkten zoals die door deze organisaties gepercipieerd worden (zoals bijvoorbeeld de positieve invloed die een programma mogelijk kan hebben op klanttevredenheid). De resultaten van deze studie zijn gebruikt bij het ontwikkelen van de omgevings- en voorlichtingsinterventies die beschreven staan in hoofdstuk 3 en 4. Het 'Attitude-Sociale invloed-eigen Effectiviteit model' vormde het theoretisch kader voor de ontwikkelde voorlichtingsinterventie. Daarnaast werd het voorlichtingsprogramma opgebouwd volgens de verschillende stadia van gedragsverandering.

In hoofdstuk 3 worden de resultaten gepresenteerd van een onderzoek naar de effectiviteit van de interventies in bedrijfsrestaurants. Het betrof een gerandomiseerd experiment met een voor - en twee nametingen. Zeventien bedrijfsrestaurants en in totaal 1013 klanten van hen namen deel aan de studie. De dataverzameling geschiedde door middel van vragenlijsten bij klanten en het bijhouden van verkoopcijfers van een aantal producten. Hoewel klanten een positief oordeel hadden over de interventies, bleek dat het programma niet in hoge mate als persoonlijk relevant werd ervaren. Ook gaven respondenten aan dat ze niet meer kennis van gezonde voeding hadden gekregen 


\section{Samenvatting}

als gevolg van de interventies. In deze studie werden geen effecten op het voedingsgedrag van de gehele studiepopulatie gevonden, zowel niet op de korte als lange termijn. Het labelingsprogramma had significant een positief effect op de totale vetconsumptie van respondenten die zelf dachten dat ze te vet aten. Dit effect werd echter alleen gevonden op de korte termijn. Er werden geen relevante effecten van de omgevingsinterventies gevonden op de gedragsdeterminanten van het eten van minder vet en meer groente en fruit. Analyse van verkoopcijfers leverde een significant effect van de labelingsinterventie op voor desserts, maar niet voor andere producten.

Hoofdstuk 4 beschrijft een onderzoek naar de effectiviteit van een labelingsprogramma gericht op een vermindering van de vetconsumptie, uitgevoerd in supermarkten. Hetzelfde design en dezelfde dataverzamelingsmethoden werden gebruikt als bij het experiment in bedrijfsrestaurants. Dertien supermarkten en 2203 van hun klanten namen deel aan de studie. Als gevolg van diverse problemen bij het verzamelen van de verkoopcijfers werden deze uiteindelijk niet gebruikt om de interventies te evalueren. Respondenten uit de supermarkten hadden eveneens een positief algemeen oordeel over de interventies. De respondenten die iets van de interventie gezien hadden, rapporteerden dat de interventies een positief effect hadden op de determinanten van het eten van minder vet. Iets meer dan de helft van deze respondenten rapporteerden dat ze bewust naar hun eigen vetconsumptie hadden gekeken als gevolg van het programma, en bijna de helft zei de intentie te hebben om één of meer tips met betrekking tot gezonde voeding uit het programma op te volgen. Echter, ook in deze studie werden geen effecten gevonden van de interventie-programma's op vetconsumptie, consumptie van de gelabelde producten of de psycho-sociale determinanten van het eten van minder vet.

Om inzicht te krijgen in mogelijke redenen voor de ineffectiviteit van de interventies, is een kwalitatief onderzoek verricht bij eenentwintig managers van bedrijfsrestaurants en supermarkten waar de interventies zijn geïmplementeerd. De resultaten van deze studie staan beschreven in hoofdstuk 5. In aanvulling op de verklaringen die naar aanleiding van de evaluatiestudies naar voren kwamen (zoals bijvoorbeeld de lage gepercipieerde persoonlijke relevantie van de programma's), laat dit onderzoek onder meer zien dat labeling wellicht beter zou kunnen werken wanneer 'merkgericht' zou worden gelabeld. 
Dit houdt in dat labeling gebruikt wordt om binnen een type product onderscheid te maken (bijvoorbeeld in vetgehalte) tussen de diverse merken. Ook bleek dat de beperkte beschikbaarheid in de groothandel van magere producten die geschikt zijn voor verkoop in bedrijfsrestaurants een belangrijke barrière was om een aanzienlijke uitbreiding van het assortiment te realiseren.

Eén van de onderdelen uit het algemene voedingsvoorlichtingsprogramma, de zelfhulpgids, is in een aparte studie geëvalueerd met behulp van vragenlijsten die door 79 respondenten die de gids hadden aangevraagd werden ingevuld. De resultaten van dit onderzoek die beschreven staan in hoofdstuk 6, laten zien dat de gids goed werd gebruikt en positief werd beoordeeld door degenen die de gids gelezen hadden. Het lijkt dat de gids positieve effecten heeft op de vet, groente en fruitconsumptie, en de bijbehorende gedragsdeterminanten.

Geconcludeerd kan worden dat het gebruik van omgevingsinterventies in Nederlandse bedrijfsrestaurants en supermarkten haalbaar is. Echter, de effectiviteit van een interventie met uitbreiding van het aanbod in bedrijfsrestaurants kan niet worden aangetoond. Evenmin kan de effectiviteit worden bewezen van een labelingsinterventie in bedrijfsrestaurants en supermarkten. 


\section{Dankwoord}

Veel mensen hebben de afgelopen jaren bijgedragen aan de wording van dit proefschrift. Ik wil hen hiervoor hartelijk danken. Patricia van Assema heeft als copromotor een belangrijke rol gehad in de begeleiding. Bedankt voor je vele waardevolle adviezen en voor de vrijheid die je me gaf om het project op mijn manier in te vullen. Gerjo Kok keek als promotor vooral vanaf de zijlijn mee. Op momenten dat we het echt niet meer wisten mocht hij bijspringen. Bedankt voor die keren dat je met een paar woorden de zaak weer helder kreeg en me op het juiste spoor zette. I also would like to thank Karen Glanz, my promotor from the University of Hawaii. Thank you for your advice during the project and your useful comments on my draft papers. Gerard van Breukelen is onmisbaar geweest bij het uitvoeren van de statistische analyses en heeft daarmee in belangrijke mate bijgedragen aan de totstandkoming van dit proefschrift. Bedankt daarvoor. Een aantal mensen wil ik bedanken voor hun adviserende rol tijdens het project. Mirande Baan, Inge van den Borne, Ineke van Dis, Anja Kroodsma, Resie Kuppens, Hilde van Oosten, Marja Slagmoolen en Hans Wijngaard, bedankt voor jullie interesse en het meedenken bij het project.

Ik wil alle cateringmanagers van de bedrijfsrestaurants en filiaalhouders van de supermarkten die hun medewerking hebben verleend aan het onderzoek bedanken. Ondanks het feit dat we hun bedrijfsrestaurants en supermarkten af en toe flink op z'n kop hebben gezet, bleven ze tot het eind toe bereidwillig meewerken om het onderzoek tot een succes te maken.

Gedurende het project heb ik hulp gehad van verschillende onderzoeksassistenten: Monique van den Broek, Astrid Reubsaet en Henrik Zoch. Bedankt voor jullie inzet en het vele werk dat jullie hebben verricht om de bedrijven, supermarkten en hun klanten te werven voor het onderzoek, te bevoorraden met voorlichtingsmaterialen en keer op keer te bezoeken. Astrid, ik denk met veel plezier terug aan de tijd die ik met jou heb samengewerkt. Ik had en heb een groot vertrouwen in je.

Ook de andere collega's van de capaciteitsgroep Gezondheidsvoorlichting wil ik bedanken voor hun hulp en gezelligheid tijdens het werk. Een speciaal woord van dank aan die collega's die mij uren- en soms dagenlang hebben geholpen met het vouwen van 
duizenden tafelstandaards en het versturen van evenzoveel vragenlijsten. Het uitvoeren van een dergelijk project is alleen leuk en mogelijk met zo veel hulp van iedereen.

Ongeacht alle hulp betekent het schrijven van een proefschrift echter ook vele uren eenzame arbeid. Dat is alleen maar prettig als die uren worden afgewisseld met uren waarin ontspanning en plezier voorop staan. Familie en vrienden zijn daarbij van het grootste belang geweest. Gezellig met z'n allen rond de open haard in Klarenbeek, vele uurtjes sporten met Jeanne en Emile, samen met Martijntje het leven vieren, skiën met Wendy, kindertelevisie maken met mijn Bert Buis collega's, theater maken met Basalt en Boemerang, of gewoon lekker kletsen met Anne-Marie, Natascha of Yvonne: dat zijn de dingen die het leven aangenaam maken en die de periode van het schrijven van dit proefschrift hebben verrijkt. Dank voor zo veel goeds.

Iemand die ik in het bijzonder wil bedanken is Geert Steenhuis. Bedankt voor je stimulans al die jaren en voor het doorzettingsvermogen dat je me meegegeven hebt. Agnes, we zijn ooit samen begonnen met onze studie in Maastricht en hebben inmiddels veel lief en leed met elkaar gedeeld. Ik wil je bedanken voor al je steun, niet alleen bij het schrijven van dit proefschrift, maar ook daarbuiten. Onze vriendschap is heel bijzonder en ik ben blij dat je daar in de loop der jaren ook Hans, Abel en Sem aan toe hebt gevoegd. Jullie betekenen veel voor mij. 


\section{Curriculum Vitae}

Ingrid Steenhuis werd op 30 maart 1970 in Ede geboren. In 1987 behaalde ze haar HAVO-diploma op het Christelijk Lyceum in Apeldoorn. In 1991 studeerde ze af aan de Hogere Beroepsopleiding tot Verpleegkundige van de Rijkshogeschool IJsselland in Zwolle/Deventer. In datzelfde jaar startte ze met haar studie Gezondheidswetenschappen in Maastricht. In 1994 studeerde ze cum laude af in de afstudeerrichtingen Gezondheidsvoorlichting, en Gezondheidsethiek en Wijsbegeerte. $\mathrm{Na}$ haar studie ging ze als onderzoeksassistent werken bij de capaciteitsgroep Gezondheidsvoorlichting van de Universiteit Maastricht. Van 1996-2000 was ze aangesteld als toegevoegd onderzoeker bij diezelfde capaciteitsgroep. In die periode werden de studies verricht die in dit proefschrift beschreven staan. In 2001 werkte ze als universitair docent bij de capaciteitsgroep Gezondheidsvoorlichting. Momenteel werkt ze als universitair docent Psychologie bij de Open Universiteit Nederland. 


\section{Publicaties}

Assema, P. van, Brug, H., Dolders, M., Kok, G., Steenhuis, I. (1996). Misconceptie van vetconsumptie; een kwalitatief onderzoek naar oorzaken. Tijdschrift Sociale Gezondheidszorg, 74, 347-355.

Assema, P. van, Brug, J., Ronda, G., Steenhuis, I. (2001). The relative validity of a short Dutch questionnaire as a means to rank adults and adolescents to total and saturated fat intake. Journal of Human Nutrition and Dietetics, 14, 377-390.

Assema, P. van, Brug, J., Ronda, G., Steenhuis, I., Oenema, A. (in press). A short Dutch questionnaire to measure fruit and vegetable intake: relative validity among adults and adolescents. Nutrition and Health.

Assema, P. van, Kok, G.J., Hospers, H., Steenhuis, I. (1998). Gezondheidsvoorlichting en beïnvloeding van voedingsgedrag. In: Informatorium Voeding en Diëtetiek, hoofdstuk 14.

Brug, J., Steenhuis, I.H.M., Assema, P. van, Vries, H. de. (1996). The impact of a computer-tailored nutrition intervention. Preventive Medicine, 25, 236-242.

Brug, J., Steenhuis, I., Assema, P. van, Glanz, K., Vries, H. de. (1999). Computer-tailored nutrition education: differences between two interventions. Health Education Research, 14, 249-256.

Steenhuis, I.H.M., Brug, J., Assema, P. van. (1995). Voedingsvoorlichting-op-maat: werkwijze en evaluatie. Tijdschrift Gezondheidsbevordering, 16(3/4), 117-127.

Steenhuis, I.H.M., Assema, P. van. (2000). Omgevingsinterventies. In: Brug, J., Schaalma, H., Kok, G., Meertens, R.M., Molen, H.T. van der. Gezondheidsbevordering en gedragsverandering. Een planmatige aanpak. Assen: van Gorcum \& Comp. B.V..

Steenhuis, I.H.M., Assema, P. van, Glanz, K. (2001). Strengthening environmental and educational nutrition programmes in worksite cafeterias and supermarkets in the Netherlands. Health Promotion International, 1, 21-31.

Steenhuis, I.H.M., Assema, P. van, Reubsaet, A. (2000). 'Eet smakelijk, eet gezond': Evaluatie van een zelfhulpgids. Tijdschrift voor Gezondheidswetenschappen, 7, 412-418.

Steenhuis, I.H.M., Brug, J., Assema, P. van, Imbos, T. (1996). The validation of a test to measure knowledge about the fat content of food products. Nutrition and Health, 10, 331-9. 